\title{
"Mother Nature's Best Kept Secret": The Principles and Practices of Ecotourism in Belize
}

\author{
By \\ Bryan W. Myles, B.A.
}

A thesis submitted to the Faculty of Graduate Studies and Research in partial fulfillment of the requirements for the degree of

Master of Arts

Department of Sociology and Anthropology

Carleton University

Ottawa, Ontario

April 15, 2008

(C) 2008, Bryan W. Myles 


$\begin{array}{ll}\begin{array}{l}\text { Library and } \\ \text { Archives Canada }\end{array} & \begin{array}{l}\text { Bibliothèque et } \\ \text { Archives Canada }\end{array} \\ \begin{array}{l}\text { Published Heritage } \\ \text { Branch }\end{array} & \begin{array}{l}\text { Direction du } \\ \text { Patrimoine de l'édition }\end{array} \\ \begin{array}{l}\text { 395 Wellington Street } \\ \text { Ottawa ON K1A 0N4 } \\ \text { Canada }\end{array} & \begin{array}{l}\text { 395, rue Wellington } \\ \text { Ottawa ON K1A 0N4 } \\ \text { Canada }\end{array}\end{array}$

Your file Votre référence ISBN: 978-0-494-40607-6 Our file Notre référence ISBN: 978-0-494-40607-6

NOTICE:

The author has granted a nonexclusive license allowing Library and Archives Canada to reproduce, publish, archive, preserve, conserve, communicate to the public by telecommunication or on the Internet, loan, distribute and sell theses worldwide, for commercial or noncommercial purposes, in microform, paper, electronic and/or any other formats.

The author retains copyright ownership and moral rights in this thesis. Neither the thesis nor substantial extracts from it may be printed or otherwise reproduced without the author's permission.
AVIS:

L'auteur a accordé une licence non exclusive permettant à la Bibliothèque et Archives Canada de reproduire, publier, archiver, sauvegarder, conserver, transmettre au public par télécommunication ou par l'Internet, prêter, distribuer et vendre des thèses partout dans le monde, à des fins commerciales ou autres, sur support microforme, papier, électronique et/ou autres formats.

L'auteur conserve la propriété du droit d'auteur et des droits moraux qui protège cette thèse. $\mathrm{Ni}$ la thèse ni des extraits substantiels de celle-ci ne doivent être imprimés ou autrement reproduits sans son autorisation.
In compliance with the Canadian Privacy Act some supporting forms may have been removed from this thesis.

While these forms may be included in the document page count, their removal does not represent any loss of content from the thesis.
Conformément à la loi canadienne sur la protection de la vie privée, quelques formulaires secondaires ont été enlevés de cette thèse.

Bien que ces formulaires aient inclus dans la pagination, il n'y aura aucun contenu manquant.

\section{Canada}




\begin{abstract}
Ecotourism is often touted as a new and responsible form of travel that is intended to ameliorate the negative social, cultural and environmental impacts of the traditional or mass tourism industry. As ecotourism is often promoted as a principled response to these impacts it is often presented in a light that accentuates its participatory, empowering and sustainable potentialities. While the popularity of ecotourism is rapidly increasing, its application as a tool for sustainable development is often cited as one of the main incentives for people who undertake this form of holiday travel. Drawing on a mix of library and ethnographic data, this thesis examines the ability of ecotourism to live up to it virtuous principles by observing ecotourism and ecotourists in the Belizean context. Through observations and information gained while participating as an ecotourist in Belize and by examining a large body of literature on the subject, my findings suggest that attempting to provide participatory, empowering and sustainable development to Belize is not often represented in the practice of being an ecotourist or the larger ecotourism industry. Rather, what motivates ecotourists and structures their behaviour is often an attempt to have an individually oriented experience of nature and culture. The primacy of these experiences for the ecotourist supersedes the stated principles of ecotourism and generates negative impacts reminiscent of the traditional tourism industry. Consequently, this thesis suggests that the specific experience of nature and culture most sought after by ecotourists tends to contradict ecotourism's stated purpose of providing economic development and modernization to the Third World.
\end{abstract}




\section{Acknowledgements}

The completion of this thesis would not have been possible without the support and encouragement of a number of people. First I would like to thank my thesis supervisors, Dr. Peter Gose and Dr. Blair Rutherford for their important thoughts and contributions to the project. Their knowledge of the issues I have sought to better understand has proved invaluable to my academic development and the completion of this project. It has been sincerely appreciated. Peter, I would especially like to thank you for your words of encouragement and the guidance and feedback that you have given me. You have kept me oriented toward my goal and though I might not show it you have helped me work through some tough concepts and frustrating times.

I would also like to thank everyone in Belize who helped us along the way, who spent time talking with us and inevitably shared a little bit of themselves so that I could produce this document. Although our time there was short and relationships brief I cannot stress how much I appreciate the hospitality that we were shown and I hope that we can meet again someday. Thank you for making our experience an unforgettable one.

Finally, I must thank my family for all their love, support and encouragement in helping me get to where I am today. Dad I owe you special thanks for your emotional and economic investment in my university career, none of this would have been possible if you had not provided me with the opportunity. Most of all I would like to say a special thank you to Carla. Thank you for accompanying me to Ottawa and even further to Belize. I could not have maintained my focus and determination without you with me. 


\section{Table of Contents}

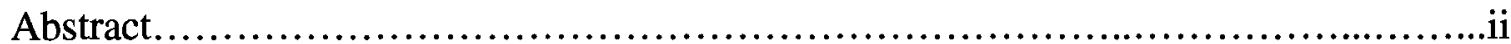

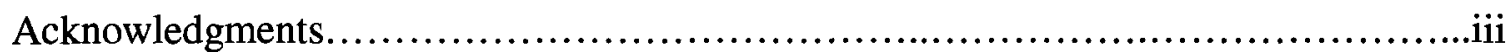

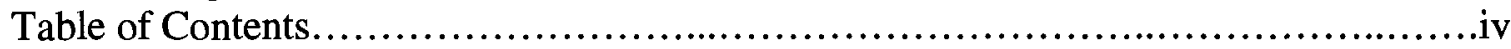

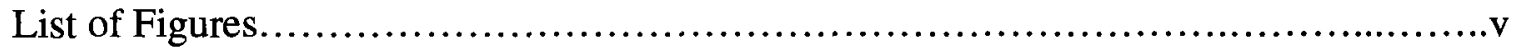

Chapter 1: Introduction.....................................................................1

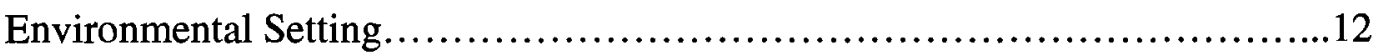



Cultural Setting........................................................21

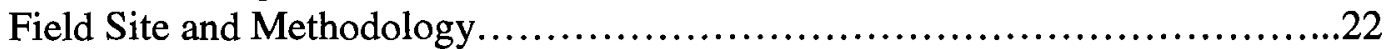

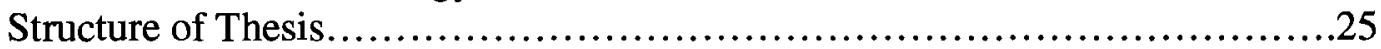

Chapter 2: The Nature of Ecotourism: exploring the literature........................28

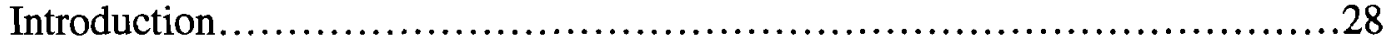

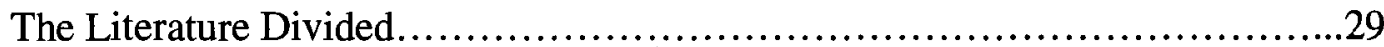

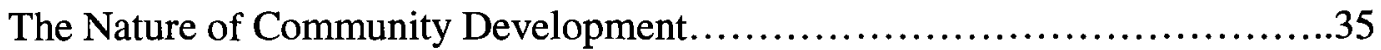

Tourism: Authenticity, Play and the Sacred Journey..........................41

Conclusion...........................................................48

Chapter 3: History and Political Ecology $\ldots \ldots \ldots \ldots \ldots \ldots \ldots \ldots \ldots \ldots \ldots \ldots \ldots \ldots \ldots \ldots \ldots . \ldots \ldots 1$

Introduction........................................................... 51

From Buccaneers to Baymen.........................................52

Mahogany, Slavery and the Road to Underdevelopment.......................56

From Settler Oligarchy to Merchant Capitalists............................66

The Demise of Forestry and the Rise of a Nation...........................69

The Era of Ecotourism...................................................... 75

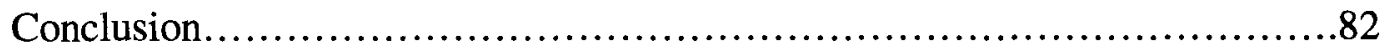

Chapter 4: "Mother Nature's Best Kept Secret"'....................................87

Introduction............................................................ 87

Belize and Ecotourism Mecca............................................88

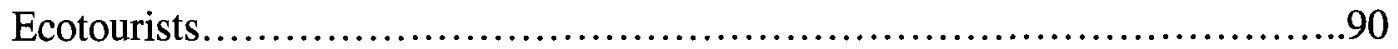

Cultural Capital.........................................................95

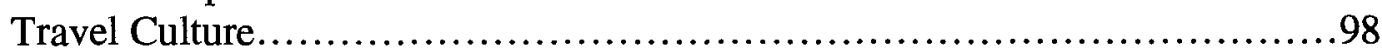

Authenticity: moving beyond binaries..................................102

Ruins, Rainforest and Reef............................................ 108

Conclusion........................................................... 120

Chapter 5: Concluding Remarks..................................................123

Bibliography..........................................................................137 


\section{List of Figures}

Figure 1.1: Map Showing Belize.............................................. 14

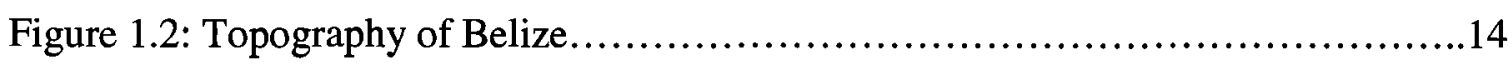

Figure 1.3: Districts of Belize................................................ 15

Figure 1.4: Protected Areas of Belize.......................................... 18

Figure 4.1: Postmodern Tourism...........................................101

Figure 4.2: Ecotourists Interacting With Stingrays I............................. 113

Figure 4.2: Ecotourists Interacting With Stingrays II............................. 113

Figure 4.3: Promotional Image of Belize.........................................117 


\section{Chapter One: Introduction}

Ecotourism is increasingly popular and is rapidly becoming a major segment of the tourism industry (Lew 1998: 92). Since the early 1990s the word ecotourism has grown in popularity and so too has the number of tourists who seek close encounters with the natures and cultures of the Third World ${ }^{1}$ (TIES 2006). Ecotourism is also recognized as an innovative new strategy that combines nature conservation with sustainable economic development (Honey 1999). Thus, as some suggest, ecotourism is a tool that can be applied to the social, economic and environmental ills faced by the Third World (Horwich and Lyon 1998).

Belize is a small Central American country that has embraced ecotourism as a development strategy and a country that may just be the world's most popular ecotourism destination. The following analysis is a close examination of the political ecological contours of ecotourism in Belize which analyses ecotourism as a social practice undertaken largely by First World travelers. While this thesis recognizes that ecotourism can produce benefits for host destinations, it at the same time explores some of the negative impacts I observed while traveling as an ecotourist/anthropologist in Belize. By bringing to light aspects of ecotourism as a social practice that have not been given much attention in the ecotourism literature, I explore the impacts that the practice of ecotourism

\footnotetext{
${ }^{1}$ Mowforth and Munt (2003:4-5) note that the history of development studies has thrown up a variety of terms that attempt to represent and categorize countries according to wealth and social well-being. 'Developed', 'underdeveloped', 'developing', 'poorer' 'North' and 'South' being but a few of these. Throughout the course of this thesis I employ the concepts First World and Third World when referring to these differences in order to emphasize the ways in which power, resources and development are unequally and unevenly shared globally. I acknowledge that the First and Third Worlds are not easily defined as geographical entities similar to nation states and that these inequalities do not only exist on a global scale but also exist within and between countries. Therefore these terms are used to generalize between the power vested in the nation states and institutions of North America, Europe, Australia, and Japan in contrast to the nation states and institutions that make up Latin America, the Caribbean, Africa and parts of Asia.
} 
and the representations ecotourists hold of their host destination have for a small Third World country like Belize.

The tourism industry is the largest scale movement of goods, services and people that humanity has ever seen. In 2005 the number of international tourist arrivals recorded worldwide grew by 5.5 percent and exceeded 800 million for the first time ever (WTO 2006). The industry is responsible for over 230 million jobs and accounts for 10 percent of global gross domestic product. If tourism were a country its economy would be second only to the United States (TIES 2006). This massive sector of the world economy is especially important for Third World countries as it is a chief earner of foreign exchange for 83 percent of these countries, and the primary source of foreign currency in a third of the world's poorest nations (ibid).

From an economic standpoint, the tourism industry is of exceptional importance to the Third World and the global economy overall. Yet it is increasingly recognized as a major contributor to a number of pre-existing problems such as the creation of currency black markets, drugs, prostitution, inflation, overcrowding and the building of high-rise hotels and golf courses in fragile environments (Honey 1999: 9). These impacts are most acutely felt in the Third World where tourism is promoted as a development strategy and where a growing number of tourists from the First World take their holidays (Stronza 2001; Honey 1999).

Ecotourism has been proposed as a way to address the negative impacts associated with the tourism industry that attempts to promote environmental and economic benefits simultaneously (West and Carrier 2004: 483). Thus, the logic of ecotourism suggests that if people can realize an economic benefit from conservation 
they will reduce destructive and/or extractive livelihood practices. This strategy is intended to create local support for conservation, facilitate economic development and thus overcome many of the negative socio-economic and environmental impacts associated with the traditional tourism industry (Boo 1990; Lindberg et al 1996; Wilshusen et al 2003).

Scholars generally agree that the popularity of ecotourism is rapidly increasing (West et al 2003; West and Carrier 2004), yet the size of this sector in relation to the rest of the industry is difficult to gauge. The International Ecotourism Society (TIES) acknowledges that ecotourism data is often lumped together with other forms of "experiential" and "alternative" tourism, but estimates that ecotourism has grown by 20 to 34 percent per year since 1990. By 2004 estimates suggested that ecotourism was growing three times faster than the tourism industry as a whole and TIES believes that within six years ecotourism could account for 25 percent of the world's travel market representing an annual value of US\$473.6 billion (TIES 2006).

As the above may suggest, it is difficult to measure the size of ecotourism and this is because an agreed upon definition of the term does not exist and likely never will (Lindberg et al 1996: 543). Ecotourism's ambiguity is largely due to the popularity of nature-based tourism activities that most tourists undertake while visiting host countries in the Third World and strengthened by the various interest groups that seek to define the term. In this sense ecotourism has gained the status of a buzzword (Cornwall and Brock 2005) in conservation and development circles and a tremendous amount of currency in the larger tourism industry. Adding to the confusion of defining ecotourism is the fact that it is often equated with other forms of alternative tourism such as adventure tourism, 
wildlife tourism, sustainable tourism and nature tourism. In an attempt to add some order to this confusion I propose that ecotourism can be best interpreted as a form of alternative tourism (alternative in relation to mass tourism) intended to be, in name or principle, socio-culturally and environmentally responsible and sustainable. This being the case, socio-cultural and environmental responsibility and sustainability are qualities that may or may not be exhibited in ecotourism as a practice (Cater 1994: 3). In fact, this study will show that the above qualities are difficult to realize in practice because attempts to define ecotourism and adhere to its standards are more often the concern of developers, marketers and policy makers rather that the tourists involved. This being the case, many definitions of ecotourism and its proposed benefits rarely represents the actions and intentions of the individuals who are labeled ecotourists. Curiously, the differences, or similarities for that matter, between tourists and ecotourists are rarely acknowledged or explored and the social practice of tourism in general is absent from much of the ecotourism promotional literature.

Ecotourism's proponents have made numerous attempts to operationalize the term. Arguably, one of the most authoritative of these definitions can be gleaned from the United Nations Environmental Program (UNEP) in accordance with the Quebec Declaration on Ecotourism. The Quebec summit, held in 2002, the International Year of Ecotourism (IYE), brought together thousands of participants from over a hundred countries for the purpose of setting an agenda and guidelines for the development of ecotourism activities (World Ecotourism Summit 2002: 1). According to the Quebec declaration, ecotourism: 
- Contributes actively to the conservation of natural and cultural heritage,

- Includes local and indigenous communities in its planning, development and operation, contributing to their well-being,

- Interprets the natural and cultural heritage of the destination to visitors,

- Lends itself better to independent travelers, as well as to organized tours for small size groups"(UNEP 2003).

There are various other definitions of ecotourism, some more vague than the above and some more specific. These and most other definitions are similar in that they highlight the benefits achieved for conservation and for the host community. Martha Honey (1999: 25) summarizes ecotourism as:

[T]ravel to fragile, pristine and usually protected areas that strive to be low impact and small scale. It helps educate the traveler, provide funds for conservation, directly benefits the economic development and political empowerment of local communities and fosters respect for different cultures and human rights.

A dominant theme among these and most other definitions of ecotourism is that communities hosting ecotourists are theoretically expected to play a large part in sharing in the benefits the industry is said to produce. Most specifically, the economic and livelihood cost associated with setting aside various landscapes for conservation should be redeemed by the revenue ecotourism generates and produce other non-material benefits (Duffy 2002: 102; Stinson 2004: 3; Lindberg and Enriquez 1994). Though these are the intended outcomes of ecotourism, official sounding definitions such as these often operate under the assumption that producing such benefits for a host a destination is the motivating force behind people undergoing this type of travel. That is, the similarities between tourists and ecotourists are rarely acknowledged and the ability of these two categories to produce very similar social and environmental impacts are, at times, left unexplored. 
Ecotourism is largely as a response to the environmental and social impacts of the traditional tourism industry. In this sense, ecotourism is an attempt to respond to conservation strategies that took place at the expense of people residing in or near protected areas. These protectionist conservation initiatives have been widely criticized for taking place at the expense of local resource users, often those who have been dispossessed or historically marginalized (see especially Brockington 2002; Igoe 2005). Conservationists, governments and NGOs involved in conservation and development issues have since started to recognize the importance of integrating environmental protection with the needs of neighboring populations. Since the early 1990s these "people-oriented" strategies have been organized under the rubrics of community-based conservation (CBC), and integrated conservation and development projects (ICDPs) (Wilshusen et al 2003: 8). These initiatives have embraced ecotourism as a shining light for its alleged tendency to produce the most tangible economic benefits for host populations. By enlisting the participation of local stakeholders and community members, ecotourism is supposed to overcome the social injustices associated with traditional conservation practices (Boo 1990; Horwich and Lyon 1999; Lascurian 1996; Lindberg and Enriquez 1994; Lindberg et al 1996). In addition, proponents of ecotourism deem a participatory, people-oriented approach to conservation and development to be by its very nature empowering, as it gives local communities and resource users a larger stake in the conservation and development initiatives affecting them (Woost 1997: 229-230).

For the above proponents of ecotourism, the concept is capable of living up to its virtuous goals, at least in theory (Stinson 2004: 3). In this sense, ecotourism is often presented as environmentally and culturally benign compared to traditional tourism (West 
et al 2006). Though there is a substantial amount of literature that highlights ecotourism's potential benefits there are also an increasing number of case studies and publications that reveal ecotourism's failure to achieve its conservation and development goals (Belsky 1999, 2000; Honey 1999; McLaren 2003; Stonich 2000; West and Carrier 2004). These studies (discussed further in Chapter 2) often highlight ecotourism's ability to facilitate and even strengthen the social and environmental problems associated with the traditional industry. Though this has been shown to be the case in a number of instances, it is important to note that ecotourism does not always recreate the same negative impacts as the mass tourism industry or lead to mass tourism development.

In a number of cases ecotourism's inability to produce its purported benefits has been attributed to industry green-washing. This means that the extreme marketability of the term 'ecotourism' has led airlines, cruise ships, tour operators, hotels, restaurant chains and tourism organizations to re-brand pre-existing practices in an attempt to increase their profits. This has provoked Honey $(1999: 48)$ to coin the term 'ecotourismlite' which she defines as the promotion of minor, cost saving environmental reforms which at times merely amount to adding prefixes such as eco- green- or bio- to the name of the product being sold. This factor is closely related to one of the most prevalent criticisms leveled at ecotourism: that the term is co-opted by political and business interests and ends up benefiting powerful local and global elites who are acutely aware of market trends and who, using political clout and economic influence, are able to muscle out less powerful stakeholders (Duffy 2002: 103; West et al 2003). These practices are a direct threat to the proposed meaning of ecotourism as they often result in a business as usual attitude approach to the industry. In this sense, such practices have also led some to 
question if ecotourism is not simply a re-labeling of the status quo and an excuse for not departing from continued economic growth (Cater and Lowman 1994: 5). What becomes evident in this discussion is that there tends to be a disjuncture between ecotourism in principle and ecotourism as it is practiced and this gap presents the point of departure for this thesis.

Studies of ecotourism often depart from one of two approaches that can be used to highlight the contrast between principle and practice. On the one hand, a large amount of writing and analysis takes ecotourism's principles prima facie and accordingly assumes the practice to be a relatively benign conservation and development strategy. Such contemporary attempts to promote the benefits that ecotourism can offer while simultaneously minimizing its negative effects operates according to a managerial logic. This position represents a policy discourse in which developers, marketers and policy makers define a set of principles attributable to ecotourists and ecotourism and on which the practice is legitimated. On the other hand, a number of authors highlight the negative effects of the ecotourism industry by drawing attention to the structural inequalities that are apparent in its practice, and thus focus on the political economic context in which ecotourism takes place. This particular approach to the topic often assumes that policy discourse expresses a set of objective interests akin to mere rhetoric functioning to provide and ideological screen for concealed intentions (Ferguson 1990: 17-18), namely, continued economic growth through the maintenance of a system of structural inequality. The project that follows addresses the issues presented in these bodies of literature by bringing to light a factor that is curiously missing in much contemporary thought on ecotourism. That is, extended analytical attention to the ecotourists themselves and the 
practice of ecotourism. As Harrison (2003:39) states, “[u]nderstanding what motivates tourists to travel is at the heart of understanding tourism", and I add, at the heart of understanding how tourists can contribute to the principles of ecotourism outlined above. Therefore, this thesis questions the logic of ecotourism by putting the spotlight on the ecotourist and asking how the practice of ecotourism is capable of upholding the principles of a participatory and empowering sustainable development.

Ecotourism's popularity is often attributed to its use as a development strategy or as a conservation tool employed to remedy the ills of the mass tourism industry. The policy discourse that presents ecotourism in this way attributes to ecotourists a deep concern for these issues and sees them as a type of tourist that seeks to take responsibility for the environmental and social impacts that may result from their trip. This representation largely ignores, or possibly takes for granted, that ecotourism is a social practice of those who have the time and money to travel to the Third World for leisure. It performs their desires and represents their motivations which may extend well beyond a concern for protecting the environment and providing development to Third World people. That is, those who are considered ecotourists within this discourse may not see themselves as such. In this sense, I suggest that the practice of ecotourism is a result of the rising popularity of visiting far-off people and places much different than those experienced in the traveler's home country. In essence, it is the experience of a perceived authenticity and a difference represented by particular types of people and places that ecotourists seek above all else and under which conservation and development concerns are subsumed. As a consequence, I question the notion of ecotourism as a new form of tourism with a guiding logic differentiating it from traditional tourism. Rather, I hold that 
ecotourism is undertaken in order to generate cultural capital through the consumption of particular tourist experiences thus creating a degree of social distinction for its practitioners. The attributes ecotourism is able to generate for ecotourists may be its most definitive characteristic and a factor that closely allies it with the traditional industry. Accordingly, I propose that analysis of ecotourism from the position of the ecotourists, their motivations, behaviors and the experiences they desire allows us to apprehend the disjuncture between ecotourism principles and practices.

An issue this thesis project addresses in relation to these considerations is the particular representations that ecotourists hold of the destination people and landscape that their eco-tour is said to benefit. In essence, ecotourism is a very political practice that imbues large tracts of land with a particular set of meanings and values that may or may not be in direct conflict with the meanings and practices of the people who occupy the same ecological space. The political nature of this practice is more than evident in Belize, a country that has taken on the marketing slogan "mother nature's best kept secret" and that promotes large tracts of its territory as 'pristine' and 'untouched' in order to attract a particular type of tourist. These claims, which I argue go unquestioned by many ecotourists, erase hundreds of years of human use and modification as well as historical struggles over the rights to use the land in particular ways. In effect, it would seem that the only group that has been attributed with having an impact on the Belizean landscape is the ancient Maya, one of the largest tourist attractions in the country. By promoting and acting upon nature in the way most desired by a group of consumers, the Belizean ecotourism apparatus consequently bypasses the claims and practices of particular populations in Belize and attempts to legitimate Belize as "mother nature's best kept 
secret", a place reserved for and to be "explored" and "discovered" by ecotourists (BTIA 2007b). Therefore, while promoting benefits for host populations, the discourse of ecotourism, at the same time, poses the threat of dispossession by redefining nature and the rights to use it.

In order to draw my conclusions, I examine ecotourism in light of some distinguishing features found in the sociological and anthropological literature on tourism and tourists. This literature highlights some of the basic qualities that seem to exist in the motivations, behaviors and experiences of almost all international tourists. By examining these qualities of tourism, this project creates a more thorough understanding of the activity of ecotourism and how this practice tends to contradict claims of sustainability, empowerment and participation. By drawing attention to these basic tourist attributes and exemplifying the pressures and consequences that result from the ecotourist's desire for an eco-experience, I intend to bring forward some of the inequalities inherent in ecotourism development that call claims made by the policy discourse into question.

By stating that inequalities are inherent to ecotourism development and that it creates disempowering consequences for some in the host destination, I am inevitably questioning the ecotourism industry's ability to benefit Belizean residents as fully as its proponents claim. In one sense, ecotourism is inherently political in nature and we cannot overlook the power of First World interests and influences. In another sense, by focusing this analysis on the discourse of ecotourism and the power ecotourists have in relation to a destination such as Belize, a concern inevitably arises regarding the agency and autonomy of the Belizean people. That is, an analysis focusing on ecotourism as an expression of power runs the risk of presenting some less powerful actors as incapable of 
resisting, negotiation or in some cases wholeheartedly accepting the changes that this development brings. Of course, this is not my intention and throughout the analysis I highlight the agency and autonomy of Belizean people and their ability to play an active role in shaping the circumstances of their existence. Therefore, this project recognizes asymmetries in wealth, influence and power but does not intend to highlight these factors as necessarily determining Belize's future but as merely one of the dynamics at work in a complex social reality that includes many contending agendas.

In relation to the post-structural underpinnings of this analysis, it is important to note that the theoretical stance I take in relation to subaltern agency is a topic that I am able to only partially explore. The study I undertook in Belize could not provide an adequate Belizean perspective on ecotourism. Belizean perspectives surely do exist and I attempt to highlight them where I am presented with the opportunity. My position as an ecotourist in Belize provided me far more access to other ecotourists and a view of the industry as a whole and in this regard the study takes this context as its focus. In response to these limitations I have presented a number of instances of subaltern agency in Belize but in a historical context as my studies and the ethnographic data I obtained only permit me to proceed in this direction up to a certain point.

\section{Environmental Setting}

Belize is a small Central American country in the far northeast corner of the Central American isthmus. Formerly known as British Honduras it gained independence from Great Britain in 1981. The country borders Mexico to the north and Guatemala to the west and south (see figure 1.1 below) and has a large eastern Caribbean coastline with 
the second largest barrier reef in the world running its full length (Bolland 1977: 1). The country is approximately $280 \mathrm{~km}$ spanning from north to south and $109 \mathrm{~km}$ running from east to west. The total land area of Belize including the over 1000 islets or cayes, is 22 $960 \mathrm{~km} 2$ (Jacobs and Castenada 1998). To put the size of the country into better perspective, Belize is roughly half the size of Nova Scotia, slightly larger than Wales and a littler smaller than he state of Massachusetts (Eltringham 2007:7).

The climate of Belize, on the whole, can be described as subtropical. Temperatures in Belize vary according to elevation, proximity to the coast, and the moderating effects of the northeast trade winds. In the area of Belize City, temperatures range from 19 to $32{ }^{\circ} \mathrm{C}$ with a mean annual humidity of 83 percent. Average rainfall varies considerably in Belize, ranging from $1,350 \mathrm{~mm}$ in the north and west to over 4,500 millimeters in the extreme south. Seasonal differences in rainfall are greatest in the northern and central regions of the country where between January and May fewer than 100 millimeters of rain fall per month (Eltringham 2007: 11).

The $220 \mathrm{~km}$ long Belize Barrier Reef Complex ${ }^{2}$ and the coastline of Belize are the country's predominant tourist attraction. Also of growing significance are the Maya Mountains or Mountain Pine Ridge Massif (see figure 1.2 below). These mountains are the most prominent inland physical feature of Belize and they dominate most of the southern half of the country. The Maya Mountains rise to $1,124 \mathrm{~m}$ at their highest point and are surrounded by rugged karst limestone hills. Beyond this outcropping of

\footnotetext{
${ }^{2}$ The Belize Barrier Reef Complex is part of the larger Meso-American Barrier Reef System. Out of the 4 coral atolls in the coral reef system Belize is home to 3 (Glovers Reef, Lighthouse Reef and Turneffe atoll). The reef system also includes the reefs off the coast of Mexico, Guatemala and Honduras (Cherrington 2004:6)
} 
Figure 1.1: Map Showing Belize

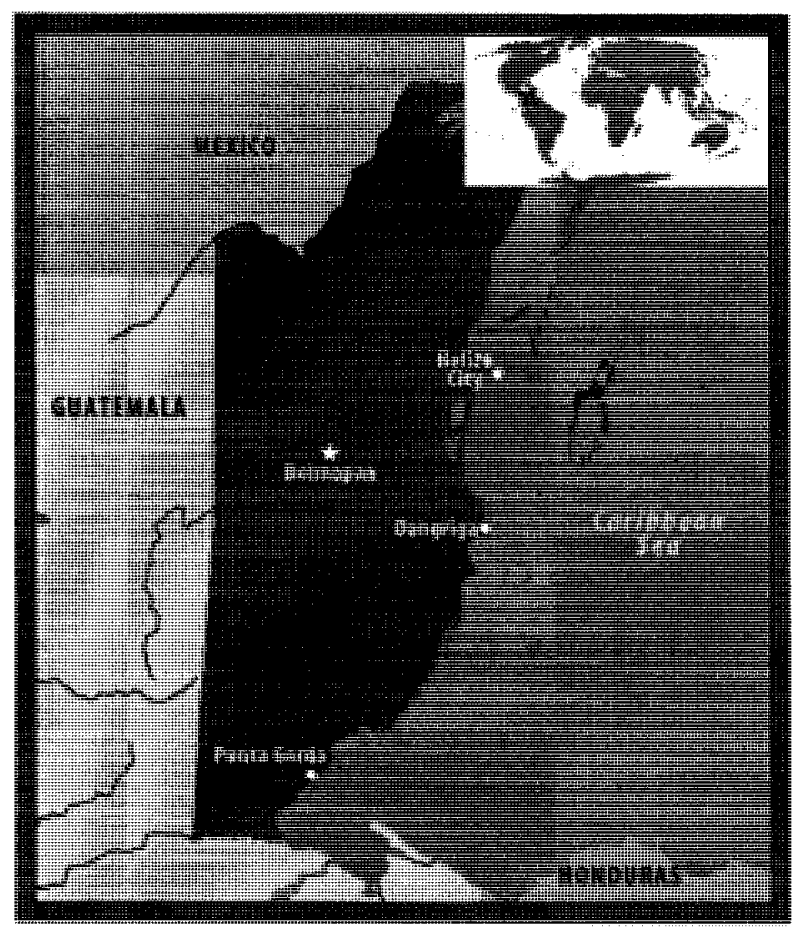

Source: PBS

Figure 1.2: Topography of Belize

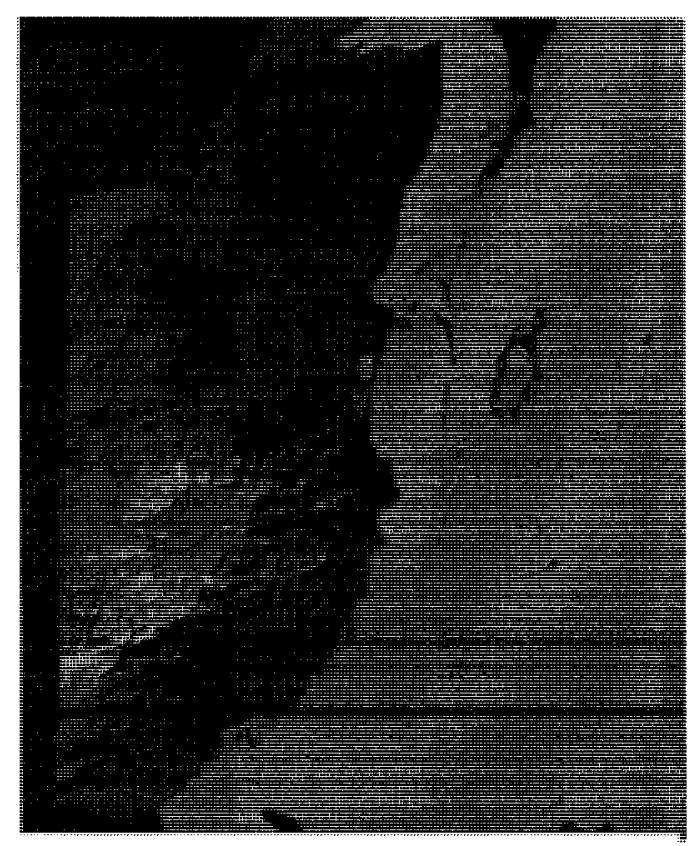

Source: Wikipedia 
mountains the remainder of the country consists primarily of low lying plains (Jacobs and Castenada 1998: 3).

Belize is divided into six administrative districts: Corozal to the north, Orange Walk in the North West, Belize in the central and coastal region, Cayo in the central west and Stann Creek and Toledo districts make up the south. Each district is home to at least one urban area or town and several smaller villages. The Capital of Belize is Belmopan which is nestled in the foothills of the Maya Mountains in the center of the country (Figure 1.3 below).

Figure 1.3: Belize Districts

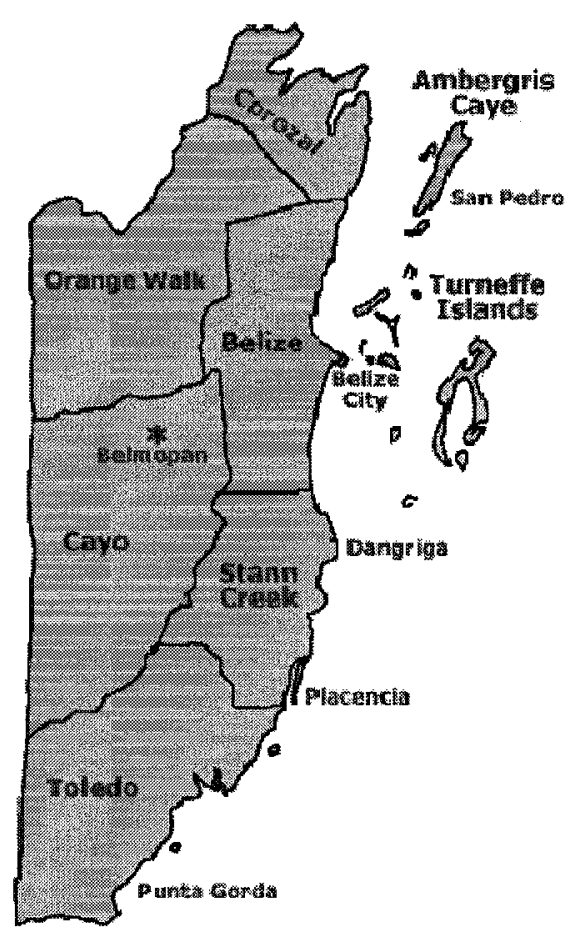

Source: My Belize Adventure 
As of July 2007 Belize's population was estimated at 295,000 people giving it the lowest population density in Central America and one of the lowest population densities in the Americas with roughly 13.5 people per square kilometer (Eltringham 2007: 7). Lindberg and Enriquez (1994:4) suggest that Belize's low population density has allowed the country to retain significant areas under natural vegetation to the benefit of both biodiversity and forms of tourism dependant on natural attractions. As Stinson (2004: 8) notes, $15867 \mathrm{~km} 2$ or 69.1 percent of Belize is under some kind of forest cover including shrub lands providing viable habitat for of a number of species under pressure elsewhere in the Central American Region where high population densities are often linked to deforestation.

Belize offers everything the eco-tourist could want. The relatively undisturbed state of nature in Belize in comparison to some of its Caribbean and Central American neighbors has become a major draw for tourists who come to enjoy the warm ocean, sandy beaches, barrier reef and rugged interior. In these settings a number of nature based tourism activities take place including snorkeling, sport-fishing, scuba diving, sailing, island tours, and jungle and forest safaris (Burks 2006: 14). Belize's landscape also contains a large number of Mayan archeological sites and ceremonial cave systems. These features are an ecotourism draw in themselves as many ecotourists are seeking cultural experiences in addition to a natural one. In effect, both the ancient and living cultures of Belize accentuate the country's natural attractions making it more attractive to ecotourists. The recognized importance of the many archeological sites and the relatively undisturbed state of the country's environment led to over 71 protected areas being declared and 42 percent of the country's land being placed under some kind of protected 
status in the last 25 years (see figure 1.4 below). Due to these factors Belize boasts the highest protected area cover in Central America and is recognized as the most conservation-conscious country in the Americas (Eltringham 2007:345). Largely due to these physical features and the associated tourism activities, Belize has recently employed the marketing slogan "Mother Nature's Best Kept Secret" in attempt to attract a specific type of tourist (Burks 2006: 14).

\section{Economic Setting}

Belize is considered a middle-income developing nation with a per-capita GDP $(\mathrm{PPP})^{3}$ of $\$ 8,400$ in 2006 . The country's economy is primarily based on tourism and the export of agricultural (citrus, sugar, bananas) and marine products (Cherrington 2004:7). Belize's overall GDP (OER) ${ }^{4}$ was $\$ 1.141$ billion in 2006 and the countries total external debt in 2005 was $\$ 1.2$ billion. While Belize has experienced sturdy GDP growth averaging nearly 4 percent in 1999-2006 a major concern continues to be the sizable trade deficit and unsustainable foreign debt. In 2006 the government announced it would seek a restructuring of its sovereign debt and has been negotiating with international creditors to find an acceptable formula for doing so (CIA 2007).

According to the Belize Development Trust (2002), a national poverty assessment report commissioned by the Caribbean Development Bank found that a large percentage of Belizeans are considered poor based on their expenditure on food and non-food items.

\footnotetext{
${ }^{3}$ A nation's GDP at purchasing power parity (PPP) exchange rate is the sum value of all goods and services produced in the country valued at prices prevailing in the United States (CIA 2007).

${ }^{4}$ A nation's GDP at official exchange rate (OER) is the home-currency-denominated annual GDP figure divided by the bilateral average US exchange rate with that country in that year.
} 
Figure 1.4: Protected Areas of Belize

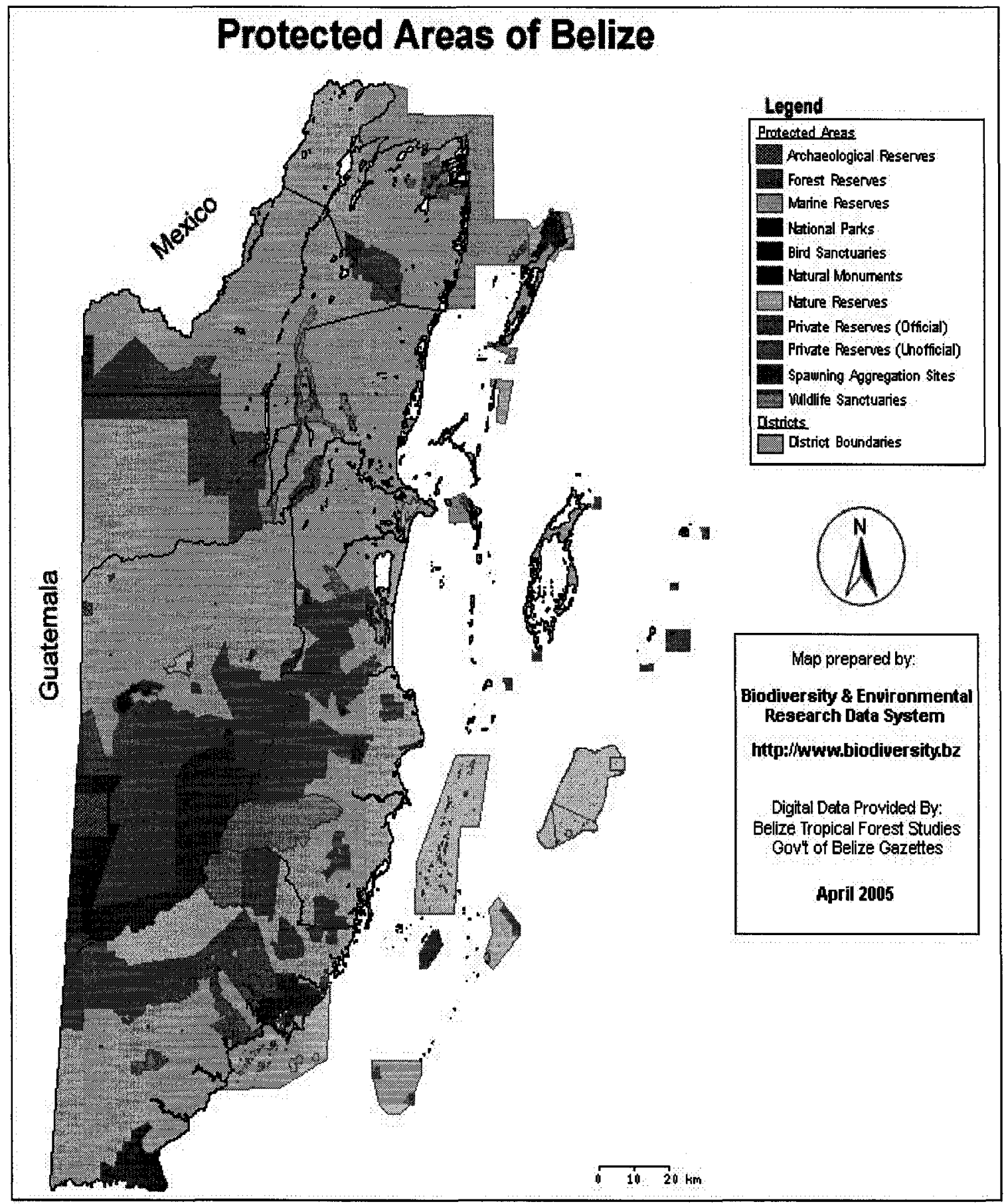

Source: Biodiversity and Environmental Research Data System of Belize 2005 
The report indicated that 25.5 percent of households and 33 percent of individuals in Belize were poor while 13.4 percent of individuals and 9.6 percent of households were extremely poor as their level of expenditure was not high enough to satisfy basic food requirements. Urban residents exhibited a lower level of poverty than the rural with measurements of 20.6 percent and 42.5 percent respectively. Cayo and Toledo districts were the poorest in the country with respective poverty levels of 19.7 percent and 47.2 percent. The Maya were the most heavily represented among the poor relative to their proportion of the population as were Central American migrants. Most people considered poor in the districts of Corozal, Orange Walk, Stann Creek, Toledo and to a lesser extent in Cayo, depend on agriculture and fishing for their livelihood. In the Belize district, those considered to be poor depend on a number of sectors for their livelihood including construction, wholesale and retail activities (ibid).

As the World Bank and International Monetary Fund (IMF) have pressured Belize to resolve deficits in its balance of payments, some hail tourism as a way to diversify the economy and as a potential sector for economic growth (Stinson 2004:11). During the twentieth-century the economy of Belize was dominated by agriculture and forestry but since independence in 1981 the country's economy has become more and more oriented toward the service sector. By 2005 agriculture accounted for 22.5 percent of GDP, the industry sector accounted for 15.2 percent and the service sector accounted for 62.3 percent of GDP (CIA 2007). Tourism in particular has experienced rapid growth in Belize over the past couple of decades. As Gould (1999: 253) indicates, tourist arrivals to Belize increased from 30000 annually in the 1970 's to an average of 225000 annually between 1991 and 1993. Recently (2006), overnight tourist arrivals to Belize reached 
nearly 250000 bringing in an estimated US\$199.4 million in tourist expenditures and accounting for 16.8 percent of GDP (Belize Tourism Board 2007). When one factors in the rapidly growing number of cruise ship arrivals to Belize which brought 851000 guests in 2004, the numbers of total international tourists to visit Belize in 2004 exceeded 1 million bringing in nearly four times the country's population in tourists that year (Belize Tourism Board 2005). As the numbers surely indicate, tourism is now the country's largest contributor to economic growth and accounts for roughly one in every four jobs (Stinson 2004: 11).

The statistics provided above refer to the growth of the tourism sector in Belize in general. As mentioned earlier it is difficult to distinguish exactly what constitutes ecotourism and to lump all tourists in Belize into this category could be contested on a number of grounds. This being the case, it is important to reiterate that ecotourism is the form of tourism that Belize is most expressly interested in promoting and that the vast majority of tourists to Belize could be placed in this category. This is especially true in the sense that it is mandatory for every guest arriving by cruise ship or flying into Belize to contribute financially to the country's conservation and development goals through the Protected Areas and Conservation Trust (PACT). The PACT is an act that was passed in 1996 and introduced a conservation fee for visitors. The tax of US\$ 3.75 is paid upon airline departure or as a 20 percent commission charged to cruise ship passenger fees. The tax is thus placed into an environmental trust fund for redistribution through a series of grants aimed toward "conservation, preservation, enhancement, and management of Belize's natural resources and protected areas" (PACT 2006). As the foundation's website states, PACT intends to "implement programs and projects which enhance the 
quality of life for Belizeans and Belize's role as a world leader in environmental conservation while supporting national developmental goals" (ibid). Taking this small tax into account, nearly every visitor to Belize can be considered an ecotourist whether they like it or not since they directly contribute to the countries conservation and development objectives.

\section{Cultural Setting}

Another aspect of Belize that attracts many ecotourists is the country's rich cultural diversity. Belize's population is primarily composed of Creole (mixed EuropeanAfrican descent) and Mestizo people (mainly a mix of Maya-Spanish descent). The Mestizos represent about 49 percent of the population while the Creoles account for 25 percent. There are three Maya ethnic groups in Belize that make up 11 percent of the population. The Yucatec Maya reside mainly in the northern and western portions of the country while the Kekchi and Mopan Maya make up 60 percent of the population in the southern district of Toledo. Belize is also home to the largest number of Garifuna (Black Caribs or people of Amerindian and African descent) in the Caribbean region (Europa World Plus 2007). The Garifuna, who make up 6 percent of the population are the descendents of the indigenous Arawaks and the Carib Indians for whom the Caribbean Sea is named (Cherrington 2004: 7). The remainder of Belize's population is composed of communities of Asians (mostly East Indians imported to the British Caribbean as indentured laborers), Arabs, Portuguese, Dutch, German Mennonites, and people of other European descent including a growing number of expatriots from North America (Europa World Plus 2007). The official language of Belize is English as it is a former colony and 
current member of the British Commonwealth. Spanish is also widely spoken but it is Creole, a language based on English but essentially Caribbean in nature that almost every Belizean speaks and understands (Eltringham 2007:8). Other languages such as Garifuna, Mopan Maya, Kekchi Maya and Yucatec Maya, as well as German and Dutch are spoken by minorities of varying sizes (Stinson 2004:7).

\section{Field Site and Method}

The research for this thesis project is based on a mixture of library sources and observations and information obtained through fieldwork. The large amount of library sources that I reviewed while producing this document came primarily from the Carleton University Library but I also obtained a large body of material through interlibrary loans and internet sources. In addition to intensive library-based research, I undertook a brief three-week visit to Belize accompanied by my fiancé between December 23, 2007 and January 13,2008 . The trip was conducted in order to gain first hand experience of ecotourism in Belize, to discuss relevant issues with Belizeans affected by the industry and to converse with and observe ecotourists in order to gain a more informed understanding of them as they undertook their holiday. It is important to note that the short time of this fieldwork limited the ethnographic information I was able to obtain but I feel that I have more than accommodated for this deficiency through the use of library sources. As opposed to first hand observation, the secondary sources that I have used to conduct and further my argument have been chosen and included because they accurately represent what I encountered and are used to fill some of the gaps that may result in my own direct observation. 
As discussed above my particular social status as an ecotourist in Belize had both positive and negative consequences and is a factor that shaped the following analysis. As the brief trip we took to Belize was not likely to permit me with an in-depth ethnographic understanding of a Belizean take on ecotourism, I chose to focus the analysis on the ecotourism industry and the ecotourists we frequently encountered (including ourselves). It is likely that an in-depth and multi-sited analysis may have presented very different results and an opportunity to conduct such research would have surely furthered my understanding of the ways Belizean people feel about and act towards the far reaching political ecological agendas impacting their lives.

The information I obtained in the analysis I was able to undertake in Belize was gained through observation and casual conversation with the individuals we encountered. The nature of these interactions has assured that most of the information gathered is representative of the everyday interactions that occur between ecotourists and between ecotourists and their hosts. I feel that the method that I employed to undertake this research is the most accurate way to approach the issues discussed in the course of this project as it presents ecotourism as it occurs on the ground allowing the words and actions of both the hosts and the guests to be analyzed.

Although time in Belize was limited in terms of conducting in depth ethnographic fieldwork, our role as an ecotourist couple did permit us access to conversations and interaction between ecotourists and between Belizean people and other ecotourists apart from ourselves. I feel it is important to note that the interactions that may have occurred if I was on my own may have produced somewhat different results and that our status as a couple partially shaped the types of encounters we engaged in and thus the information 
that was obtained. This particular status allowed us to be treated in much the same manner as any other ecotourist couple and I feel safe saying that this status was largely responsible for permitting more trust and acceptance resulting in us gaining more access to the situations and interactions I was able to observe.

The analysis I undertook was a multi-sited approach, as like most ecotourists, we attempted to see as much of Belize as possible in the time that we had. Upon our arrival we traveled to Caye Caulker and I observed marine ecotourism as it occurred at a popular reef destination. We then traveled south to the small Garifuana village of Hopkins where ecotourism was beginning to blossom and permeate the community. There I found a large contrast between the lives of village residents and the leisure of the ecotourists. From Hopkins we traveled inland to the Cockscomb Basin Wildlife sanctuary (Jaguar Reserve) and stayed in the town of Maya Center. Finally we traveled to the Placencia Peninsula, a quickly expanding tourism destination and possibly one that is on the way to becoming the most popular in Belize because of its large natural beach. In each destination we made an effort to engage in nature- and culture-based tourism activities where possible and this was not difficult as each of these destinations offers tours and trips to nearby attractions.

What I found most evident when visiting Belize and speaking to residents were the comments made by many Belizean who noted how they (the average person) receive nothing from much of the tourism development that is occurring. Also interesting was the contempt that I saw for tourists taking pictures without asking (framing thing as primitive and "Third Worldly"), the large amount of foreign ownership evident in the tourism industry and the claims of corruption at all levels of government and some conservation NGOs. These observations have been large contributing factors to the analysis that I have 
undertaken but with the above in mind it is important to note that in the pages that follow I am not insinuating that ecotourism is an unwanted development in Belize. Ecotourism surely creates many occupations and has many linkages to other industries in the country that are important for creating and maintaining jobs and local economies that many people valued highly.

\section{Structure of Thesis}

This project is divided into five chapters. Chapter Two consists of an in depth review of the ecotourism literature that analyzes both the managerial approach and the political economic approach to studying ecotourism. This chapter discusses the current discourse of ecotourism and places it in the context of its use as a tool for achieving economic development that is sustainable, participatory and empowering. In the later part of the chapter, some dominant themes in the sociology and anthropology of tourism are presented which set the stage for the discussion in Chapter Four that analyzes the practice of ecotourism in Belize. Overall, Chapter Two outlines two dominant approaches to the study of ecotourism and locates the focus of this thesis in relation to this literature. Chapter Two also presents a brief introduction to the study of political ecology, a form of analysis that the project represents in its entirety and a method of analysis used to present the history of Belize in Chapter Three.

As mentioned, Chapter Three will discuss the political ecology of Belize. It does this by taking an historical look at the various internal and external forces that have shaped the country over time. This chapter is intended to provide a background to the political economic climate of the country tracing its links to colonial powers and the 
particular human-ecological relationships that influenced Western interest in the region. This chapter also facilitates an examination of the early social structure of Belize and displays the ability of the less powerful, in this case enslaved, actors in the settlement to play an active role in determining social relations. In addition, I will analyze the role of this group in shaping a socio-ecology that gives them a particular association with the landscape today. By demonstrating the agency that early Belizeans exhibited in shaping the political, economic and ecological aspects of the country through conditions of extreme inequality, this chapter sets the stage for the main analysis which examines the contested terrain of ecotourism and questions the ability of powerful actors to assert their interests in a purely deterministic fashion.

Chapter Four takes as its focus a close examination of ecotourism and the ecotourist in the Belizean context and analyzes some important aspects of this form of tourism as a social practice. In this chapter, I analyze ecotourism as an emergent form of consumption undertaken by the growing middle classes of the First World. By looking closely at the emergence of ecotourism and the motivations, behaviors and desires of ecotourists, this discussion questions ecotourism's widespread acceptance as a sustainable development strategy. Chapter Four returns to the discussion in Chapter Two concerning the basic aspects of tourism as a social practice. Like traditional tourists, I argue that ecotourists are primarily engaged in an individualistic pursuit of experience that results in a number of negative social and environmental consequences for the host destination. The practice of ecotourism and the ecotourist's pursuit of experience inevitably make claims concerning Belizeans, about what Belize's "natural" environment should be used for and by whom. Thus, this chapter questions claims that ecotourism is a 
"new" and "responsible" form of tourism and rather presents it as more closely representing the motivations and desires of First World travelers and creating similar impacts as the mass industry.

In closing, Chapter Five will provide a brief review of the project and pose questions for further analysis. This chapter highlights the main points of the preceding project and gives consideration to the links between tourism and anthropology that this project presents. 


\section{Chapter Two: The Nature of Ecotourism: exploring the literature}

\section{Introduction}

Over the past couple of decades, the topic of ecotourism has gained institutional legitimacy and a number of organizations and academic journals have been devoted to its study (West and Carrier 2004: 483). Upon reviewing a large amount of published literature on the subject, it becomes evident that much academic thought on ecotourism can be divided into two general approaches, both of which run through much of the development and conservation literature as well. I will review and analyze these approaches here for what they offer to current understandings of ecotourism and for what each of them lacks. This review will provide the foundation of my approach to ecotourism as much of what is encountered here focuses on income generation, community participation, and impacts that the industry has on destination people and places. In this regard, much of what has been written on ecotourism and its associations with development pays little attention to the actual activity of being an ecotourist and the ecotourists' imaginings of their Third World destination. Thus, to better understand ecotourism some of the more prevalent approaches in the anthropology and sociology of tourism will be reviewed and assessed for what they can contribute to the way we comprehend ecotourists. Following an introduction to the political ecology of Belize in Chapter Three, which explores a history of people living on and using the land in various ways, Chapter Four will then analyze ecotourism in Belize using the argument developed here. I do this to question ecotourism as a sustainable development strategy by showing the disjuncture between the principles that ecotourism discourse espouses and the practice of ecotourism that tends to contradict these principles. 


\section{The Literature Divided}

Ecotourism literature, much like the wider body of literature on conservation, development and tourism, can be divided into two main approaches that represent differing schools of thought. The first can be labeled as the political economy approach and this approach is based on the idea that tourism in general has evolved in a way that is very close to historical patterns of colonialism and economic dependency (Lea 1988: 10). The other school of thought employs a managerial approach and is not as concerned with the political economic context in which tourism development takes place. In contrast to the political economic approach, which generally exhibits a negative tone toward the effects of tourism, the managerial approach pays little attention to change, politics and the historical experiences that have structured the industry (ibid).

The managerial approach is most concerned with ecotourism's efficiency in attaining maximum benefits and minimizing negative impacts. This approach represents a policy discourse that most often highlights the economic importance of ecotourism as a development strategy and downplays or ignores some of the more political aspects of conservation and development (Stinson 2004: 20). Those working from this approach often take as their starting point the notion that ecotourism provides a clear link between conserving natural habitats and providing economic development (Wearing and Neil 1999: 132). For those whose work falls within this approach, the logic of ecotourism is clear: if people are given the opportunity to realize a profit from an "intact" environment, they will rely less on extractive practices and work to protect resources becoming conservation minded in the process (see Horwich and Lyon 1998, 1999; Lindberg et al 1996). Thus, the objective of this approach often focuses on attaining economic benefits 
from ecotourism while reducing negative impacts or costs in an attempt to instill or maintain a conservation ethic in the intended beneficiaries.

The managerial approach casts problems in terms that are capable of resolution through good management and appropriate policy measures (Lea 1988: 11). Such discussions often make assumptions about the state and social actors that obviate the need for political analysis (Bryant 1991: 164; Ferguson 1990). In terms of resident populations, this discourse comprehends people as economically rational actors and expects that economic incentives can overcome barriers to conservation and development. The managerial approach thus portrays ecotourism as a way for stakeholders to become involved in protected area management by giving them incentive to pursue ecotourism rather than resource extraction. It is also important to note here that the "ecotourism boosters" as West et al (2003:105) refer to them, similarly assume that ecotourism attracts a new breed of responsible traveler intent on providing ecological and social benefits (Fennell 1999; Wearing and Neil 1999; Wearing and Wearing 1999). By operating from within this discursive climate the managerial approach to ecotourism largely overlooks, or is prevented from seeing, that this representation may not be an accurate portrayal of those people deemed to be ecotourists.

The managerial approach often operates unproblematically from within the ideological climate of neoliberalism. This particular political economic climate has become especially potent in the Third World countries where ecotourism has become popular (West and Carrier 2004: 484). The core prescriptions of neoliberalism are "privatization, deregulation and liberalization, all encapsulated within political beliefs about democracy, entrepreneurship, and individual freedom" (Peet 2002: 65). West and 
Carrier (2004: 84) contend that these prescriptions indicate two pertinent aspects of neoliberalism, "the political and the economic".

In its political aspect it stresses "the community" or, latterly, "civil society," local voluntary institutions and organizations, at the expense of state agencies. Those agencies are seen as lethargic, inefficient, and unresponsive, while local groups are seen as energetic, efficient, and democratic. In its economic aspect, it demands the reduction of state financial power and fosters market-based models of political-economic and even social life (ibid).

The economics of neoliberalism dictate that ecotourism is an attractive industry for countries with few resources available for environmental protection and rural development (Belsky 1999). Belize, like many other developing nations, has a comparative advantage in the variety and extent of its "unspoiled" natural environments. By promoting ecotourism, tourism companies and the nation state have the opportunity to capitalize on this comparative advantage while at the same time generating opportunities for both conservation and economic development (Cater 1994: 69). From the managerial perspective, ecotourism is a way to create a number of employment opportunities, especially in rural areas, while at the same time diversifying the economy and attracting much needed capital to provide infrastructural and technological improvements (Horwich and Lyon 1998).

I do not mean to insinuate that those working from within the managerial approach are purely optimistic about ecotourism. Many admit that ecotourism has a number of drawbacks and should not be treated as a panacea. Horwich and Lyon (1998; 1999), who have somewhat pioneered community based ecotourism development in Belize, note a number of issues that must be confronted and which can produce negative effects. They highlight the ability of private interests to exploit the profitability of 
community based ecotourism, the environmental degradation that occurs due to increased visitation to an area as well as the disruption of rural livelihoods due to a loss of access to resources. But in their final analysis of ecotourism, they, like many others, feel that under properly managed conditions ecotourism is a viable conservation and development tool.

Despite these drawbacks, effective ecotourism remains a viable tool that can interest and motivate rural people to protect the wildlands where they work and live. Given attainable economic incentives, true local involvement in the management of lands, and a proper framework, many rural people have shown that they will take responsibility to protect their lands (Horwich and Lyon 1998:343).

Horwich and Lyon are closely involved with a consulting firm called Community Conservation and like them, those who write from the managerial perspective are often involved in ecotourism development as consultants for the industry or employed by lending institutions, conservation organizations or the non-governmental sector. A significant amount of work has been produced from within these institutions including the WWF (Boo 1990; Lindberg and Enriquez 1994), WTO/UNDP (Poon 1989), World Bank (Brandon 1996), IUCN (Ceballos Lascurian 1996; Eagles et al 2002), TIES (Lindberg and Hawkins 1993; Sproule and Didato 1998) and Conservation International (Ziffer 1989).

Similar to what critics of international economic development have pointed out (Bryant 1991; Escobar 1995; Ferguson 1994; Sachs 1993; Sundburg 1998), the managerial approach to ecotourism situates its practice within a techno-managerial perspective. This discourse understands problems in terms of what goes wrong, why, and how they can be fixed, allowing strategies to be formulated and implemented seemingly without conflict (Bryant 1991: 164). 
The other main approach to the study of ecotourism is the political economy approach that draws heavily upon dependency theory (Lea 1988: 11). This approach suggests that international tourism flourishes in a world economic system characterized by severe distortions and imbalances. According to those writing from this persuasion, tourism often perpetuates the unequal relationships between the First and Third World (Britton 1982; Lea 1988; Pattullo 1998). Third World ecotourism emanates from the desire of affluent middle classes in First World countries to travel abroad and it is companies in these countries that have emerged and positioned themselves to service this demand (Lea 1988: 12). Small underdeveloped countries like Belize are placed at a disadvantage due to these circumstances that often derive from a history of colonial domination and exploitation (Britton 1982; Hall 1994; McLaren 1998).

This approach holds that neoliberal economic policies have effectively prevented small entrepreneurs and locally owned business from competing with large foreign investments. As discussed above, globalization and the neoliberal world order have opened countries to foreign investment and lowered trade barriers. Through free trade agreements such as the General Agreement on Trades and Services (GATS), the power of governments to protect and control their labor markets and resources are undermined (McLaren 1998: 14). Such developments have spurred further economic integration throughout the tourism industry as a whole meaning that the foreign ownership of travel agents, tour operators, hotels, transportation companies and suppliers is on the rise. These developments, coupled with the billions of dollars dedicated to ecotourism by international lending and aid agencies, amount to subsidies for the private sector as state run enterprises are shutting down and being replaced by state supported corporate 
developments (Honey 1999: 14). The effect of this has been an undermining of ecotourism's stated goal of socioeconomic involvement by local people (Moreno 2005: 218). Foreign firms from industrialized countries and multinational tourism conglomerates, seeing profitability, often make their way into the ecotourism market and monopolize tourism benefits (Honey 1999: 86). These conglomerates, usually allied with local elites, control ecotourism and squeeze out local operators in a structural process that is often created, enhanced and preserved by power and influence relations throughout the tourism sector (Duffy 2000, 2002: 127-54; West et al 2003: 105). According to West et al (2003: 105), a World Bank report stated that 55 percent of tourist spending in developing countries eventually leaks back to developed countries as many goods and services are imported and profits are repatriated.

The political economic approach to ecotourism often highlights the similarities between traditional tourism and ecotourism treating both as a threat to local economies, cultures and environments (Hall 1994; McLaren 1998; Mowforth and Munt 2003; Munt 1994a, 1994b; Pleumarom 1996, 1999). As Pleumarom (1996) notes:

Many of the claims concerning the benefits of eco-tourism have been exaggerated, or owe more to labeling and marketing, as such projects are often planned and carried out without local consent and support, and indeed threaten rather than benefit local people's cultures, their subsistence economies and life-sustaining natural resource base. It is because of this that critics regard eco-tourism more as an "eco-facade" and as a tactic to conceal the consumptive and exploitative practices of the mainstream tourism industry - by "greening" it.

Thus, the political economy approach sees the sustainable development discourse that informs ecotourism as largely manipulating the perceptions of Third World governments and communities by promoting ecotourism as empowering and participatory (Stinson 2004: 25). Further, Pleumarom (1999) contends that it is more 
often the case that tourism in developing countries is a continuation of former colonial relations because from the very beginning, tourism has benefited from international economic relationships that structurally favor the advanced capitalist countries in the North. Unequal trading relationships, dependence on foreign interests, and the division of labor have relegated poor countries in the South to becoming tourism recipients and affluent countries in the North to the position of tourism generators (Pleumarom1999:1). As previously mentioned, the political economy approach is replete with references to colonization and imperialism and there are numerous authors who highlight this aspect of the industry (Hall 1994; Mowforth and Munt 2003; Munt 1994; Southerland 1998; Wearing and Wearing 1999; West et al 2003). McLaren (2003: 14) suggests that in a cultural sense "ecotourism sends the shock troops of middle class values and tastes encouraging the abandonment of language and traditional ways of life". Southerland (1998) and Pleumarom (1996) similarly equate environmentalism as similar to the missionization that took place in colonial times and contend that these ideas are exported to the Third World in a similar fashion. Munt goes as far as directly equating ecotourism with colonization in that it contains nostalgia for a romanticized sense of exploration and discovery. He goes on to rename the three S's of traditional tourism (sun, sea and sand) as "subservience, subjugation and servitude in the content and outcome ecotourism" (Munt 1994: 54).

There are numerous scholars that have implemented a political economy approach to ecotourism in Belize and have used it to demonstrate the influence of foreigners, expatriots and multilateral and bilateral donors in the Belizean tourism industry and environmental movement (Cater 1994; Dufy 2000, 2002; Honey 1999; Medina 2005; 
Moreno 2005; Mowforth and Munt 2003; Pattullo 1996; Southerland 1998). These scholars represent a wide spread concern noted by many commentators on Belize that local residents are often excluded from the development process and that benefits of ecotourism accrue to wealthy foreign and local elites (Stinson 2004: 27).

While both of the above approaches to the study of ecotourism offer a different outlook on ecotourism development they can each be seen to offer something of value to its study. The managerial approach, though unconcerned with what could be termed the 'deep' issues of ecotourism, takes a pragmatic approach to the subject working within a particular ideological system and attempting to better the practice. As the political economic critique has demonstrated though, such efforts are likely only capable of creating minor improvements since there are deep-seated structural constraints that go largely unaddressed. On this note, the value of the political economic approach lies in its critique of managerialism and its emphasis on the centrality of multilateral and bilateral donors (Duffy 2002; Honey 1999; McLaren 1989), foreign ownership (Moreno 2005; Wearing and Wearing 1999; Mowforth and Munt 2003), structural inequality and the primacy of the wider political economic climate (Carrier and West 2004; Hall 1994; Moberg 1992; Medina 2004).

Apart from having obvious merits in terms of their respective purposes, both of these approaches can be seen as lacking. The managerial approach can be seen as deficient in terms of the apolitical discourse it espouses and on which grounds the political economy approach bases its criticism. On the other hand, much of the political economy literature can be criticized on the grounds that it overemphasizes the power of conservation and development interests in which outcomes are seen to represent a set of 
objective interests that are uncharacteristically effective (Bebbington 2000; Crewe and Harrison 1998; Thomas 1994). The following paragraphs present a short discussion of a debate central to the field of international sustainable development. By briefly presenting this argument, this section provides a picture of the development encounter as containing an improvisational and interactive dimension. Similar to what Nicholas Thomas (1994) has shown to occur in the colonial encounter, this discussion is intended to show that development and especially ecotourism development is less monolithic, more complex and more experimental than it is generally imagined to be in both of the academic approaches described above.

\section{The Nature of Community Development}

The most prominent perspective from which to depict conservation and development as Western impositions have been poststructuralist accounts which emphasize a concern with power/knowledge institutions and regimes of truth (Escobar 1995; Ferguson 1990; Sachs 1993). These authors, though distinct in their approach and subject matter, are all similar in that they heavily criticize the technocentric and managerial discourse employed by the managerial approach. Sachs (1993: 11) observes that phrases like 'integrated approach', 'rational use', 'sound management', 'better information' and 'increased coordination' all treat sustainable development in the Third World as homogenous, passive and subject to the plans and desires of powerful First World interests. Critical stances such as Sachs' portray global sustainable development initiatives in a light that makes their logic nearly insurmountable and unchallengeable. As Sachs (ibid) notes, discourses of "sustainable" development and managing the global 
environmental commons never seem to question or even acknowledge First World consumption practices. Scholars who write from a postdevelopment perspective tend to focus on the efficacy of development discourse to construct the development encounter between the First and Third World. The most emblematic of this type of analysis is Arturo Escobar's Encountering development: the making and unmaking of the third world (1995). In his account, Escobar draws heavily on Foucauldian discourse theory, and Edward Said's (1979) Orientalism relating that the development establishment which emerged at the end of World War II has constructed the Third world as an object of analysis and intervention by discursively creating the people that live there as undeveloped (Escobar 1995: 4). In his analysis Escobar argues that Third World people are constructed through development discourse with a number of negative features such as "powerlessness, passiveness, poverty and ignorance"; these attributes, he argues, function to legitimate development interventions (ibid: 4-8).

A criticism often leveled at this approach to development discourse, and by extension the sustainable development discourse, is that it overemphasizes the power of discourse and undermines the ability of Third World people to shape development interventions through attempts to improve their material conditions of living (Bebbington 2000; Edelman 1999; Moss 2001). As Escobar (1995) presents the development encounter, the role of developers is to develop while the actions of intended beneficiaries are responses to development (Crewe and Harrison 1998: 18). The result is an oversimplified scenario in which "there is development and there are victims of development" (Grillo 1997: 21). Crewe and Harrison suggest that many circumstances may influence responses to development and developers, and that they are often 
unconnected to development activity itself. Escobar's polemical (de)construction of the development encounter negates the ability of Third World people to accommodate, negotiate or subvert the plurality of discourses to which they are subject, let alone generate any of their own.

Thus, poststructuralist analysis usually presents development discourse as a powerful and unitary project (Thomas 1994). These accounts often leave the impression that development discourse is omnipotent, unchanging and reified beyond the point of control by people (Rangan 1996: 207). Extrapolating from this argument, the political economy approach to ecotourism can be criticized on similar grounds as the postdevelopment literature. Authors writing from this approach (see especially Carrier and West 2004; McLaren 1989; Southerland 1989; West et al 2006) often assume that conservation, and by association ecotourism, are expressions of global environmentalism and capitalism, which they equate with oppression and acculturation. Much like the postdevelopment literature, this assumption seems to appeal to a romanticized notion of Third World people as ecologically noble, living largely outside modernity and threatened by it (Bebbington 2000; Edelman 1999). As a number of authors note, these images are transposed onto rural communities and often misrepresent them as being steeped in tradition, homogenous, static and spatially bounded (Agarwal and Gibson 1999; Leach et al 1999; Li 1996; Nygren 1999).

Ironically, the managerial approach to ecotourism often employs a similar representation of the "local community" to advance claims of participation and empowerment that often impacts the way communities are engaged by ecotourism projects. By conflating the rhetoric of community involvement with actual participation, 
proponents convince themselves that they are following the optimal strategy. Johnson (1998: 306-7) shows that in the Belizean village of Crooked Tree participation in ecotourism has become a point of contention. She suggests that the way conservationists pursue community participation, or a bottom-up approach, more closely resembles a top down phenomenon.

In reality, in cases too numerous to name, government officials and conservationists who have a great amount o power set agendas, set times and make decisions, while the rural people who are supposed to be "participating" are merely invited to sit and listen and perhaps occasionally ratify something through a vote (ibid 307 ).

In effect, she suggests the representation of the "local community" held by planners result in a context of top down planning, top down funding, and upward accountability that negate real participation (ibid)..$^{5}$

Recently there has been a call for a more informed representation of "local communities" and their participation in community development projects (Watts 2000). This call has largely been answered by a number of scholars employing a political ecology approach (Belsky 1999; Peet and Watts 1996; Stonich 2000; Stronza 2000, 2005; Watts 2000). Political ecology is concerned with how political relations work themselves out through different ways of understanding and acting upon an environment which simultaneously represents the by-product of varying human conceptualizations, activities and regulations (Escobar 1999). Increasingly, discourse analysis is being used in political ecology and from this analytical perspective it can bee understood as the formation of apparently stable environmental regimes produced discursively through signifying practices of various sorts (Biersack 2006: 4). Political ecology explains how human-

\footnotetext{
${ }^{5}$ See Belsky 1999, 2000, 2003 for similar discussions concerning the American consulting group Community Conservation and the village of Gales Point Manatee.
} 
environmental interaction is linked through various scales ranging from the global to the local (however they may be defined). One of the most central features of such analysis is the relative power of social actors that affect access to, management and even discursive definition of, natural resources (Stonich 2000: 21). In effect, political ecology can be seen as an attempt to understand the way that the environment embodies relations of power and inequality in particular locations and societies (Bryant 1991). Such analysis has been employed in Belize by Belsky (1999) in the village of Gales Point and by Johnson (1998) in Crooked Tree. ${ }^{6}$ By employing a politicized understanding of human-environment interactions they have shed light upon the diverse interests and influences that affect the projects they study. Both Belsky and Johnson provide empirical evidence to critique the essentialist images which conservation and development personnel often employ while at the same time demonstrating the nature of communities as inherently tied to wider political and economic forces not necessarily opposed to them (Watts 2000: 21-2). As Belsky states in reference to the conservationists who initiated the Gales Point project:

The conservationist imaginings of the Gales Point community did not acknowledge differences within the community, how these differences could affect ecotourism and use of natural resources, local politics, strategies for pursuing multiple interests within and beyond the local community, or the complexity of layered alliances that extend across numerous levels of politics.

As Belsky $(1999 ; 2003)$ demonstrates, some of the people in Gales Point accepted and participated in ecotourism, some resisted (with arson!) and others imbued the concept of community ecotourism with a private entrepreneurial logic moving it beyond recognition as a community endeavor. In this sense, and contrary to the political economic approach, ecotourism developments should not be seen as an oppressing Western influence that

\footnotetext{
${ }^{6}$ Stinson (2004) also employs a political ecology approach in his stake holder analysis (SA) concerning the Indian Creek Trail Project (ICTP) in Belize.
} 
forces people into positions of subservience. Rather, it may often be the case that communities actively pursue ecotourism as a means of generating income or as a way to assert claims to land and resources.?

The above discussion has focused primarily on presenting some of the issues and influences that have played a large role in current understandings of ecotourism and the larger sustainable development framework that informs it. An important problem with these literatures, in my opinion, is that ecotourists themselves and the actual practice of ecotourism have been largely omitted from most analyses. Even the political ecology approach, for all of its strengths, does not pay a significant amount of attention to the actual ecotourist or the practice of ecotourism. The literature discussed above seems to suggest that the popularity of ecotourism stems from its use as a development strategy or from its use as a conservation tool and largely ignores, or possibly takes for granted, tourism as a social practice performed by those who have the time and money to do so. In my experience, there is much more to the motivations and behaviors of ecotourists than a concern for protecting the environment and providing economic development for Third World people. In effect, for the sake of argument, one could claim that ecotourists do not want development for their hosts since it is the undeveloped state of the destination that attracts them in the first place. Yet, much of the literature seems to insinuate that not only is conservation and development the ecotourists' objective, but that these effects are intrinsic to their role as ecotourists. Conservation and development are seemingly the

\footnotetext{
${ }^{7}$ The Toledo Ecotourism Association (TEA) is a good example of how a number of Maya communities in the South of Belize have attempted to assert their rights to land and resources through ecotourism. The TEA is considered the largest indigenous ecotourism association in the western hemisphere. Though successful in a number of respects and an example of a controlled and participatory development strategy the TEA is currently facing competition from foreign investors and travel agents who are setting up similar village programs, some of which are much better funded. This being the case, the TEA is now using ecotourism as a platform from which to voice political and environmental concerns and assert their autonomy in the area (Pattullo 1998: 122).
} 
main topic of discussion in the three-way conversation between ecotourists, host populations and Third World landscapes. As will be discussed further in Chapter Four, the perspective of ecotourism planners and proponents is largely disconnected from the perspective of ecotourists, whose motivations and objectives are not as explicit as the former makes them out to be. In fact, I show that many ecotourists would not identify themselves as such and though they do not reject the principles of ecotourism, they are acting on a different set of motivations. Thus, the practice of ecotourism throws into question claims that ecotourism is a participatory, empowering and sustainable development strategy.

In order to facilitate discussion and analysis in Chapter Four, the following section presents some salient features of the literature on tourism in general. This discussion will draw out some of the basic qualities present in most tourist motivation, behaviour and experiences. I argue that ecotourism as a form of tourism cannot be separated from these generalities and that the information presented here is valuable for understanding ecotourists and how their practice fits into notions of sustainability, empowerment and participation in the host destination.

\section{Tourism: Authenticity, Play and the Sacred Journey}

What motivates tourists to travel is a question that has provoked numerous studies and numerous interpretations of what it means to be a tourist. The following section will briefly summarize three dominant themes in the tourism literature concerning tourist motivations, experience and behaviour. These three categories can be defined as follows; tourism as a quest for the authentic self (MacCannell 1989); tourism as a form of play 
(Cohen 1984) and the understanding of tourism as a sacred journey (Graburn 1977, 2001). Though presented here as separate and possibly even competing representations, these tourism theories should see be seen as complementary to one another, each contributing aspects others have overlooked.

Dean MacCannell's now famous The Tourist first published in 1976 was one of the earliest to address the now ubiquitous concept of authenticity in tourism. For MacCannell, all tourists are seeking authenticity. He suggests that to the extent that tourist's are alienated from their modern home society they develop an interest in the 'real life' of others (1989: 91). "For moderns, reality and authenticity are thought to be elsewhere: in other historical periods and other cultures, in purer, simpler lifestyles" (MacCannell, 1989: 3). Paradoxically, the commoditization that MacCannell sees occurring in tourism is said to destroy the authenticity of local cultural products and human relations while in its place, a covert, 'staged authenticity' emerges (MacCannell 1989: 91-109). MacCannell thus divides tourist areas into "front" and "back" stages in which tourists attempt to penetrate the front stage, contrived for them, in order to get a glimpse of the authentic back stage. Increasingly, these back areas are staged for tourist consumption and thus localities are promoted as being remote, or "non-touristic ("Mother Nature's Best Kept Secret"), in order to induce tourists to discover them (ibid).

Therefore, in MacCannell's view, what is taken to be entry into a back region is often entry into a front region that has been staged in advance for the tourist. As MacCannell sees the modern tourist as the embodiment of the religious pilgrim and tourism as a surrogate for religion, it is implicit in his analysis that there is no salvation in tourism. The fully developed tourist system surrounds the tourist with staged tourist 
spaces, from which there is no exit and the modern tourist pilgrim is thus damned to inauthenticity. That is, "the more tourism flourishes, the more it allegedly becomes a colossal deception" (Cohen 1988: 373).

Tourism is often tied to the metaphor of voyage, the idiom of exploration and the separation of home from away (Harrison 2003: 26). These are concepts that are embedded in Western thinking and which have been used to draw numerous comparisons between the tourist and the religious pilgrim. The tourist as pilgrim concept is one that was heavily drawn upon in the 1970s by an anthropologist named Nelson Graburn (1977, 2001). Taking what Suvantola (2003: 54) calls a Turnerian approach to ritual, Graburn drew upon Van Gennep's (1908) The Rites of Passage and Victor Turner's (1974) notion of the liminal in his study of the tourist's experience (Suvantola 2003:54-55) ${ }^{8}$ Thus Graburn suggests, "Tourism is a kind of ritual, or sacred journey, one in which the special occasions of leisure and travel stand in opposition to everyday life" (2001: 42, emphasis in original). Graburn claims that touristic travel represents a negation of many of the features of the everyday social structure, and affirms another order of things.

Vacations involving travel (i.e., tourism) are the modern equivalent for secular societies to the annual and lifelong sequences of festivals and pilgrimages found in more traditional, God-fearing societies. Fundamental is the contrast between the ordinary/compulsory work state spent "at home" and the extraordinary/voluntary metaphorically "sacred" experience away from home (Graburn 2001: 43).

Tourists decide to leave or "get away" from home because there is something there that they want to get away from, and they choose a particular destination because they believe

\footnotetext{
${ }^{8}$ Liminality is a term strictly tied to the rites of passage. Liminality was a natural part of initiative rituals in tribal and early agrarian societies. Thus experiencing it was an obligation for all members of a society. In industrial and post-industrial societies rituals are separated from the sphere of work and obligation and are thus more or less based on voluntary participation. Thus Turner and Turner (1978) employ the term 'liminoid' to refer to optative stages more characteristic of modern secular contexts, such as leisure (Suvantola 2003:55).
} 
that they will experience something positive there that they cannot experience at home.

The ritual inversion of daily life that Graburn speaks of is not a total opposite, but a close reflection of the felt needs of the tourist, or what they look for or forward to in their travels. For example, the erudite professor does not seek to become ignorant on his/her holiday nor does the athlete try to become physically incompetent. "The felt needs of the tourist are indeed the product of, or an inherent part of, the values of the home class and lifestyle" (Graburn 2001: 43).

Cohen (1984), similarly draws upon the Turnerian approach in order to point out a significant issue that he sees omitted from MacCannell's analysis, namely, the suspension of everyday obligations, the freedom that tourists enjoy and their license for playful, nonserious behaviour in the far-away place. He suggests that through travel, tourists achieve the liminoid stage marked by the removal of responsibilities and roles they have at home. Travel becomes a play in which we can act out our new roles and engage in ludic behavior seemingly without worry or consequence (Harrison 2003: 31).

In the Turnerian approach to tourism, the tourist is very similar to that which MacCannell theorized. The tourist leaves home goes to a distant location and returns home. While at the far place the tourist, like the pilgrim, engages in 'worship' of shrines which are sacred, albeit in different ways, and as a result gains some kind of uplifting experience (Urry 1990: 100). The difference is in the idea that travel is anti-structure; it is a liminoid period between leaving home and returning when the usual everyday norms of behaviour can be abolished (Suvantola 2003: 57-8). This explains the playful aspects of tourism and travel that MacCannell's approach misses. Therefore, by combining these two approaches tourism can be seen as an attempt to achieve both authenticity and fun. 
These two theories of tourist motivations may still be lacking in that they are unable to extend their claims to all tourists. What is to be made of trips and vacations that more closely represent a holiday version of people's everyday lives? The luxuries and amenities of home are something that many tourists would not consider going without and in many instances these elements of home are even exaggerated at the destination. As Graburn (2001: 43) suggests, retaining these familiar comforts is an essential characteristic of tourist experience. This familiarity can be further examined as it is achieved within the tourist's environmental bubble (Cohen 1972). As Cohen states: "The modern tourist is not so much abandoning his[/her] accustomed environment for a new one as he[/she] is being transposed to foreign soil in an environmental bubble of his[/her] native culture" (ibid: 166). This environmental bubble, which can also be referred to as the "tourist space" (Cohen 1995: 13), includes the various amenities and characteristics that provide the tourist with a homelike experience and from which provide the physical frames for the tourist's experience. This concept illustrates how tourists occupy a space that is in certain ways ontologically, culturally, and conceptually distinct from the space that many Belizean residents inhabit and which prevents an authentic experience of local life. But not all tourists require the same environmental bubble; this is especially true of ecotourism where the desired tourist space varies greatly depending on the individual ecotourist. For example, those ecotourists who patron community ecotourism projects in Belize often stay in the homes of village residents and eat the same meals that their hosts eat. In contrast, an increasing number of ecotourists that travel to Belize stay in luxury condos, private cabanas and hotel rooms eating food prepared specifically for them and much different form the meals that their hosts are eating. Therefore, it is necessary to 
recognize a spectrum that represents various degrees of desire for authenticity, where at one end there is a desire for a truly authentic experience and at the opposite pole there is a total lack of concern for an authentic experience.

In a paper entitled 'A Phenomenology of the Tourist Experience' (1979) Cohen introduces the notion of the 'center', which can be loosely described as the ultimate values of the tourists' society. As the tourist must conform to that society's ultimate values, this conformity creates tension and dissatisfaction from which leisure and recreational activity create release (1979: 180). Therefore, Cohen suggests that tourism is a temporary get away from one's 'center' but in relation to an individual's biography, his/ her life plan and aspirations, the center remains significant.

As discussed above, in relation to tourism as pilgrimage, tourism is a temporary reversal, a period of "no-work, no-care and no-thrift", often devoid of deeper meaning (ibid: 181). Cohen sees modern tourism differing significantly from the pilgrimage in that the latter reverses the tourist's trajectory. Whereas pilgrims move from the profane periphery to the sacred center, tourism "is a move away from the spiritual, cultural, even religious center of ones world into its periphery, toward the centers of other cultures and societies" (ibid: 182). From this understanding Cohen develops a phenomenological typology of tourist experience. In this typology he distinguishes five modes of touristic experience ranging from the 'recreational mode' to the 'existential mode' (ibid: 183-4). At the low end of the spectrum, or the recreational mode, the tourist is recreated rather than re-created because self realization and self-expression are not the main reason for travel. In this sense the tourist enjoys the trip because it functions to restore his/her mental and physical powers and elicits a general sense of well-being (Cohen 1979: 184). 
At the existential pole, the touristic experience is phenomenologically analogous to the pilgrimage (ibid: 190). The only meaningful real life for this tourist is seen to exist at the 'elective external center' and this center, like that for the pilgrim, sustains the traveler in daily life. Therefore, the nature of such touristic experiences may well be spiritual, as for example, one may feel deeply moved by communing with nature (Graburn 2001: 48). Of course, Cohen notes, the existential pole still falls within tourist experience as long as people are not able or willing to move permanently to their elective center (ibid 190).

It is clear from the above discussion that there are many issues to monitor when considering tourist motivations, behaviors, desires and experiences. Individuals undertake travel and tourism for very different and complex reasons and it would be erroneous to assume that these reasons are static and unchanging. As Cohen himself recognizes, a tourist could pass through all of the modes of touristic experience on any one holiday (Cohen 1979: 191). Therefore, it is extremely difficult to create a typology of ecotourists that will ever be complete or comprehensive. Conversely, in order to study ecotourists and their ability to contribute to a form of conservation and economic development that is promoted as sustainable, empowering and participatory there have to be some criteria from which it is possible to define who to study. The above theories concerning what tourist are seeking (MacCannell 1989), what they experience (Cohen 1972, 1979) and why they may behave in the ways they do (Graburn $(1977,2001)$, are important pieces of the tourist picture that can be useful for understanding the nature of ecotourism. In Chapter Four I give these ideas further attention by applying them to ecotourism in the Belizean context. 


\section{Conclusion}

This examination of the ecotourism literature has presented some of the general arguments and some of the more specific aspects of ecotourism in Belize, all the while situating the discussion in the larger sustainable development debate. In the process, I have tried to illuminate the nature of development as a negotiation involving various interest groups employing differing understandings of key concepts and events. While ecotourism development has been shown to exist at this intersection of a plurality of interest groups, Chapter Four of this thesis is largely concerned with the actual practice of taking an eco-tour. That is, it focuses heavily on one particular interest group. As mentioned in the introductory chapter, this heavy focus on the ecotourist is a result of the nature of my analysis and in so doing I do not intend to position ecotourists at the center of the equation in a way similar to the deconstructors of development. Rather, this discussion has shown that ecotourists to Belize are only a part of the equation in stakeholder terms and that ecotourists are not the main cause of change in a society (Smith 1989: 20-2).

Since ecotourists in Belize exhibit most of the attributes that have been shown to exist in the generic act of tourism, the voyage they take and the holiday they embark on can be seen as intimately tied to their own individualistic pursuits of a playful and authentic holiday experience. Ecotourists in Belize arrive fully armed with preconceived notions of the people and landscapes they will visit, the nature of their visit, how they will behave on their visit and the personal experiences they wish to achieve while away. With this in mind, the objective of providing conservation and development promoted by ecotourism boosters can be seen to have less meaning for ecotourists than the former 
suggests. Accordingly, Chapter Four will give further consideration to the practice of ecotourism showing it to have consequences for host destinations. In effect, since participation, empowerment and sustainability do not appear to be of primary importance or even a consequence of the ecotourist's visit, the ability of ecotourism to achieve these goals is questioned.

In the following chapter I present the political ecology of Belize, tracing the development of the country through its days of logging and slavery to the present era's focus on ecotourism as the primary development strategy. This chapter will pay close attention to the political, economic and ecological factors that have facilitated and led to this current development strategy and the varying local and transnational influences that have allowed Belize to proclaim itself "mother nature's best kept secret". This chapter also shows the political ecological contours of declaring Belize "mother nature's best kept secret" as this designation implements an erasure of the very history I recount. By erasing this history and pretending that Belize's landscape is somehow "pristine" or "untouched", the historical presence of groups who have occupied the land and used it for generations is made less visible while its use and occupation by ecotourists and powerful interest groups become legitimated. That is, the overall discourse of "natural" areas and exotic people that informs the practice of visiting this destination would seem to contradict notions of participation and empowerment and, as will be demonstrated, more closely represents a conceptual and material dispossession.

Though this is the case, I hold that the less powerful actors in Belize do play a role in constructing the current Belizean context. The following historical chapter presents the ability of the less powerful stakeholders in Belize to shape social relations 
and the environment through their various practices. In this sense, Chapter Three addresses my concern with subaltern agency that my fieldwork in Belize was not able to accurately represent. By presenting this data here I am able to uphold my theoretical position though my ethnographic analysis was not oriented toward producing these results. 


\section{Chapter 3: History and Political Ecology}

\section{Introduction}

As discussed in the previous chapter, political ecology treats the environment as a political artifact. It is an approach to human-ecological relations that foregrounds the larger political and economic structures which shape the conditions of those relations and their ecological ramifications. This chapter takes a political ecological approach to the history of Belize looking back at the various forces and influences that have played a role in shaping the country's politics, economics and environment. The chapter begins by discussing the arrival of the Spanish and the British, their contests over the rights to settle and extract resources, and how an economy predicated on forestry came to shape labor, life, and landscape in early Belize. The discussion then continues on through the twentieth century, paying further attention to the dynamics of local and extralocal forces that have shaped Belize historically. In particular, I argue that in the Belizean context, issues such as conservation, tourism and development have strong ties to extralocal processes as well as a long and contested history. The values and meanings accorded to these issues are important and still contested in today's Belize and are essential to a more thorough understanding of the context in which ecotourism takes place. By addressing these issues this chapter characterizes Belize historically as a place that has been deeply influenced by transnational forces since its "discovery" and entry into the European world-view. Thus, this chapter critiques claims that Belize is "mother nature's best kept secret" by revealing that the land has been occupied, used and altered by human influences for thousands of years. Such an historical understanding facilitates a more 
informed representation of Belizean people and landscapes and calls claims of ecotourism as a relatively benign conservation and development practice into question.

\section{From Buccaneers to Baymen}

The Spanish originally claimed the geographical area of Belize as part of the territory comprising Guatemala. However, much like the Petén, Belize was not formally settled by the Spanish who focused most of their military and economic activity on the areas surrounding Merida in the Yucatan and Antigua in Guatemala (Platt 1998: 126). The reason the Spanish ignored the lowland area of Belize was because of its marginal agricultural status. It is also significant to note that the Spanish may have avoided the area because their dominance over the indigenous Maya of the lowland forests was tenuous until the end of the seventeenth century (ibid). ${ }^{9}$ Considered unproductive relative to its Central American neighbors, the area now known as Belize and its Mayan inhabitants were largely left to their isolated independence. Though the indigenous people of Belize were adversely affected by the Spanish expeditions of the sixteenth and seventeenth centuries, largely by the spread of European disease, these incursions were not as socially disruptive as they were in areas such as the Yucatan. Showing little interest, the Spaniards only passed through the area on their route to Tayasal (present day Flores) making brief and unsuccessful attempts at converting the Maya (Bolland 1977: 23).

In the late seventeenth and early eighteenth centuries, what is now present-day Belize was a remote backwater that attracted British pirates and buccaneers. The area's

\footnotetext{
${ }^{9}$ The successful Spanish conquest of the Maya in the area occurred due to the Maya voluntarily inviting the Spanish to do so after their calendrical cycle had run its course. At this time the Maya formally invited the Spaniards to conquer and evangelize them (Reiffler-Bricker 1981).
} 
geographic isolation, its position outside the central shipping lanes, and the hazardous coral reef running offshore made the coast of Belize an excellent buccaneer haven from which to raid the Spanish galleons loaded with cargoes of gold (typically imaginary) and logwood (Johnson 2003: 600). Logwood was a particularly important commodity in the eighteenth century as it is a tree with dark purple heartwood from which a red dye was extracted and a rapidly growing textile industry back in Europe fueled its rising value. ${ }^{10}$ Spanish wood-cutters had been cutting and exporting logwood from the Campeche Bay and Mosquito Coast since as early as the mid-sixteenth century but as its value increased so too did an unofficial British presence (Ashcraft 1973: 26). The earliest official British presence in the area dates to the capture of Jamaica in 1655 , which roughly coincided with the beginnings of British settlement in the Bay of Honduras region (Bolland 1986: 12). This, it was not the seafaring way of life that initiated British settlement in the Bay but the value located in its forests (Ashcraft 1973: 26).

By the middle of the seventeenth century, British buccaneers who had previously plundered the Spanish logwood ships started cutting the trees themselves in parts of the Yucatan. After the Treaty of Madrid (1667) suppressed privateering, British presence in the area shifted from buccaneering and raiding toward logwood cutting and settlement. As the waterlogged lowlands of central and northern Belize were home to dense stands of logwood, British woodcutters began to settle the plains and river-banks. With the rivers being the only means of transportation, early logwood cutters would cut wood in the dry season and use the flooded rivers in the wet season to float their product out to the coast

\footnotetext{
${ }^{10}$ Logwood is chiefly used in dying colors such as blacks blues and purples and was heavily consumed by the woolen, linen and cotton manufacturers in Britain. Prior to the settlement in the Bay of Honduras the price of logwood was $£ 50$ per ton. By 1763 their were 40 to 75 ships loaded in the bay continually until 1770 when the price continued to drop until it reached about $£ 5$ or $£ 6$ per ton.
} 
where it could be loaded and shipped to Europe (Platt 1998: 126). This erstwhile group of rogue pirates decided that cutting and selling logwood was more lucrative than raiding Spanish galleons and so became the first Europeans to settle Belize (Johnson 2003: 600). By the year 1670 there were 700 of these adventuresome ex-pirates known as the Baymen living in the coastal lowlands of Belize (Southerland 1998: 18). According to Ashcraft (1973: 27), it was also in the year 1670 that a British official noted that British woodcutters were the main suppliers for the lucrative logwood trade.

The British wood-cutters faced constant harassment from the Spanish and were expelled from the Bay of Campeche in 1717. Due to this migration many British cutters decided to move south to the desolate, reef guarded coasts in the Bay of Honduras region (Bolland 1977: 25). A major economic difficulty that the British faced in the logwood trade was frequent skirmishes with the Spanish who would assert their jurisdiction and expel the British from the area destroying their provision grounds and other small-scale infrastructure. Since the Spanish made no attempt to permanently settle the area the British would simply return and reestablish their operations (Southerland 1989: 18). ${ }^{11}$ Not until the Treaty of Paris in 1763, following the Seven Years War, did the British settlement at the Bay of Honduras achieve legally recognized status in Europe (ibid). It acknowledged the Baymen for the first time with usufructory rights while Spain retained its sovereignty over the area (Bolland 1977: 27). As Ashcraft (1973: 27) notes, and unfortunately for the Baymen, it was shortly after the Treaty of Paris in the late 1760's that logwood's economic importance began to decline due to overstocking in Britain, followed much later by the introduction of cheaper synthetic dyes.

\footnotetext{
${ }^{11}$ Bolland (1977:26) notes that despite numerous Spanish attacks (1724, 1733, 1747 and 1751 among others) the British woodcutters maintained their presence in Belize and expanded their trade.
} 
In 1779 , shortly after a new war had been declared, the Spanish swiftly captured the unfortified settlement on St. George's Caye where most of the woodcutters resided and European settlers largely deserted the Bay of Honduras until the peace of 1783 when the Baymen returned (Bolland 1977: 27). The Treaty of Versailles, signed in 1783, established similar logwood rights for the Baymen but the economic importance of the commodity was declining and the Baymen petitioned for a new agreement. In 1786 Spain agreed (in the Treaty of London) to extend the size of the territory allotted to the British in exchange for the full-scale evacuation of the Mosquito Coast in what would become Nicaragua (Johnson 1998: 42). Thus, the Baymen gained permission to cut logwood and mahogany but they could not build forts, establish government or develop agriculture (Bolland 1986: 14).

The eagerness of the Baymen to reestablish their operations after the peace of 1783 was not due so much to the attractiveness of logwood as it was the value of mahogany, a commodity that was growing in accordance with the luxury furniture industry in England. The Baymen had been poaching the commodity long before the Spanish permitted it and according to Bolland (1977: 27), it accounted for one quarter of the total exports from the settlement as early as 1765 . After fifteen years of relative peace and mahogany extraction, the Spanish attempted another attack on St. Georges Cay in 1798, which the settlers repelled with the help of the British Navy. Though the reasons for the attack are somewhat blurry in the literature, it was likely due to the appearance that the presence of British woodcutters was intended to be permanent. It is also safe to say that this was likely the intention of the British as they were now involving the navy in skirmishes between the Spanish and the settlers, a move that would seem to challenge 
Spain's sovereignty. The 1798 battle, known as the Battle of St. Georges Caye, is still celebrated in Belize today as the decisive British victory over the Spanish. It was not long after the battle that the Spanish lost control of their mainland colonies and British possession of the bay settlement remained stable and unchallenged even though British Honduras was not declared a colony until 1862 (Bolland 1986: 14).

\section{Mahogany, Slavery and the Road to Underdevelopment}

The specific time that the earliest slaves arrived in the British settlement is somewhat contested. Bolland (1986: 15) suggests that the first slaves in the bay area came shortly before 1724 whereas Johnson (1998: 38) presents evidence of a slave presence dating to the early $1600 \mathrm{~s}^{12}$ The average logwood cutter at this time was likely too poor to own slaves but the wealthier of them may have brought a small number to extract logwood as it was not a job for more than a few men. Johnson (1989: 38-9) states that during the early days of logwood extraction, there was probably an equal numbers of African and British people in the settlement, who together, under conditions of inequality, began to create a common language and began to form a common culture. As logwood became more lucrative and more British people moved to the settlement, they imported more slaves (Johnson 1998: 41). Throughout the eighteenth century there came to be far more African slaves than Europeans and by mid-century there were many more African slave women than British women, an imbalance from which Belizean Creole culture grew most rapidly (ibid). ${ }^{13}$

\footnotetext{
12 Johnson's evidence stems from an account of a "Negro healer" living in the Campeche Bay area in 1626 suggesting the early presence of slaves in the region (1989:38).

${ }_{13}$ For instance, in 1797, there were only 46 white women, 515 slave women and 132 free women of color (Bolland 1977:42).
} 
The demand for mahogany had grown steadily throughout the 1700s and peaked around 1840 at the height of railway coach building in Britain ${ }^{14}$ (Ashcraft 1972: 27). By 1770, mahogany had taken precedence over logwood and was to dominate the settlement's economy for nearly two hundred years (ibid). Mahogany cutting and extraction was much more labor- and capital- intensive than logwood cutting. Mahogany trees are much larger than logwood and typically grow in high ridge areas at a greater distance from waterways. The location of the trees meant that mahogany cutters typically lived in isolated camps for six to eleven months at a time employing a gang of slaves that ranged between 10 and 50 individuals (Johnson 1998: 48).

Mahogany extraction bore a similarity to logwood extraction in that the timber was still being extracted from the northern plains. This meant that there were a number of large rivers in close proximity that could be used to float the wood out to the coast. One of the most labor-intensive aspects of this industry was getting the logs to the river's edge. Using temporary paths in the bush, cattle pulled them on sleds or wheeled trucks (Ashcraft 1973: 52). This meant that the greater the distance to the water's edge the more arduous and tedious the labor of extraction was. Once a crew accumulated a significant amount of wood and the river reached a desirable height they formed rafts of up to 200 logs and floated them down the river to booms. ${ }^{15}$ There woodcutters claimed the logs and resorted them into new rafts for their final journey to the rivers mouth (Bolland 1977: 54).

\footnotetext{
${ }^{14}$ It is interesting to note that Belize may have had connections to the mass tourism market as early as the 1830s when mahogany was in high demand for building luxury rail coaches in England. Urry (1990) notes that it was during this period (1830-1850) that rail service to English seaside resorts expanded significantly and facilitated the growth of what he acknowledges as the beginnings of mass tourism.

${ }^{15}$ Booms were locations where large cables had been placed across the river at different eddies or falls. Once the rafts arrived here the logs were claimed by each party and the general mass was once again sorted into rafts. At times it was possible for more than one thousand logs to be supported by the booms (Bolland 1977:55).
} 
Due to the intensive labor required, the mahogany industry was only profitable due to slavery and many slaves developed valuable skills in the distinct occupations that this industry required. The mahogany gangs required a specific division of labor that broke the crew down into fairly small and independent groups. There were the axmen, who worked singly or in pairs and who stood on a springy platform twelve feet above the ground felling the trees. Their work was extremely arduous and required great skill and technique that gave them a particular status among the gang and most likely a sense of pride (Bolland 1977: 55). There was a group of slaves that trimmed the tree after it had fallen, squared the trunks at the river's mouth and cleared the hauling path through the bush. Another group fed and worked the cattle. There was also a group responsible for food and provisions, most likely women and youths (ibid). The most important member of the mahogany gang was the highly skilled huntsmen who climbed the tallest trees to locate mahogany then led the entire gang to the locations he discovered. This was a highly valued and skilled position upon which the whole enterprise depended, one that gave the particular slave considerable independence and advantages (ibid: 57). The remainder of the crew included the white slave owners or settlers who rarely numbered more than two and were basically the foremen in charge of integrating the work of the various parties (ibid). Though still cruel and dehumanizing, the slavery that resulted from this particular industry was quite different from that which characterized the sugar plantations in other parts of the Caribbean (Sutherland 1998: 23).

The chief property of a woodcutter was his slaves, most of which he purchased in Jamaica and the additional passage to Belize raised the cost. Due to restrictions placed on settlement by Spain woodcutters also faced the high price of provisioning their slaves 
with imported goods. Adding to the high cost of buying and maintaining slaves was the proximity to Latin American neighbors who offered a haven for runaways. Work in a mahogany gang also required good health, strength and a certain amount of skill. As Ashcraft notes, "Not all slaves were fitted to the rigors of forestry work, and the man who qualified brought a good price.... Labor, not land, was the scarce item in the settlement" (Ashcraft 1973: 33). ${ }^{16}$

The freedom that Belizean slaves had, relative to those working on sugar plantations, may have also played a role in forming a certain master-slave relationship that did not exist elsewhere. As Ashcraft states: "in Belize there were no Negro whip drivers as there were on the plantations and the slaves were armed with machetes, cutlasses, axes and even guns-a condition feared by Europeans in the islands" (1973: 34). Though the Belizean slaves may have experienced liberties that slaves in other parts of the Caribbean did not, it would be erroneous to assume that relations between master and slave were egalitarian. Despite the nationalist origin myths of Belize which highlight the role of racially white woodcutters working side by side with their black slaves to generate wealth from the forest, relations between the two were much more tenuous in actuality (Johnson (2003: 601). According to Bolland (2003: 29) the slaves constantly demonstrated hatred of the institution of slavery through revolt and escape and these actions frequently threatened the existence of the colony. The remote working conditions of forestry work in early Belize also meant that chances of escape were many and the

\footnotetext{
${ }^{16}$ Ashcraft (1973:33) quotes a British officer in 1805 who noted the average cost of a slave amounted to more that $£ 35$ Jamaica currency, "an expense which in the history of Caribbean slavery, is probably without parallel". By the 1820 s the average value of a Honduran slave had increased to over $£ 120$; in contrast a Jamaican slave was valued at $£ 45$.
} 
history of Belize is marked by numerous cases of maroonage, runaways, revolts and protests (Ashcraft 1973; Bolland 1977, 1986).

Contrary to Ashcraft's statement, that the settlers did not fear their slaves having access to weapons, Bolland presents a much different scenario where the white settlers were in constant state of paranoia concerning the very real possibility of the slaves revolting and taking over the settlement. The geographical conditions and knowledge of the "bush" heavily favored the slaves if they were to engage in guerilla warfare and the remote independent communities that did exist as a result of runaways and maroonages would have provided adequate bases from which to conduct such activities (Bolland 2003: 26). The possibility of such an insurrection became very real in the 1760 s and 1770s when logwood slumped in value and the settlement was thrust into economic crisis. The slaves were forced to bear the brunt of the economic crisis and in the period between 1765 and 1773 there were three slave rebellions (Bolland 2003: 26). The largest was in 1773 when a group of 50 slaves revolted, took five settlements and killed six white men. They then retreated to the bush to escape retaliation and reportedly traveled over 100 miles over a five-month period to reach Spanish asylum (ibid). This revolt was the largest in Belize's history, and like most others, is better described as an armed escape. This is a testament to the fact that the most popular response to slavery and deteriorating work conditions in early Belize was not revolt since freedom was so easily to attain through escape.

In all likelihood, it was the very real threat posed by the number of slaves in the settlement and the geographical conditions they worked in that forced the slave masters to accord their slaves more respect and freedom than was customary for traditional 
master-slave relations. In effect, some of the small liberties which the slaves enjoyed probably ensured that the entire slave population did not simply revolt or flee. As the above indicates, the slaves that worked in mahogany camps gained an intimate knowledge of the "bush" where they lived for months at a time, hunting, fishing and clearing small plots for subsistence agriculture (Sutherland 1998: 23). Johnson (2003: 607) notes that cultivation of small plots called plantains likely offered a bit of freedom for slave planters and were a critical aspect of their lives that allowed them to support their wives and children. Largely due to the high price of provisioning slaves masters often allocated these provision grounds to their slaves for their own subsistence production. As long as a slave's agricultural practices did not interfere with their timber work they were able to dispose of their crops however they saw fit, which included selling it in logging camps for cash. Some of the more enterprising individuals even took their produce to Belize City to sell in the market (Ashcraft 1973: 80). Ashcraft goes on to note that there was considerable amount of time to engage in such labors as the average work-week in the Belizean timber camps lasted five partial days with most activity being done in the morning hours. On Saturdays slaves were free to contract themselves out to another woodcutter or pursue their own endeavors on their small plots of land (ibid).

There are a number of factors that partially explain why the slave population did not simply take over the settlement or just pick up and leave. Bolland (1977: 57) suggests that it was surprisingly easy for a Belizean slave to obtain their freedom and there were a number of avenues through which it could be obtained, all of which were fairly prevalent in Belize. A slave could buy their own freedom, have it purchased by another, acquire it through the last will and testament of their owner or receive it as a gift from their owner. 
The close quarters of the mahogany camps could also be seen as forming solidarity among small groups of slaves while at the same time limiting their communication with others. This pattern of living may have facilitated small-scale escapes and revolts but prevented anything large and coordinated from occurring (Bolland 1977: 81).

Many slaves did not rebel against their oppressors because of the relatively better conditions they enjoyed in Belize. Most started off in West Africa and were taken to Jamaica from where they went to the Mosquito Coast and eventually to Belize. When in Belize they would have been shifted from camp to camp and could not have been expected to develop a commitment to the area or its land (ibid). This constant shuffling led many slaves in Belize to be familiar with the harsh conditions of slavery elsewhere and to prefer the local alternative. I might add that the ever-present possibility for escape in Belize may have seemed a type of freedom in itself that made slavery much more bearable than elsewhere in the Caribbean.

Through these particular political, economic and ecological conditions, the racially and economically marginalized people of Belize developed ways of using natural resources based on small-scale agriculture, hunting and fishing. Therefore, from very early on in the history of the settlement we can see that colonialism and forms of exploitation such as slavery were not passively received or accepted. Through a number of practices and movements the earliest Belizeans struggled to improve their situation socially and materially searching for ways to assert their autonomy in conditions of extreme inequality. The slaves in the Belizean timber industry frequently demonstrated their ability to run away and revolt and the masters were continually haunted by these threats. The masters on the other hand were forced to respond and protect their 
investment by taking care of their slaves and allowing them some subtle liberties. It was not as the nationalist origin myth of Belize would have it, it was not the woodcutter's egalitarian spirit that led to these circumstances, but the masters' own sense of realism and self-interest. He was necessarily cautious not to anger his ten to fifty slaves armed with machetes, axes and sometimes muskets while working with them in his remote timber camp.

Importantly, the increasing importance of mahogany extraction did not just impact the slave and laboring populations of the settlement but affected its entire social structure and beyond. The increase in mahogany production also had definite consequences for the Maya who lived in the region. Up until mahogany became the prime export from the colony, the settlers had but a few problems with the Maya. The location of mahogany scattered throughout the forests of Belize meant that the British woodcutters and their labor gangs were encroaching onto Maya territory and upon their way of life. Bolland (1977: 23) suggests that this is due the fact that logwood grows in large thickets in waterlogged areas, meaning that early timber activity and settlement occurred near the coast. As a result of extracting mahogany trees much deeper in the interior, the end of the eighteenth and the beginning of the nineteenth century were marked by Mayan attacks on mahogany works. These attacks were frequent (Bolland 1977: 23-5) but did not have much of an effect on woodcutting operations since Mayan forces were relatively small and disorganized. In effect, the Maya who resisted the British incursions into their lands lost decisively. Defeating the Maya was also in the British economic interest since they saw Maya agricultural techniques as a threat to forest resources. Consequently, they forced the Maya into interior forests from where they 
reemerged later in the nineteenth century to be incorporated into the social structure of the colony as a dispossessed people (ibid 1977: 24).

\section{From Settler Oligarchy to Merchant Capitalists}

Since the earliest days, Belize has been characterized by a very small white economic and political elite ruling over a majority black slave population with a mid size free colored, free black and poor white population occupying the middle of this hierarchy (Johnson 2003:600). As mentioned above, the British colonial powers were not interested in organizing life in the settlement as they did not want to provoke the Spanish who still claimed sovereignty up until 1798 . The Baymen on the other hand, or at least some of the most wealthy among them began to call themselves the "Principle Inhabitants" and organized "Public Meetings" in which they established some basic rules of land use and rights. Thus, as Johnson notes, from very early on "the Principal Inhabitants established themselves as the principal authority ignoring or resisting both Spanish Colonial law and British Colonial process" (1998: 43).

The land use agreements and rights that these men established became more and more restrictive as the logwood and later the mahogany industry became more lucrative. When the Baymen returned in 1783 after being evicted by the Spanish they asserted their rights to the timber works they had used prior to the Seven Years War and through their Public Meetings they placed heavy restrictions upon land ownership to deter the large number of Mosquito Coast evacuees (many of them free colored) from owning land. ${ }^{17}$

\footnotetext{
${ }^{17}$ The evacuation of the Mosquito Coast was a significant development in the history and social structure of the Bay settlement. The number of evacuees that came to Belize in 1787 outnumbered the existing population by 5 to 1 (Bolland 2003: 32). The Baymen stipulated that new residents had to have a certain
} 
Through a series of resolutions passed in 1787 the Principal Inhabitants simply allocated land to themselves and treated it as freehold private property (Bolland 1986: 19). Within months of the laws being passed the Superintendent of the territory, appointed by the Colonial Office, noted that twelve of the Baymen held four-fifths of the available land granted in the 1786 treaty and that the twenty largest estates possessed half of all the slaves in the settlement (roughly 1,085 in 1790) (ibid). With the consolidation of land titles into fewer and fewer hands the class/color hierarchy became increasingly skewed in favor of the whiter and wealthier while the darker poorer inhabitants became increasingly marginalized from the development of the colony (Judd 1998: 137-38). Concerned with the extreme difficulty that the Mosquito Coast evacuees had finding land in a relatively uninhabited territory and the threat posed by the political and economic power of the Principal Inhabitants, the superintendent had declared all unoccupied lands as Crown land by 1820 (Ashcraft 1973: 30).

The settler oligarchy that developed in Belize maintained control by monopolizing the land, not for their use but to deny its use to others and hence ensuring an abundant labor force. The same men using their London connections developed the food import trade, which was vital to all aspects of the settlement as cultivation was still prohibited through treaty with the Spanish. ${ }^{18}$ Consequently, this group controlled all aspects of retail and created a state of dependency for all of the inhabitants in the settlement (Johnson 1998: 52).

amount of capital, or own a certain number of slaves in order to qualify to occupy a "works". The restrictions were greatest for blacks, slightly less for free colored, and least for whites (Johnson 1998: 44). ${ }^{18}$ Of course cultivation was taking place in the settlement but it was in the form of small provision grounds for slaves and woodcutting estates. It is unlikely that the Spanish were heavily enforcing the ban on cultivation to a great extent after the battle of St. Georges Caye in 1798 and more feasible that the Principle Inhabitants were doing so in order to create a state of dependence on the goods they were importing. 
When slavery was abolished between 1834 and 1840 the social structure of the settlement remained relatively the same. Post emancipation society was very similar to the days of slavery and while many slaves left the area the majority returned to work because there was no viable alternative. There was no established agricultural tradition, internal marketing system, or even a demand for locally grown food. These factors in combination with a nonexistent communication system, relatively high wages (according to local standards) and transportation limited exclusively to rivers, meant that many manumitted workers were obliged to keep working in forestry (Ashcraft 1973: 35). These conditions made it very difficult to make a living from farming alone and when one factors in the possibility of severe drought, heavy rains or pestilence wiping out an entire season's work, income from logging was often a real necessity (Ashcraft 1973: 81-4). The settler oligarchy also acted quickly to establish a system of debt bondage called the advance truck system where contractors offered ready cash in December when they recruited their work force. Much of this money would be spent over the Christmas season and the following months would be spent working off the debt. While away at work the ex-slaves would also be charged exorbitant amounts for food, provisions, moccasins and axes, adding to their debt (Ashcraft 1973: 84).

For the first seventy-five years of the nineteenth century, mahogany extraction remained the settlement's primary industry and British merchant banks became increasingly involved in the settlement's affairs. Between 1830 and 1860 British Honduran mahogany was the favored timber for railroad coach building and because the settlement was officially outside the boundaries of the Empire, merchants were free to seek the valuable American market as well (Ashcraft 1973: 37-8). As the value of 
mahogany peaked, colonial interests began to merge with the interests of metropolitan corporations. New land title acts allowed land to be bought and sold even if title was insecure. This allowed larger landholders to buy out smaller holders with less political clout (Johnson 1998: 52). Johnson notes the lawyers of the Belize Estate and Produce Company (BEC), formed from the purchase of consolidated land and the foreclosure of other large holdings, wrote the land title legislation and consequently benefited most from it (ibid). Within a few years of the passage of the Honduras Land Titles Acts of 1858 and 1861 the BEC owned roughly one million acres of land or more than half of all the privately held land in the territory (Johnson 1998: 52).

We can see the chain of political and economic events that characterized most of the nineteenth century in Belize was set in motion by the colonial authorities in order to break the political and economic dominance of the Principal inhabitants. In the 1820 s the settler oligarchy was faced with growing demands from the free black and colored population and accepted to relinquish some of its political control allowing the Superintendent to appoint magistrates in the settlement. Furthermore, when the British government insisted on extending civil rights to the free colored population and abolishing slavery it was asserting its control even though Belize was not officially a colony. Thus, political control by the settlers was significantly diminished and the land acts referred to above allowed the colonial authorities, in partnership with metropolitan corporations, to break the settler's economic dominance as well. As Judd (1998:136) notes, the "eighteenth-century adventurers and pirates were replaced by nineteenthcentury merchant capitalists". 
Most of the early woodcutters, lacking the opportunity to invest in land or industry, took their profits home and the settler class was all but extinct by 1850 (ibid). After this time few white families settled in Belize, instead transient white males passed through while attempting to make a profit. A statement in 1883 quoted by Bolland (1986: 21) is particularly telling of this condition and is eerily reminiscent of ecotourism in the present: "White people but look upon it as a resting, not an abiding place, one from which they hope eventually to return enriched to their native soil." Of course, as is discussed in the following chapter, the enrichment today's whites are seeking is more existential or spiritual than monetary. With the loss of the settler elite the white population dropped dramatically and by 1881 the white population was 375 out of 27452 people, or just over 1 percent (ibid).

It was not until 1862, at the peak of mahogany production, that Britain considered British Honduras to be of enough economic importance to officially declare it a colony. Yet with this designation the secondary importance of the territory was evident as the colonial power never made significant steps toward developing infrastructure or systematically managing forest resources. Instead, the top priority of the British seemed to be serving the needs of the metropolitan companies engaged in timber extraction (Johnson 1998: 65-6). The concentration of land and capital in the hands of a few companies meant that the direction of the colony's economy was largely decided in company boardrooms and that land for agricultural development was kept out of reach of most Maya, Garifuna and Creole individuals.

Another major factor that has shaped current day Belize and one that marked the transition toward agricultural development was the large influx of refugees that occurred 
during the mid nineteenth-century as a result of the caste wars in Mexico. For the most part, the Yucatecan migrants were not wealthy, but they were skilled agriculturalists who had experience hiring and supervising Mayan laborers (Judd 1998: 135). These new residents were able to start growing because the productive lands in the north had been logged out and the wealthy timber barons, who had secured a large supply of Creole and Garifuna laborers, were not threatened by the possible emergence of an agricultural peasantry (Johnson 1998: 73). Nonetheless, the extraction and export of timber dominated the economy up until 1959 and because of this the development of agriculture and accompanying infrastructure such as roads and railroads was virtually non-existent until much later. As Judd (1989: 135) notes:

In this, the Colonial Office assisted, repeatedly vetoing the private construction of railroads, roads, ports, or industry out of fear of native self-interest, at the same time refusing to allocate the necessary Crown resources to open land for cultivation or encourage agriculture. In so doing they permitted the perpetuation of what amounted to debt servitude for black woodcutters on large tracts of metropolitan-owned land. As a result the colony passed from the nineteenth to the twentieth century with no roads and railroads nor electric lights, and almost without a local modernizing capitalist class or a free wage-earning class.

\section{The Demise of Forestry and the Rise of a Nation}

Ashcraft gives two main reasons for the decline of forestry in Belize: fluctuating prices and economic shortsightedness (1973: 37). As the demand for mahogany grew steadily in the mid 1800 s, trade and production increased accordingly. However, the unsystematic method of exploitation eventually forced woodcutters into less accessible areas and raised their production costs. This get-rich-quick mentality drove contractors to exploit the forests and negate pleas for planning and reforestation. This tendency, in tandem with declaring the settlement the domain of the British Empire cut off access to 
the valuable American market. Also, as the contribution of Honduran mahogany to the total British timber market was fairly small, England became more interested in increasing consumption from the Baltic region and Canada, in effect damaging the industry and once again underlining the insignificance of the colony to Britain (Ashcraft 1973: 37-8).

Early in the twentieth-century the chewing gum fad hit the streets of America and the demand for a forest product known as chicle, from which gum was originally made, grew rapidly. The shift marked the production of a new commodity in Belize which became the colony's number two export after mahogany and also marked the growing orientation toward the United States market (Johnson 1998: 70).

Britain's interest in administering the colony also began to grow at this time, especially in the area of rationalizing and regulating forestry. The colonial government had been aware as early as the 1830 s that rapid deforestation had been occurring in the region but did little to manage resources until the 1920s (Ashcraft 1973: 31). In 1922 the Colonial Forestry Department was created to manage forestry and to make it more competitive and sustainable (Platt 1998: 127). Many of the laws initiated in this regard were explicitly conservation-oriented such as the forest ordinance of 1927 , which established a legal basis for the creation of protected areas, legitimated public Forest Reserves and called for conservation to coincide with the development of the forestry industry (Platt 1998: 127-28). This time also saw the introduction of the first fish and game conservation laws. Johnson (1998: 71) notes that these laws and the restrictions on fish and game would have not gone over well with many of the rural inhabitants. The regulation of natural resources would have limited their ability to market the natural 
bounty of the country and place greater restrictions on the way of life they had become accustomed to.

The economic depression of the late 1920s and 1930s hit Belize hard. The mahogany industry slowed considerably as did chicle and other industries and again the laboring class bore the brunt disproportionately (Bolland 1986: 32). Johnson (1998: 72) notes that a desirable solution to the plummeting wages would have been to flee to the land but the BEC's land monopoly in northern and western portions of the colony prevented most people from doing so. Instead, many workers began to petition, strike and riot in order to register their dissatisfaction. To add insult to injury, Belize was hit with the worst hurricane in its history in 1931 which killed 1000 people and destroyed at least three quarters of housing (Bolland 1986: 32). The hurricane had a significant effect on rural life in Belize and those who had the option and skill chose to move back to the land. In most instances people were squatting on land which was claimed as private property by large landowners but they lived on the land and planted small scattered plantations that were not easily located or removed by the BEC or the other landowners (Johnson1998: 75). Johnson also notes that some older individuals in Crooked Tree told her that the hard times created by the hurricane initiated a large increase in the hunting of game to be sold in Belize City. ${ }^{19}$ The large amount of flooding at the time caused deer and other game to high ground creating favorable hunting condition and a resulting surplus to sell in the surrounding towns and Belize City (ibid: 74). The economy

\footnotetext{
${ }^{19}$ Johnson conducted her ethnographic fieldwork in a small Creole community called Crooked Tree in the North West corner of Belize District. Though much of the information she provides on the impacts of the 1931 Hurricane come from ethnographic sources in the area there is evidence presented by Bolland (1977, $1986)$ and Belsky $(1999,2000)$ to suggest that the hurricane had similar effects throughout the colony. Though individuals in other parts of Belize may not have been pitted against the BEC specifically there were other large landholders and metropolitan companies against which they struggled.
} 
continued to decline in the years following the hurricane and prolonged the severe hardships that the laboring and poorer classes experienced.

When the depression hit Belize the government was in the process of attempting to revise the colony's land laws so more residents could claim ownership but the colonial officers often found themselves at odds with the interests of the BEC, which probably had more power than they did. Not until the late 1940s, when mahogany slumped indefinitely, did the government gain control of significant portions of land previously held by the BEC and begin to implement laws favoring small holders (Johnson 1998: 74).

It is important to note that rural inhabitants moved back to the land with relative ease, which shows that the large private landowners' claims likely existed more on paper than in actuality. Throughout the history of Belize land use has been largely defined by the ability of someone to occupy and use it and this is in fact the way that the first property rights were established in the Public Meetings (Ashcraft 1973: 28). It was not until the mid 1800s that land obtained through a system of grants, a system more familiar to colonial officials, was even adopted in the settlement. In relation to the low population density of the area, even today it is very likely that land claimed as freehold is often inhabited and used in accordance with the needs of residents who lack official title. Johnson (2003) demonstrates how the rural Creole population of Belize has transformed, though very subtly, the marginal areas of Belize that were not valued for agricultural production and devoid of marketable timber species. The local economies that these communities established have existed for over two hundred years and have altered the landscape, imprinting it with a distinct Creole socio-ecology. In this sense, the "bush" has become closely associated with rurality and Creoleness in Belize. This association is 
often one that has negative (backward) connotations but there is also a growing positive connotation attributed to this association. This is especially true in light of the growing popularity of ecotourism and the new value being placed on rural communities through it.

With the above in mind, it is apparent that claims to freehold private property in Belize are somewhat difficult to enforce. To suggest that the laboring classes of Belize had no access to these large tracts of land would be erroneous. Obviously there are competing interest groups concerning land use and land rights in Belize and each group seeks to define title to land through their various practices. Though there is significant evidence to suggest that much of the forests in Belize have been shaped by rural subsistence patterns, the question of who has the ability to define and control access and what that access or lack thereof might entail, is a contentious issue and one that requires further investigation.

The reduced economic importance of forestry after the depression permitted the government to openly confront the once-powerful absentee landowners (Johnson 1998). Using the anti-colonial sentiments of the population, government leaders associated the idle lands with the political and economic evils of colonialism (Ashcraft 1973: 68). Mindful of the government's antagonisms the landowners refused to invest in their lands leaving them idle until real estate values increased. ${ }^{20}$ In turn, the government refused to support a forestry redevelopment program because the landholders would not relinquish their hold on fertile lands (ibid). Possibly as a direct result of the above dispute, in the

\footnotetext{
${ }^{20}$ Bolland (1986: 77) provides striking evidence of the heavily skewed land distribution at the end of World War II noting that it was virtually the same as at the end of the nineteenth-century. In 1971, 3 percent of the landowners owned over 94 percent of freehold land, farmers with 100 acres or less made up 91 percent of land owners and owned 2 percent of the land. These inequalities are sharpened by the fact that in 1971 foreigners owned 93.4 percent of all estates over 100 acres and over 90 percent of all freehold land in Belize, with BEC alone in possession of 42 percent.
} 
1950s the colonial government decided to reduce forestry expenditure and investment drastically. Replenishing depleted species was halted, fire prevention programs canceled, scientific studies continued on a sporadic basis and efforts to oversee use of public lands ended. In effect, many activities and restrictions mandated by law could not be pursued due to lack of funding (Platt 1989: 128). Ashcraft sums up the prominence and later decline of the forestry industry in Belize (1973: 66) as follows.

For all practical purposes, forestry as the primary commercial enterprise and dominant way of life in the colony and as the manipulator of political and economic events, ended with the Depression. However, it was not until 1959 that the combined value of citrus and sugar exports could surpass the export value of forestry.

In 1934, facing deteriorating working conditions augmented by a natural disaster, the dissatisfaction of the lower classes culminated in a series of demonstrations, strikes and riots which coincided with the Garveyite movement marking the beginning of modern politics and the independence movement in Belize (Bolland 1996: 32-3). ${ }^{21}$ In 1954 the population of Belize achieved universal adult suffrage and produced a constitution that created a legislative assembly. The constitution authorized mass participation of Belizeans in their own political affairs and the Crown colony government was to be replaced (Bolland 1986: 107). By 1964 the stage was set to declare independence from Britain as a cabinet of ministers presided over by an elected prime minister had taken their place in the Westminster style parliamentary system. ${ }^{22}$ But because Guatemala had maintained its claim on Belize, asserting its inheritance from the

\footnotetext{
${ }^{21}$ Marcus Garvey was a Jamaican-born Black Nationalist leader who started the Universal Negro Improvement Association (UNIA) which was the most prominent Black power organization of the 1920s. The Garveyite movement and associated Garveyite Church was a symbol of anti-colonialism and promoted the involvement of the African diaspora in African affairs (Reddington 2008).

${ }^{22}$ Between 1964 and 1981, the British government retained authority through a governor over foreign affairs, defense, internal security, and the terms and conditions of appointment of the civil service, leaving all other matters to the premier and his cabinet (Bolland 1986: 108).
} 
Spanish, Belize chose to remain as a British protectorate and did not formally declare its independence until $1981 .^{23}$

At the time of the new constitution and turn toward self-government, the momentum of the country's economy began to shift. In order to diversify the economy and reduce the country's dependence on one market (timber), the government began to emphasize agriculture. In 1966 the government of Belize instituted a new set of land reforms which imposed strict penalties on parcels of undeveloped land that were greater than 100 acres. Due to this new policy the government acquired over one million acres due to unpaid taxes, much of it from the BEC. Thus, large amounts of land became available and a new economic focus emerged on developing agricultural products such as sugar, bananas and citrus (Stinson 2004: 52-3).

\section{The Era of Ecotourism}

Conservation initiatives in Belize can be seen to date back as far as the Forest Ordinances of 1924 and 1926 briefly referred to above. Much like the implementation of these ordinances, many of the landmarks in the country's conservation history are associated with the arrival of some new person from the U.S. or Europe. As mentioned, the first of these individuals was the colony's first forester, an English citizen who had

\footnotetext{
${ }^{23}$ After Spain lost control of the region in 1821, the British government still acted as if the 1786 treaty (The Convention of London) was in effect and did not claim the territory. Nevertheless, Britain frequently violated the terms of that treaty and asserted its control informally and unsystematically. The independent republics that emerged from the remnants of the Spanish empire in the 1820s claimed to inherit the sovereign rights of Spain within the area of its previous jurisdiction and Britain never accepted this doctrine. The argument continued throughout the years resulting in the flexing of military muscle by both Guatemala and the British. Seeming not to have a say in its own affairs the Belizean government took its case to the international community between 1975 and 1981. Support for Belize's position began to grow starting with support from the Non-Aligned Movement in 1975 and in 1980 the UN passed a resolution demanding secure independence for Belize calling upon Britain to continue defending Belize in the process (Bolland 1986: 128-134).
} 
done similar work in India and who was essential in passing the first forest ordinances. In the 1950s, as agriculture became the focus of the colony's development trajectory, discussions about further diversifying the economy began and a commission formed to discuss the ways Belize could develop a tourism industry. The panel decided that the biggest draw would be the colony's natural resources and discussions were centered on the creation of wildlife sanctuaries as well as fishing and hunting guide services. Despite these recommendations little was done to develop these services and tourism remained insignificant catering to a very small clientele of American and British sportsmen (Johnson 1998: 77). As the 1960s and 70s saw conservationist thinking expand from particular species and habitats to entire ecosystems and ecological processes, whole ecosystems were considered for protection in Belize. ${ }^{24}$ Considerations for placing large areas of Belize under protected status largely resulted from a 1964 request by the UN for a report on the status of the country's national parks. Not having any protected areas at the time, the legislature was forced to report that there were none. In the mid 1960s another group of tourism consultants was hired, this time from New York, and they also recommended the establishment of parks and protected lands to contribute to the country's tourism potential. It is interesting to note that the areas that the consultants recommended to be put aside for parks and conservation areas were based on the attractiveness of the sites and not their conservation value (ibid: 92-4). This signifies that even before tourism to Belize became popular, the economic importance of conservation and nature's attractiveness to tourists were taking precedence over any notion of its

\footnotetext{
${ }^{24}$ Western and Wright (1994) note the expansion of the environmental consciousness at this time was due to a number of factors including the damages being caused by large scale capital intensive development projects, the declaration of earth day, the first views of earth from space, indigenous social movements and protests, and especially the oil shocks of the 1970s.
} 
intrinsic value. These were the sentiments that initiated the country's conservation movement.

During the mid 1960s, two American tropical biologists were conducting research in Belize and they were to become deeply involved in revising the country's wildlife legislation in the 1970s and 1980s. One of them, Dora Weyer, became the driving force behind the formation of the Belize Audubon Society (BAS), the first environmental NGO in Belize (Sutherland 1998: 100). By this time, the value that the global community was putting on environmental and conservation issues was not lost on the Belizean legislators. Within two months of claiming independence in 1981, the Belizean House passed two pieces of conservation legislation: The Wildlife Protection Act and the National Parks System Act (NPSA) (Johnson 1998: 93-4). In 1984 the government handed BAS responsibility for the management and protection of all areas that fell under the NPSA. Since this time BAS has financed, developed and operated these and many other of Belize's protected areas (Sutherland 1998: 101). Sutherland also notes that this transaction may be the first example of a country's government handing over the management of a large number of protected areas to an NGO (ibid: 102).

The above discussion shows that the conservation movement in Belize has always been closely linked to tourism and attempts to diversify the economy. Despite these attempts, it was not until the 1980s that tourism actually accounted for a significant amount of revenue. The earliest tourists to Belize (apart from a few sportsmen) were part of the counter cultural movement of the 1960s and 1970s and though Belize became popular among this group through word of mouth, it remained virtually unknown to the international tourism industry. Sutherland (1998: 93-4) describes these early tourists as 
offbeat individuals with a sense of adventure and a back-to-basics, back-to-nature mentality. She notes that these travelers were sickened by the trappings of modernity (some of them physically) and found Belize to be the perfect escape (ibid: 95). For the most part, these travelers congregated on Caye Caulker, drawn by the laid-back demeanor of locals and the lack of modern communications (ibid). ${ }^{25}$

Twelve miles North of Caye Caulker in the small fishing community of San Pedro on Ambergris Caye, a small group of American businessmen began to develop a number of hotels, restaurants and a tourism industry predicated on nature and recreation (sport fishing, windsurfing, kayaking and diving). The contrast between this particular tourism market and the nearby, largely government initiated, tourism developments in Cancun made Belize popular in a fairly short time. By the 1980s a number of hotels and restaurants, mostly foreign owned, had sprung up in San Pedro and land speculation had put all but the most marginal pieces of land out of financial reach of many locals (ibid). ${ }^{26}$

In the years following Belize's independence, tourism was not considered a desirable development. Rather, an outspoken and prominent government official condemned it as "whorism" (Belsky 1999: 647). The industry was largely seen as elite controlled and as reinforcing patterns of international inequality and exploitation. ${ }^{27}$ In 1984 Belizeans elected a new political party into power and the United Democratic Party (UDP) replaced the long-standing rule of George Price and the People's United Party

\footnotetext{
${ }^{25}$ Caye Caulker today is still associated with this type of traveler and is known as a laid back island which attracts a number of alternative individuals and is discussed further in chapter 4.

${ }^{26}$ Chapter Four provides further discussion on the unsustainable growth of tourism in the Cayes, especially Ambergris and Caulker, noting some of the environmental degradation that has occurred there over the years.

${ }^{27}$ Pattullo (1996: 62) further develops this point by noting that there is a deep-seated resentment of the Caribbean tourism industry at every level of society which probably stems from the socio-cultural associations of race, colonialism and slavery.
} 
(PUP). ${ }^{28}$ The UDP government stood for liberal economic policies, encouraged foreign investment and was extremely friendly to the United States (Sutherland 1998: 63). ${ }^{29}$ Like many other countries in Central America during the late 1970s and early 1980s, Belize was facing a severe balance of payments deficit. Due to these financial difficulties the newly elected government was forced to start borrowing from the IMF the same year it came into power subjecting Belize to the IMF's infamous Structural Adjustment policies (Moberg 1992: 1-2). Due to pressure exerted by the IMF and the World Bank, tourism became an attractive way to diversify the economy and in their final year in office (1989) the UDP approved the Integrated Tourism Policy and Strategy Statement. This statement acknowledged the significance of tourism to the UDP government who made it the countries second economic priority next to agriculture (Mowforth and Munt 2003: 280).

When the PUP regained power between 1989 and 1993, they confirmed the government's shifting position by supporting what they termed "new tourism", namely respecting and restoring nature, preserving and valuing local culture, and building sustainable development (Belsky 1999: 647). Therefore, in the late 1980s tourism in Belize was reinvented as "ecotourism". The industry became oriented toward up-market tourism in which visitors are said to respect and express interest in local natural history and culture and build support for environmental conservation (Boo 1990; Lindberg et al 1996). New marketing strategies were developed in order to appeal to international

\footnotetext{
${ }^{28}$ For 20 years (1961-1981) George Price governed Belize. He was the first Premier of the colony, and after independence he was the first Prime Minister until the elections of 1984 (Sutherland 1998:62).

${ }^{29}$ Sutherland (1998: 61) notes that the United States turned its attention to Belize in the 1980s to ensure the stability of the fledgling government and to promote U.S. business interests. The U.S became the country's principal trading partner and through the USAID program poured investment funds into the economy and infrastructure. In addition over 100 Peace Corps volunteers were operating in the country at this time.
} 
tourists who are interested in a more "authentic", "individualized" and "natural" tropical experiences (Belsky 1999: 647).

The restructuring and reimagining of tourism that occurred throughout the $1990 \mathrm{~s}$ featured close cooperation with foreign and national NGOs. International tourists to Belize have thus been enticed to move away from the traditional sun, sea and sand tourism of the cayes and venture inland for nature- and culture-based experiences involving hiking, wildlife viewing, visiting archeological ruins and staying in traditional Creole, Garifuna and Maya villages (Belsky 1999: 648). The turn to community-based ecotourism has been initiated with the aim of giving rural residents access to the lucrative tourism industry, while at the same time tying local livelihoods to the preservation of wildlife and habitats as tourist attractions (ibid).

One of the first effects of opening up Belize to investment and promoting it as an ecotourism destination was a dash of foreigners who arrived to buy land. Today, it is estimated that 90 percent of all coastal developments in Belize are owned by foreigners (Pattullo 1989: 121) and according to Cater (1994: 75), since this property was sold as freehold it is now permanently out of the hands of the Belizean people. ${ }^{30}$ A closely related development has been the emergence of a powerful expatriate group that owns and manages many ecotourism lodges and small hotels. The Belize Tourism Industry Association (BTIA) is a USAID-initiated body that acts as an umbrella group representing private interests. The Belize Tourism Industry Association states that it is a "non-government membership, advocacy organization promoting and monitoring

\footnotetext{
${ }^{30}$ According to McMinn and Cater (1998: 677), Belize's close proximity to the U.S., stable political history and language (English) combined with the fact that it is possible to own property freehold means that the country "is somewhat atypical of most developing nations in terms of the extent of 'residential' or second home based tourism" and "expatriate involvement in relatively small scale tourist accommodation development"
} 
sustainable tourism, while safeguarding the natural and cultural integrity of Belize for the benefit of all" (BTIA 2007a). According to Medina (2005), BTIA is an organization dominated by foreign interests whose membership in 1992 was 65 percent expatriate. Furthermore BTIA boasts membership on every government, legislative, advisory, consultative and licensing committee in Belize, which the association claims is proof of its commitment to national development. “[A]s a direct consequence of BTIA's initiatives, tourism has become the fastest growing industry and has been pushed to the forefront of government priorities" (BTIA 2007a).

A number of scholars have commented on similar deficiencies and contradictions inherent in ecotourism and specifically the Belizean ecotourism industry. Cater (1994: 73) for example, observed that of the 350 delegates that attended the First Caribbean Conference on Ecotourism (held in Belize in 1991), at least half were either U.S. based or expatriate. A year later at the 1992 First World Congress on Tourism and Environment in Belize City, more than 40 percent of the 300 delegates were from Canada or the U.S. and 29 percent that registered as Belizeans were expatriates (Mowforth and Munt 2003: 208). In addition, the 1992 conference charged a fee of nearly one half of the average monthly Belizean wage, which ensured the only local representation was by professionals representing and paid for by government departments and NGOs. Mowforth and Munt (1998: 281) also note a significant contradiction in these conferences as each was hosted in a luxury hotel — the construction of which necessitated stripping the protective mangrove cover-on the ecologically fragile outskirts of Belize City.

Belize's transformation from an underdeveloped colonial backwater into "Mother Nature's best kept secret" occurred seemingly overnight. By its tenth anniversary as an 
independent nation Belize had placed one-third of its territory under some form of protected status. Today, Belize has 71 protected areas in both marine and terrestrial environments accounting for 40 percent of the county's territory (Eltringham 2007: 345). By the mid 1990s, less than ten years after tourism was given secondary importance to agriculture, the industry accounted for 48 percent of the countries total export receipts and by 1997 was the country's number one source of foreign exchange earnings (Stonich 2000: 8-9).

\section{Conclusion:}

Throughout most of its history, Belize has been dependent on the state of external markets for particular tropical products and fluctuations in these markets have had a substantial effect upon the politics, environment and the social structure of the country. Logwood was of primary economic importance up until the 1760 s and 1770 s. As the value of the commodity declined it created a crisis in social relations. The rise of mahogany as the new primary product saved the settlement but also transformed it as it led to a greater concentration of land and property (including slaves) leading to the dominance of the settler oligarchy. This oligarchy remained heavily dependant on the health of metropolitan markets and this is evidenced by the fact that when mahogany slumped in the mid nineteenth-century, land was further consolidated and ownership became dominated by metropolitan companies (Bolland 1977: 194). Nearing the end of the twentieth-century, after trying to develop an export economy based on agriculture, structural adjustment policies compelled the government to promote foreign investment in new growth sectors like tourism, cut funding for social programs and remove price 
incentives for staple crop production (Moberg 1992: 2; Belsky 2000: 291) ${ }^{31}$ The result was a massive increase in foreign owned tourism infrastructure, land titles and a reduced social security system that has made many rural communities more dependant on terrestrial and aquatic resources for subsistence (Belsky 2000: 291). In addition, the development of the tourism industry has also gone hand in hand with the creation of protected areas, which often restrict or prohibit resource use by local residents and facilitate use by wealthy foreign tourists. These developments have been accompanied and largely facilitated by an increase in environmental NGOs and transnational conservation organizations.

The above suggest that many people in Belize are subject to developmental and environmental discourses that implement far reaching international political economic agendas. These discourses, coupled with tourists' desires for "pristine" nature and exotic cultures may be constructing a representation of Belize that may be best described as a type of green orientalism in which the people and places of Belize are rendered as a reflection of what these various interest groups desire (Lohman 1997). Of course this construction is not occurring over the heads of Belizeans but is partially constituted by their actions and reactions to these circumstances as it has been in the past.

A particularly interesting development that has occurred as Belize has oriented itself toward the ecotourism market is the primacy of transnational tourism interests and the influence of foreign and expatriate tourism owners and operators. The tourism industry in Belize seems to be heavily influenced, if not controlled by these external

\footnotetext{
${ }^{31}$ Moberg notes that by cutting producer price incentives for staple crop production and retaining price controls at the retail level national self-sufficiency in food production declined. At the same time food in the city's remained relatively cheap allowing people to get by with less and ensuring a comparative advantage in low cost labor (1992: 2).
} 
interests, who culminate in the organization called BTIA. The power and influence that this membership-based organization has is reminiscent of the Principle Inhabitants discussed above. It would seem that BTIA sets the rules of engagement and controls access to the country's tourism industry through the dominant role it plays marketing the country and representing it to the rest of the world. It is BTIA that has adopted and promotes the "mother nature's best kept secret" slogan in an attempt to draw ecotourists to Belize. By promoting Belize as a tropical paradise devoid of all but the happiest local people this representation contradicts the daily lives of many Belizeans and has very little to do with promoting a participatory and empowering way forward for local communities; the intended beneficiaries of ecotourism development.

This chapter has presented a summary of the political, economic and ecological factors that have played an important role in shaping Belize today. Since the time the marginal swampy forests of Belize were known to Europeans they have been imbued with an economic value that has played a large role in shaping the politics, economy, physical landscape and even the culture of those who freely and those who were forcibly settled there. While presenting this historical summary this chapter has highlighted three closely related themes.

First, the selective timber extraction that occurred in Belize has facilitated a relatively intact environment in which ecotourism flourishes. Belize's economy had been defined by colonial resource extraction with no return of capital investment or infrastructural development. "For hundreds of years Belize has produced what it does not consume and consumed what it does not produce" (Johnson 1998: 90). The country passed into the twentieth century with no modern forms of transportation or 
communications and largely in the hands of foreign merchants and metropolitan companies. In effect, throughout the majority of its known existence to the European world Belize has been treated as a piece of real estate. The development of tourism and the current focus on ecotourism today is a direct result of this particular form of extraction and resulting underdevelopment. Even though the "natural" habitats and "pristine" landscapes sought after by ecotourists today are the result of centuries of human use and modification, it is the notion of an untouched paradise that best represent the present imaginings of Belize as "Mother Nature's best kept secret". ${ }^{32}$

The second theme is that the landscape of Belize embodies a history of struggle and the actions of the numerous interest groups and stakeholders that have interacted over the years in a matrix of social and material relationships. It is pertinent to note that within this matrix even the most disenfranchised individuals exhibited agency and autonomy in conditions of extreme exploitation and inequality. The rural and poorer classes in Belize have worked within these powerful structures manipulating and negotiating the environment and their place in the social structure of the country respectively. As Johnson (1998: 68) suggests, living in rural Belize has always meant being able to move around in the bush, to know the various places that there are to live and work, and to be able to sustain oneself in each of these microenvironments.

Finally, in presenting this historical overview, I have intended to show that the history of Belize is marked by a number of interventions, methods of production and the exploitation of people and landscapes which call current ecotourist imaginings of the country into question. This chapter has presented alternate images and historical

\footnotetext{
${ }^{32}$ When taking the ancient Maya into account, humans have modified the forests of Belize for thousands of years.
} 
perspectives that are meant to challenge and dismantle the fictitious ecotourist representation of Belize. As Belsky (2000: 297-98) notes, the Belizean landscape evolved from the hand of human activity: logging, farming, hunting, fishing and an unsentimental approach to animals. In contrast, the current ecotourism thrust in Belize has meant that "Western idealized images of tropical rurality are being sold devoid of associations with Third World poverty, inequalities and globalization" (ibid: 307 ). This has meant that the reality of British colonialism, slavery, racism, extensive forest extraction and farming are being bypassed in many tourist conceptions of Belize (ibid).

In the following chapter I will further these discussions and show that tourism (eco- or otherwise) is not, and probably never will be, strictly focused on creating environmental and social benefits for host communities. This is not to deny that these are the intentions of many ecotourists or to say that hosts will never realize some benefit. Rather, I suggest that ecotourism is first and foremost about an individualistic pursuit of experience that marks the traveler as socially distinct from other classes and class fractions in the home society. Because of this distinguishing aspect, ecotourism destinations such as Belize are under pressure to create the authentic experiences desired by ecotourists and this has consequences for the host destination. In effect, the following chapter maintains that the goal of ecotourism is directly focused on creating a sort of altered reality or what Bruner (1991) refers to as a Lacanian reflection of the tourists' own wants and desires. The destination is thus pressured to reflect these images and provide these experiences in order to perpetuate itself as an ecotourism destination, a consequence that does not seem to fit with the rhetoric of participation and empowerment that current sustainable development discourse espouses. 


\section{Chapter 4: "Mother Nature's Best Kept Secret"}

\section{Introduction}

Chapter Three outlined the emergence of ecotourism in Belize and the political ecological relationships that have shaped the country's landscape. This chapter will focus more closely on ecotourism and the ecotourist analyzing some important aspects of this form of tourism as a social practice. By looking closely at the emergence of ecotourism and the desires and expectations of ecotourists, this discussion intends to question its widespread acceptance as a sustainable development strategy. As Chapter Two explained, traditional forms of tourism are about an individualistic pursuit of experience that this chapter will show to have a number of negative social and environmental consequences. This chapter questions ecotourism as a "new" and "responsible" form of tourism through a number of observations made while participating as an ecotourist in Belize's ecotourism industry.

In order to facilitate the discussion this chapter will begin by adding to the information presented in Chapter Three by briefly noting some of the more recent developments in Belize's embrace of sustainable tourism. Next I analyze how ecotourists differ from traditional or mass tourists. After discussing some of the general attributes of ecotourists, I will turn to the notion of authenticity and the importance of this concept to ecotourism. Following this analysis I discuss some popular ecotourism attractions in Belize and assess the extent in which they are impacted by the ecotourists' desire for an authentic ecotourism experience. Through this analysis I intend to show that ecotourism in Belize does not appear to conform to the notions of sustainable and participatory development that many of its proponents claim it does. I will question the idea that ecotourism is a new form of tourism with a guiding logic that differentiates it from 
traditional tourism and emphasize instead how this alternative form of tourism creates social distinction through the consumption of particular tourist experiences. The ecotourists' concern for a socially distinct self and the cultural capital gained through ecotourism encounters are, I argue, strong motivating factors for undertaking such travel.

\section{Belize: An Ecotourism Mecca}

As mentioned earlier, Belize is a country that has been touted for its various ecotourism successes as have other eco-friendly countries such as Costa Rica, Ecuador and to a lesser extent Mexico (Singh and Singh 1999: ix). In fact, Belize has promoted itself as an ecotourism destination with sufficient success to be referred to as an ecotourism Mecca (Cater 1994: 73) and was recognized globally in 2004 as a premiere ecotourism destination (Mongaby 2007). As a testament to its ecotourism commitment, Gould (1999: 253) notes that Belize may be the only country in the world with a combined Ministry of Tourism and Environment and it is the first to make ecotourism a national policy. Belize has apparently learned from its Caribbean neighbors and has made policy commitments to environmental management in attempts to prevent "the decline of coasts, coral reefs, wetlands and rainforests" so as to use "tourism to protect the environment rather than destroy it" (Pattullo 1996: 182). As the London based Belize High Commission states on its website:

Belize's vision is to develop the tourism sector as a national priority, with a primary focus on responsible tourism, aimed at marine activities, natural history, and adventure markets. Development and promotion of the industry will be carried out to encourage a strong "eco-ethic" to ensure environmental and socio-cultural sustainability, to promote equitable distribution of economic benefits, and to develop a strong, positive image for Belize. As a lead sector of our economy, a competitive tourism industry will be a major force with respect to the future economic 
development efforts of the Government of Belize. (Belize High

Commission 2007)

Belize's first national tourism strategy came in 1998 with the Blackstone Report, which established the context for tourism development in Belize (BTB 2008). The report identified the development of community-based initiatives and micro-enterprises as part of the key to a successful ecotourism industry (Smith and Duffy 2003: 140). Produced in 2005, The White Paper on Tourism Development in Belize presented a number of considerations for updating the national tourism strategy. This document highlights information provided by a World Tourism Organization (WTO) think-tank that identifies tourism trends as increasingly oriented toward experiential tourism markets. Two of the most popular segments emerging in the tourism industry are historical/cultural tourism and geo-tourism, which overlap significantly and are based on similar values to those of ecotourism (BTB 2005). ${ }^{33}$ In the implementation of each of these strategies Belize has sought to attract specific types and numbers of tourists. The 1998 National Tourism Strategy set a minimum yearly target of 120000 visitors by year 5 and 140000 by year 10. Actually, international visitor arrivals (overnight and same day) reached 800000 in 2003 and exceeded 1 million in 2004 with the cruise sector accounting for the majority (ibid). Numerous types of tourism have emerged in past decades, many of which operate simultaneously in Belize. The extent to which these labels or types of tourism can be used interchangeably is, of course, a debatable point. Though this is the case, I contend that the type of tourism Belize most overtly pursues falls under the category of sustainable

\footnotetext{
${ }^{33}$ Historic/cultural travelers are those who tend to include some type of historical or cultural activities on their trips. Geo-tourists are consumers whose attitudes, behaviors and travel habit profiles show a higher incidence of travel and distinct preference for culturally and socially related travel. They tend to participate in educationally and socially-oriented activities and are socially and environmentally conscious (BTB 2005).
} 
tourism, of which ecotourism is the best and most popularly recognized representative. The following is an analysis of ecotourism in Belize and what I see as the defining characteristics of ecotourists as they engage in this social practice.

\section{Ecotourists}

In an analysis of a practice such as ecotourism, it is important to point out the obvious fact that not all people get pleasure from the same things and following from this, that ecotourists do not form a single group with a clear set of similar interests. Keeping this in mind the following is a generalization of some characteristics that ecotourists tend to exhibit. These generalities are in no way intended to be exhaustive of all ecotourists nor do they attempt to indicate that these attributes are only found in this particular type of tourist.

Ecotourists are more likely to want vacations that provide opportunities to learn about host cultures, societies and/or environments; they like to visit wilderness areas and see as much as possible in the time available (Duffy 2002: 24). Duffy refers to this as a search for novelty and an 'authentic' preindustrial nature and she notes that this quest can be seen as a distinguishing factor between ecotourists and those who prefer mass tourism (ibid). Ecotourists also seek out experiences as an individual or in small groups rather than as part of a large group. The concern with solitude in tourism has been linked the romantic tourist gaze in which "large numbers of people seek in their visual consumption, solitude, privacy and a personal, semi-spiritual relationship with their environment, whether this is physical or built"(Urry 1992: 9). Ecotourists embrace this gaze and it is 
the notions of "the remote", "the untouched", "the unspoilt" and even the "primitive" that are markers of what ecotourists desire (Duffy 2002: 24-5).

Arguably two main types of ecotourist exist within the wider tourist population. These two types can be roughly categorized by age and affluence into two different groups that are defined in terms of the growing middle class of western society. These groups are the "new bourgeoisie" and the "new petit bourgeoisie" (Bourdieu 1984).

Due to social change in the First World there has been an expansion of the middle class and a contraction of the traditional working class, which has resulted in an increased proportion of people with higher education and managerial jobs (Duffy 2002: 23). Within this expanding middle class, Bourdieu (1984) has identified new class fractions (Mowforth and Munt 2003: 115-40) that coincide well with my observations in Belize. The first category of ecotourists closely resembles what Bourdieu identified as the "new bourgeoisie" (ibid). This group exhibits high levels of economic and cultural capital and are often highly educated and employed in a professional or managerial position. This group conforms most closely to the stereotypical view of individuals who take luxury tours to off-the-beaten-track locations, in part, to distinguish their holidaying experiences from more traditional forms of vacationing. There are a significant number of these types of ecotourist in Belize, largely attested to by the many luxury eco-lodges and jungle resorts on offer to those with discriminating tastes. For instance, the Indian Creek Lodge in Toledo district sits at the edge of a 13000 acre private nature reserve with two artificial lagoons. There is a private zoo on the grounds of the lodge with numerous exotic animals including a black jaguar from Mexico (Eltringham 2007: 282). Quite common throughout Belize, minus the zoo, these types of lodges are often constructed 
within or on the outskirts of private nature reserves. Offerering an unadulterated view of the surrounding environment, these establishments enforce the romantic tourist gaze through the creation of a very exclusive vantage point.

Apart from the more affluent class fraction, Bourdieu also identified a large segment of the middle class he called the "new petit bourgeoisie" (Munt 1994a: 102). This class fraction, who often lack the financial capital of the upper classes, engage in less formalized travel pursuits such as backpacking and trekking partly to distinguish themselves from the classes above and below them. This group is also well educated and mature but is more likely to include younger individuals such as those in the somewhat liminoid state between finishing university and entering the work force. Another group to note in this fraction, and one especially important to ecotourism in Belize, are the large number of students who travel and study abroad as part of organized field schools and research groups. These types of programs are ubiquitous in Belize where there are over ten archeological field schools (Eltringham 2007: 336-7) and what seems like an unlimited number of conservation organizations, NGOs, field stations and education centers ready to accept paying students and volunteers.

Munt (1994: 50-1) refers to the new petit bourgeoisie, as the 'taste makers' and notes they popularize and transmit a number of ideas and consumption practices. They deem themselves unclassifiable or 'excluded' and in terms of popular tourism discourse their travel practices are best described, and sometimes self-described, as "alternative". ${ }^{34}$ Often ecotourists from within this class fraction are the most concerned with experiencing what could be termed "genuine" Third World peoples and places (Errington and Gewertz: 1989: 40). This pursuit of the "genuine" and notions of what constitutes

\footnotetext{
${ }^{34}$ Interview with Kevin, Kismet Inn, Hopkins village: 30, 12, 07.
} 
this characteristic are usually defined by these ecotourists in contrast to the "fake" experiences that the more affluent or luxury ecotourists pursue. The Indian Creek Lodge discussed above is a good example of what this less affluent class fraction would perceive as a contrived experience and this is partly due to the lodge's ability to enforce exclusiveness through its fortress-like characteristics (Brockington 2002). Therefore, the less affluent ecotourists, generally seek much closer encounters with the "primitive", "exotic" and "natural" in attempts to verify their alternative status. This is not to say that the wealthier and more mature ecotourists do not desire encounters with what might represent for them the 'primitive' or 'natural', but that the way they go about it and the reasons for doing so are somewhat different.

The more affluent ecotourists are more likely to accept and validate the economic system that has brought them success. Thus they are more accepting — to an extent—of the change that they see occurring in a destination (Errington and Gewertz 1989: 45). These individuals have the economic capital to confer taste by consuming positional goods and are able to ensure certain areas are not polluted with tourists or that fewer will be encountered along the way. Again, the Indian Creek lodge is a good example of this as is another eco-lodge located in Northern Belize called Chan Chich Lodge. This "premiere jungle lodge" is located on a 130000 acre private reserve which includes the classic Maya site of the same name. ${ }^{35}$ It offers only "twelve individual thatched roof cabanas"

\footnotetext{
${ }^{35}$ The Belize Estate and Produce Company (BEC) once owned over 1 million acres of Belize or one fifth of the country. The site of the Chan Chich Lodge and the 130000 acre Gallon Jug estate is the private property of the last owner of the BEC, a wealthy Belizean named Barry Bowen. Bowen bought BEC in 1983 and attempted to sell it to Coca-Cola to develop citrus. The development was to receive aid from USAID and the government of Belize but after a large scandal which would have resulted in Coca-Cola buying the land for US\$10 per acre (compared to US $\$ 500$ and acre in other citrus growing areas of the country) and dubious involvement by a number of government officials, the deal was called off and the land was divided up into four large parcels. The majority of the land was given away by Coca-Cola and is now called the Rio Bravo Conservation Area and is managed by a Belizean NGO called Program for
} 
and promises an authentic jungle retreat (Chan Chich Lodge 2008). It is clear from the exclusiveness of these holiday destinations that what is important is an unobstructed view of "pristine" environments including private Mayan ruins on which only a few may and will gaze.

The less affluent ecotourists, in opposition to the luxury ecotourists, identify themselves as "travelers" and condemn the other as "tourists". MacCannell (1989: 10) refers to this condemnation as the tourist critique of tourism and finds it to represent a long-standing tourist attitude that should be included into the study of tourism not understood as a reflection on it. He notes:

The touristic critique of tourism is based on a desire to go beyond the other mere tourist to a more profound appreciation of society and culture.... All tourists desire this deeper involvement with society and culture to some degree; it is a basic component of their motivation to travel.

This critique of the "tourist" often involves the notion that they are the ones who commodify relationships and corrupt destinations by being content with superficial or inauthentic experiences (Errington and Gewertz 1989: 42). This became evident when speaking with an ecotourist in the town of Hopkins who I see as representing the alternative type of traveler. He spoke of the absurdity of the luxury accommodations being built next door to where we stayed and described them as an "altered reality". ${ }^{36}$ In effect, this group sees nearly everyone outside their travel practices as destructive and commodifying "tourists", and ironically, as reducing the value of people and places at a destination.

Belize. Bowen retained 130000 acres for himself which is now used for ecotourism and some small-scale forestry operations (Sutherland 1998: 21).

${ }^{36}$ Interview with Kevin, Kismet Inn, Hopkins village: $30,12,07$. 
Take for instance these ecotourists quoted while engaging on a three-day trek through the forest along the Indian Creek Trail in Belize district. "[Our guides] made us things like tea from vines and knew about the tropical broadleaf forest vegetation and animals. It felt more genuine I guess to have local people with us" (quoted in Stinson 2004: 76). Stinson quotes another ecotourist relating that:

[If the whole country were carved up in trails] it would take away from the uniqueness of the experience. Also, if trails are catered to "tourists" and not "travelers" the environment and wildlife will likely be harmed and it wouldn't give the same feeling of seclusion (Ibid).

It is clear from the above statements that these particular ecotourists are interested in a "genuine", "unique" and "secluded" experience which differentiates them from mere "tourists". Yet, as noted above, it is somewhat ironic that these travelers, while claiming the moral authority to use the forest and trails as a "traveler", are unable to reflect on their own impact as someone that is creating further demand for this type of experience. I think that statements such as these indicate the value placed on experiencing particular people and places and the validation that many ecotourists are seeking through their travel practices. In other words, encountering the "genuine" Third World is often seen in the First World as taking and making a certain kind of person.

\section{Cultural Capital}

Cultural capital is different than economic capital in that it cannot be strictly bought and sold. Instead, it is a capital that relies on the ability of individuals to join in a game of being able to "know" and "appreciate" what kinds of things to eat, drink, wear and what types of holiday to take (Mowforth and Munt 2003: 120; Urry 1990: 79). It should be apparent from the above that engaging in ecotourism is a distinguishing 
practice and one that can produce a significant amount of cultural capital for its participants. For the luxury ecotourists the exclusiveness of their holiday may be sufficient to distinguish their tastes from other class fractions. But for the new petit bourgeoisie, who do not have the financial ability to distinguish themselves, gaining cultural capital through travel experience is seen as a way to confer a particularly desirable identity (Ibid: 122).

The consumption of holidays has assumed a significant role in class differentiation and the Third World has an increasingly important role to play as it is seen as a sizeable asset (Munt 1994: 49). For the less affluent and often younger traveler, the attributes gained by embarking on eco-tours are experiences that ascribe a number of personal characteristics. While reviewing ecotourism and alternative travel brochures and literature, Munt (1994: 51) found numerous personal characteristics and qualities that ecotourism is said to reflect in an individual. These include strength of character, adaptability, sensitivity and worldliness. Travelers were also said to be adventurous, broad minded, independent, intrepid, real and true. It is "traveler" characteristics such as these that are used to gauge what was gained by undertaking this particular type of tourism.

Stinson (2004: 77-9) shows in his stakeholder analysis of an ecotourism project in Belize that many participants undertook ecotourism as a way to achieve a level of cultural capital. He relates that a number of ecotourists he interviewed cited personal growth in emotional, spiritual and intellectual terms as an expected outcome of engaging in an ecotour: "learning about the environment", "learning about myself" and "becoming more independent" where some of the motivations related by his participants (Stinson 2004: 
77). Similarly, ecotourists Duffy (2002: 31) interviewed in Belize were observed to speak of their destinations and experiences mainly in terms of their own benefits, their travels were about "self-improvement", "self-recreation" and as a "time to reflect on their own personality" (ibid: 42). ${ }^{37}$

Significantly, the older professional ecotourists are not as embedded or concerned for that matter, with the taxonomy game where distinguishing oneself as a traveler with certain characteristics is critically important. Rather, this more affluent class of travelers can be better theorized as in a competition with peers at home where they are already accomplished individuals. At home they are more likely to focus their effort to display pictures and tell stories of themselves as having led unusually full, interesting and successful lives (Errington and Gewertz 1989: 45; Bruner 2005: 24).

It can be seen from the attributes listed above that self-satisfaction is an overriding concern of the ecotourist. Similarly, from this information it can be gathered that ecotourism is largely undertaken in order to increase the volume and valuation of cultural capital and hence distinguish the "traveler" from the elitist "tourist" and the coarse lower "masses" (Urry 1990: 80). Furthermore, travel to developing countries and experiencing people and landscapes different from home is increasingly recognized as producing currency with real exchange value upon ones return. Ecotourism, with its assumed benevolence toward nature and culture, has become an important informal qualification with a passport acting as a record of achievement and experience (Munt 1994a: 112). Not only is it the travel industry that recognizes these achievements when hiring staff and guides but there are a growing number of occupations where overseas

\footnotetext{
${ }^{37}$ These perceived benefits were also confirmed by ecotourists I spoke with. Interview with Kevin, Kismet Inn, Hopkins village 30, 12, 07; Interview with Group of Scottish ecotourists Water Taxi Terminal, Belize City 25, 12, 07; Interview with Shaun, Caye Caulker 26, 12, 07.
} 
travel is a significant component and even a prerequisite for various professions

(Mowforth and Munt 2003: 121). Overseas development work is possibly the most prominent profession that comes to mind but travel experience in general is socially accepted as generating the qualities listed above and people, including myself, find it pertinent to list such experiences on their resume.

\section{“Travel" Culture}

The above should not take away from the fact that the desire for a holiday has become a felt need in the First World. Ecotourists, like all tourists, expect their trips to be a form of relaxation, escape, freedom, hedonism or a means of self-discovery. As the Turnerian approach to tourism in Chapter Two demonstrated, tourism is a means of leisurely escape, but as is shown above it also serves the need for status recognition from others (Duffy 2002: 25). Of course, it is not a new development that travel is being used as an expression of taste, as Urry (1990: 16-37) demonstrates, it has been a mark of class distinction since the $19^{\text {th }}$ century. ${ }^{38}$

What is interesting is that travel has never been so widely used as it is at present and the number of people taking holidays has never been so high. But as travel practices become more and more a mark of identity and distinction this felt need to "get away" becomes translated into expectations and trips are expected to really be a "getting away from it all" experience (Duffy 2002: 25). These expectations have led to tourism practices conforming to very personal and individual desires, or what Mowforth and Munt (2003:

\footnotetext{
${ }^{38}$ Urry (1990: 16-37) shows that the first mass tourists were the industrial working class in England in the $19^{\text {th }}$ century. The beginning of the mass industry was predicated on the popularity of seaside resorts first visited by the upper classes for the curing and medicinal properties of mineral water. With the large-scale expansion of rail service to these coastal destinations and their proximity to industrial centers the working class quickly transformed these small coastal towns into bustling seaside resorts.
} 
124) refer to as the democratization of travel. Ecotourism is a perfect representation of this process and can be seen to portray how individuality and distinction are gained through customizing the experience toward what one might deem authentic or real.

All ecotourists are, in a general sense, considered to be environmentally aware and culturally sensitive travelers, and indeed being environmentally aware is an important signifier of social position (Duffy 2002: 41). According to Wearing and Neil (1999: 119) ecotourists are generally concerned with visiting wilderness, national parks, tropical forests and viewing birds, mammals, trees and wildflowers. They want to experience new lifestyles and cultures and see their dollars contributing to conservation and local economies. These characteristics are attributable to ecotourists but Wearing and Neil's definition is somewhat narrow and misses a number of important pursuits that this group of travelers engages in and which reveals much about ecotourism as a distinguishing social practice.

In addition to experiencing nature, ecotourists often engage in a number of other activities including intellectual or academic pursuits. Activities like mountain biking, kayaking, trekking, climbing, snorkeling and scuba diving as well as dabbling in such subjects as archeology, anthropology, ecology and science can all be placed under the banner of ecotourism. This marriage of tourism with a number of arguably non-touristic activities can be seen as a defining characteristic of tourism in a postmodern era (Munt 1994a; Urry 1990, 1992). The combination of tourism pursuits with these other activities is an aspect of what is termed de-differentiation, a feature which others have related as a defining characteristic of post-modernity (Lash 1990; Urry 1990). In a sense, modernism can be understood as a process of differentiation where spheres of social activity are 
separate, distinct and self-legislating (Lash 1990: 9). For example Academics, aesthetics, morality and science develop as separate institutional and normative spheres (Urry 1990: 76). In a postmodern society these spheres implode into one another and hence are dedifferentiated (ibid). This process has led to an infinite number of possible tourism activities and an $\mathrm{A}$ to $\mathrm{Z}$ of new tourisms of which ecotourism is one and yet cuts across many other spheres of tourism (see figure 4.1 below) ${ }^{39}$

The de-differentiation of tourism products into what Poon (1989) calls new tourism is intricately related to an attempt to distinguish holidays from the mass tourism industry, so famously derided for its attendant ills. Urry (1990: 86-7) refers to this as a quest for "real" holidays in which the real-holiday "traveler" attempts to spatially separate themselves from mass-packaged tourists. This concern for separation and "real" holidays is represented not only in the identification struggle between "traveler" and "tourist" but also in the emergence of specialist agents and tour operators and their promotion of more individually centered and flexible packages. Currently, tourism brochures, ads, and websites are full of these descriptive phrases offering "customized tours", "specialized packages" and "personalized experiences". The Pine Ridge Lodge in Cayo district, Belize offers to:

Open the door to the entire Mountain Pine Ridge Forest Reserve. Whether you're interested in Maya Ruins, bird watching, caving entomology, biology, or botany, we cater to you to maximize your Belize experience (Pine Ridge Lodge).

\footnotetext{
${ }^{39}$ The diagram below is an example of how different forms of 'alternative' or 'new' tourism can overlap and coincide with one another. It is meant as a visual aid that represents the de-differentiation of tourism and does not claim to represent all of the possible permutations of the ways in which this could happen. For example, cultural tourism and wildlife tourism do not overlap in the diagram yet they obviously do in African ecotourism (see Bruner 2005).
} 


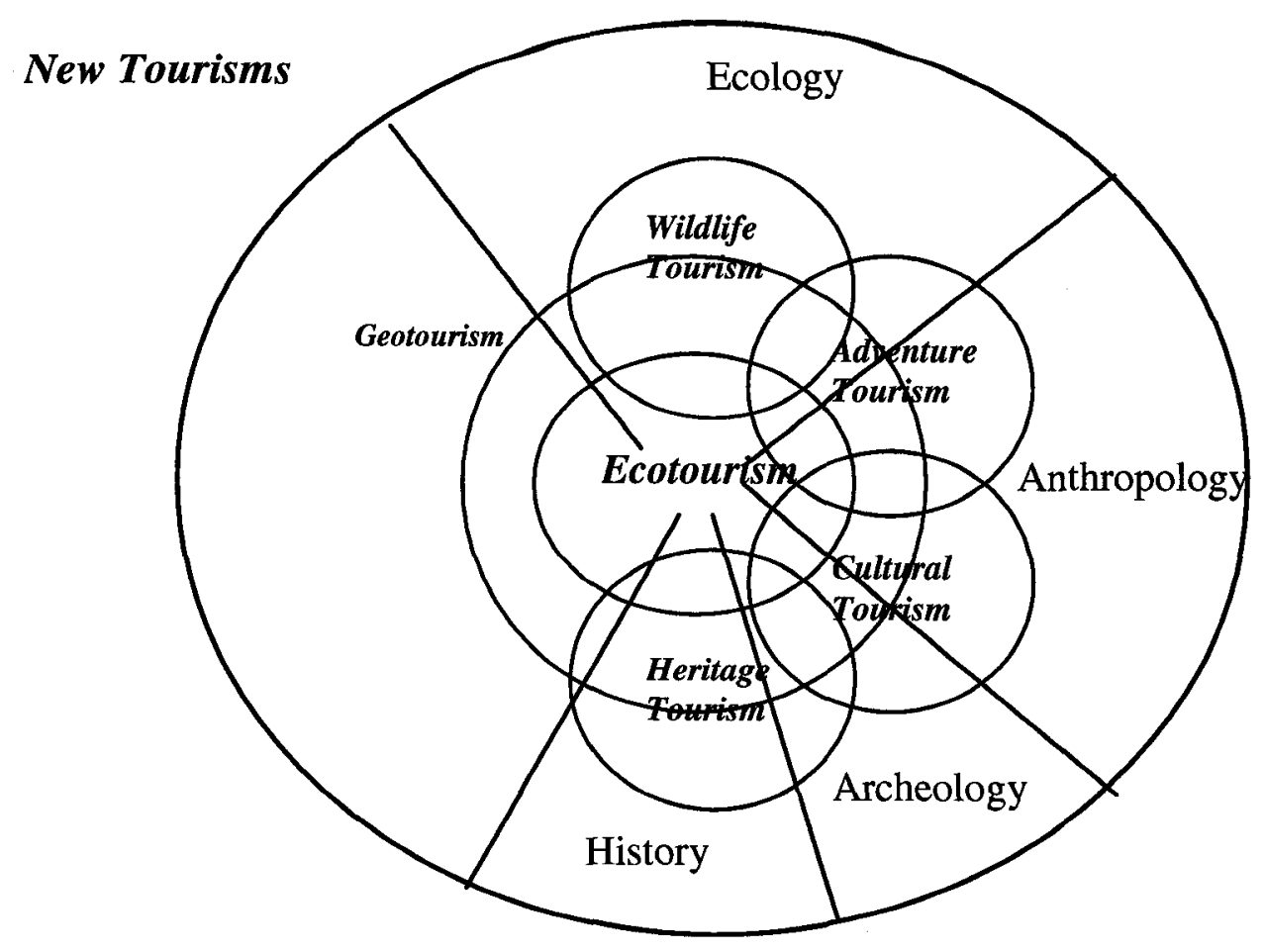

\section{Figure 4.1: postmodern tourism}

Operators and agents also further differentiate their product in order to offer services to very precise consumer groups. For instance, Adventure Women offers packages specifically to women over 30 .

The emergence of the desire to partake in "real" holidays and a more individuated market connotes an epoch of post-Fordist consumption or, as Harvey (1989: vi) put it, "a new dynamic phase of capitalism". In this new phase, the consumption of mass-produced goods gives way to the consumption of very specific goods and services. In the case of ecotourism, what is bought and sold is an individually oriented, ephemeral holiday experience combining a number of activities that have precise meanings for specific individuals. These developments represent a consumer reaction against being part of a mass tourism industry (Urry 1990: 86-7) and it seems that this distaste runs to the depth of condemnation of mass packaged holidays. 
The disparagement of all-inclusive (package) holidays can be found in the everyday interactions of many First World tourists. I was once invited to a friend's wedding at an all-inclusive resort near Cozumel, Mexico. What was interesting about this trip was that when telling people about where I was going, I (and others invitees) felt the need to verify that the all-inclusive trip was chosen because that was where the wedding was. There was, and obviously is, a real stigma attached to all-inclusive "Cancun-type" holidays. It is important to note that in my experience it is rare that people have spoken negatively about these vacations because they are "irresponsible" or environmentally "unsustainable"; rather, reference is more often made, no matter how implicit, to how unfashionable it is in terms of an un-authentic holiday experience. The words "you don't get to see the 'real' Mexico that way" were often spoken.

\section{Authenticity: Moving Beyond Binaries}

As discussed in Chapter Two, authenticity is possibly one of the most dominant topics in discussions of tourist motivations. The distinguishing quest for a "real" holiday such as the ones ecotourists undertake in Belize is deeply laden with notions of authenticity, no matter how contrived some tourist attractions may be in reality. One would assume that if ecotourists seek an authentic experience in the Third World they would be more willing to forego the concept of an environmental bubble discussed by Cohen (1972) in Chapter Two. As the information related in this chapter may suggest, however, and based on the observations I made in Belize, this did not at all seem to be the case. 
Though the notion of authenticity has been a driving force in tourism research for a number of years there are many who disagree with MacCannell's view. Urry (1991: 51), for example, notes that the search for authenticity is too simple a foundation for explaining all of contemporary tourism. Bruner $(1991,2005)$ suggests that authenticity is "somewhat of a red herring, only to be examined when tourists, locals or producers use the term" (Ibid 2005: 5). He notes that while many tourists are satisfied with their society, most are not alienated, nor are they seeking an authentic experience elsewhere. "They are upset if what is presented to them is an outright fake, but otherwise they are quite content with a theatrical suspension of disbelief. Tourists are willing to accept a reproduction, as long as it is a good one..." (1991: 240). Bruner (1989: 438) states his point clearly in a paper analyzing the Denis O'Rourke film Cannibal Tours:

The tourists are aware that New Guinea has been pacified and that cannibalism is prohibited, but they want to experience the primitive, to visit a place where cannibalism had been practiced, to observe the peoples whose ancestors had eaten human flesh, and to hear stories about the wild, the savage, and the exotic. If cannibalism were still practiced, or if there were any real danger, or if the infrastructure of luxurious river boats, first class air-conditioned hotels, and modern air transportation were not present, the tourists, of course, would not go to New Guinea. They seek the titillation of a vicarious brush with danger. They want to see firsthand the ultimate savage Other, with penis sheath, painted face, and spear, but only from the secure and safe vantage point of luxury tourism, and only after the disappearance of the original object. Tourism prefers the reconstructed object, and indeed, this preference for the simulacrum is the essence of postmodern tourism, where the copy is more than the original.

There is significant evidence in Belize to suggest that ecotourism there is very similar to what Bruner describes above. The emergence, popularity and ubiquity of luxury jungle resorts and eco-lodges in Belize appear to provide the same vantage point and exhibit the same characteristics as are described for New Guinea tourism. O'Rourke's tourists, though not ecotourists per se, seem content with a copy of what is 
referred to as the 'original', but it seems problematic to conclude from this that the authenticity of their experience is not a concern. After all, they are traveling to the "real" New Guinea and visiting its "real" inhabitants and this must, at some level, symbolize a concern with the genuine or authentic.

Recalling Cohen's (1979) phenomenology of tourist experience, it is evident that not all tourists are concerned to the same degree with the authenticity of their experience. In a later paper, Cohen (1988: 374$)$ reiterates this notion stating that authenticity is a socially constructed concept and that its social connotation is therefore not given but negotiable. Cohen sees individuals who are less concerned with the authenticity of their experience as more prepared to accept as 'authentic', an attraction that others, who employ stricter criteria, will reject as 'contrived' (ibid). Since, as we have seen, the nature of ecotourism to the Third World is concerned with penetrating deeper into societies and landscapes and differentiating the ecotourist from the masses, I argue that many ecotourists can be described as seeking Cohen's 'existential mode of touristic experience' (1979: 190). Arguably, these people are not seeking a purely existential experience but if placed on the spectrum Cohen developed, their holiday motivations and desired experiences would surely orient toward this pole.

Seemingly, ecotourists seek a deeper, more romanticized experience than most rank-and-file tourist and have stricter criteria concerning what constitutes the authenticity of this experience. This is not to say, that ecotourists demand total authenticity, something that the French post-structuralists have shown to be unattainable anyway (Bruner 1991: 241). Ecotourists, though seriously concerned with the authenticity of their experiences, will often focus judgment on some traits of the destination people and 
landscape while disregarding others. Therefore, ecotourists will accept a commercialized object as "authentic", as long as they are sure that it contains some of what they deem 'traditional', 'natural' or 'true', even though it may be altered, contrived or (re)produced specifically for their consumption (Cohen 1988: 378). Therefore, Cohen's negotiation of authenticity could be seen in terms of semiotics or as the cultural interpretation of signs. Rather than there being an inauthentic front stage and an authentic back stage, what is authentic is then defined as something that offers itself to the ecotourist as a sign of itself (Smith and Duffy 2003: 117). National parks and nature reserves, managed and maintained by human intervention, signify the "natural", "pristine" and "untouched". Restored Mayan ruins with kept grounds signify a lost time or a primitive past and are a place to discover and explore. The Maya, Creole and Garifuna people in Belize signify the exotic other, or at least a simple and unhurried life. Any of these sites could be gazed upon from a private luxury eco-lodge or from a wooden shack on the side of a hill, but as long as they conform to a certain criteria and are able to symbolize the ecotourist's desires they can be seen as markers of authenticity.

What I propose is closely in line with Bruner's New Guinea example above but I suggest that ecotourists maintain a concern with "authenticity" even though they are aware that attractions are contrived in some way. It is not the copy that the ecotourist values more than the original because no copy can exist if there is no original. What is authentic then, is that there is an authentic tourist experience created by the ability of a sign to represent the ecotourist's expectations and desires. In this sense, watching the monkeys swing by while you are sitting in the Jacuzzi, as the Chan Chich lodge advertises you can (Chan Chich Lodge 2007), is still an authentic ecotourism experience 
that differentiates the ecotourist from those who are only able to see monkeys in a more controlled setting, a zoo for instance. In addition, since ecotourists are said to have relatively higher levels of education, experience, and a desire for differentiating or authentic experiences, they hold particular signs to a stricter criteria and paradoxically create pressure in a destination to conform to these expectations. Of course, from the perspective of some, this is not a bad development as this demand can lead to the creation of conservation areas and policies to protect the environment. But on the other hand, and as will be shown in the following pages, such demands are political in nature as they seek to redefine who has the right to access the land as well as what practices may be conducted on it. As many ecotourists have particular desires and expectations in terms of their environmental bubble, there becomes an increasing demand, figuratively speaking, for more monkey-viewing Jacuzzis from which to cast the romantic tourist gaze.

The reason I have focused so much attention on the notion of authenticity is because the ecotourist quest for what is deemed more authentic or more "real", and therefore distinguishing, has a significant impact on ecotourism destinations such as Belize. As ecotourists seek more authentic experiences than the traditional or mass crowd and hold destinations to stricter criteria of authenticity, it creates somewhat of an ethical dilemma when considering ecotourism as a socially and environmentally responsible development strategy. As ecotourists seek to penetrate deeper into Belize, local people and the tourist industry work to fulfill the fantasies and desires of these visitors creating a representation that often overlooks the lived reality of the host's everyday lives. The actual landscapes of Belize, therefore, become more closely identified with what the ecotourists desire and locations are pressured according to what this image entails. 
In regards to the anti-structure or liminoid state that ecotourists' may exhibit while on holiday, the result of this position on the host destination can result in ludic, self indulgent behaviour that at times can be very disruptive. Examples of disruptive behaviour that occurs partly as a result of this permissive state are common knowledge for most people who have embarked on any type of Third World tourism. Ecotourism, for all of its purported benefits, does not seem to escape these negativities. Duffy (2002: 305) cites numerous examples of Belizean ecotourists engaging in intrusive and insensitive behaviors. She highlights the excessive drinking and drug taking that occurs in numerous tourism destinations throughout Belize, especially in the more popular spots of Ambergris Caye and Caye Caulker. In many cases tourists engage in hedonistic activities, create an atmosphere of sexual freedom and some engage conspicuously in the sex industry (ibid). Duffy goes on to note that engagement in drug use and sex tourism were noted frequently in her interviews with tour guides and that one of the ecotourists she interviewed was keen to demonstrate that his ecotourism was based around taking cocaine and marijuana for two weeks (Duffy 2002: 34). The socially disruptive, insensitive and at times blatantly out of hand behaviors of ecotourists became apparent to me while in the bustling tourism town of Placencia. As we were walking on the beach we became engaged in a brief conversation with a man who recounted the story of a group of drunken Americans in the town of San Pedro. ${ }^{40}$ He said that on a night he was there a group was purposely driving their (eco-friendly) golf cart into and hitting local residents and laughing hysterically while they were doing it. ${ }^{41}$ In reference to the information presented above it becomes obvious that the nature of tourism as a permissive, playful

\footnotetext{
${ }^{40}$ Conversation with man from San Diego, Trade Winds Guest House Placencia, Belize. 9, 01, 08.

${ }^{41}$ On the Cayes, particularly Ambergris and Caulker, golf carts are the preferred mode of transportation; they are rented out by the day or hired as a form of taxi service.
} 
and hedonistic period imbues ecotourism with the capability to create the same effects and even replicate some of the problems associated with the mass tourism industry.

\section{Ruins, Rainforests and Reef}

The phrase "ruins, rainforest and reef" is one seen and heard throughout Belize. Not only is this a term that is used by the Belize Tourism Board (BTB) but it is also widely used by the private sector to promote Belize as an ecotourism destination (Duffy 2002: 30). The phrase refers to the three main ecotourism attractions in Belize; ruins: the large number of Maya archeological sites; rainforests: inland jungle excursions and the numerous nature and wildlife reserves; reef: the Belize Barrier Reef which supports a plethora of diving, snorkeling, fishing and other marine activities. In addition, each of these attractions is often overlaid or associated with one of the various ethnic groups of Belize, which enhances the experience for ecotourists. For example the Creole village of Gales Point offers the experience of traditional Creole culture while the visitor is able to explore the surrounding forest and lagoon ecosystems (Horwich and Lyon 1998, 1999; Belsky 1999). Similarly, the Cockscomb Basin Wildlife Sanctuary, managed by the BAS and often referred to as the Jaguar Reserve, provides a visitor trail map which gives a self-guided nature walk highlighting the Mayan names and traditional uses for the forest species encountered (Belize Audubon Society 2007). Also, in the case of the Maya and Garifuna, and to a lesser extent the Creole, Mennonite and Mestizo, local culture itself is a tourist attraction. The Garifuna town of Hopkins still has "traditional houses" (Eltringham 2007: 252) and it is where "time moves like a turtle; the men of the village fish and carve canoes while the women can be found weaving baskets and singing 
together" (Toucan Trail 2006). Similarly, the village of Maya Center at the entrance road to the Jaguar Reserve is "a perfect place to learn about forest life and to experience Maya culture" (Eltringham 2007: 263). The above statements and advertisements are significant because they give a taste of what kinds of destinations and associated experiences ecotourists pursue. For most ecotourists that visit Belize these attractions come to be seen as a type of check-list in which one tries to gaze upon as many as possible in the allotted time of the holiday. Even the most alternative and independent ecotourists who visit Belize are informed by guide books, often of the Lonely Planet, or Rough Guide series. These books, similar to the country's tourism industry, point out what attractions to visit (ruins, rainforest, reef) and by extension what ones not to. The nature and cultures of Belize are thus presented as a list of predetermined sights and attractions structured for ecotourist consumption. Though often not taken into account by the ecotourist, this structuration tells the traveler where to go and what to see, the time it will take and the best time to go. With this in mind the independent and flexible ecotourism holiday is controlled and predetermined and in many ways runs contrary to claims of an unstructured "real" holiday.

Rosaleen Duffy has conducted numerous interviews with ecotourists while in Belize and in her book A Trip Too Far (2002) she relates a number of tourist expectations and assumptions concerning the country. Using her interview material and some of the observations and interviews I was able to obtain in Belize, the following pages will discusses some of the pressures ecotourism presents for Belize and conclude that ecotourism is not the radical alternative to mass tourism its protagonists claim it to be. 
What an ecotourist deems to be authentic may very well be informed more by the content of tourism brochures, nature programming and national geographic magazines than by a desire to experience Belizean nature and culture on its own terms. As mentioned above, the main tourist attractions in Belize are the ruins, rainforests and reefs but the image that most ecotourists hold in their mind, and part of what attracted them to Belize are those of a Caribbean destination teaming with white sand beaches, turquoise water and palm trees (Duffy 2002: 28). ${ }^{42}$ In fact, Belize has very few natural beaches and most of the low lying coast and cayes are covered in mangroves that are act an important habitat for marine species and protect against erosion and storm surge flooding (Greenberg et al 2000). In Belize, mangrove and sea grass habitats are often destroyed in order to provide ecotourists with the appearance of silver Caribbean beaches and unobstructed views of the water. ${ }^{43}$ Ironically, these habitats are important nurseries for many of the reef fish that ecotourist attempt to view on their diving and snorkeling trips (Duffy 2002: 45).

The construction of tourist spaces and the associated views desired by ecotourists also include sand mining and the dredging of the seabed to build foundations for large hotels and condominiums (BAS 2007a). This practice disturbs the sea floor and causes fine silt particles to cover the coral reef doing irreversible harm (UNEP 2002). The demand for private island resorts and condominiums that has accompanied the growth in the Belizean tourism sector has facilitated this practice throughout the country (BAS 2007a). It has mostly occurred around Ambergris Caye, the most touristically developed destination in Belize and where over half the tourists that come to the country visit

\footnotetext{
${ }^{42}$ Duffy's informants remarked that their images of Belize were of "islands and sunshine", "pirates, seriously, and palm trees", "filled with reggae music" or as a "relaxed place to chill out" (2002: 28). ${ }^{43}$ Interview with Orlando Alamailla, Lorraine's Guest House, Caye Caulker, 28, 12, 07.
} 
(Eltringham 2007: 130). ${ }^{44}$ There is a large demand for these particular views and holiday experiences in Belize and it has led to the proposal of very large-scale tourism developments. For instance, developers have proposed the dredging of 336000 cubic meters of ocean bottom just off the Placencia peninsula in Stann Creek district. This development is being proposed in order to build two hotels, time share villas and over the water cabanas (Slauder 2008) that will provide ecotourists with an authentic Caribbean experience while allowing quick and easy access to surrounding ecotourism attractions.

Another major draw to Belize is the perceived closeness to nature one can attain including the possibility of seeing the country's many species of terrestrial and marine life. Black howler monkeys, sea manatees, whale sharks, stingrays, a plethora of bird species and the elusive jaguar are the most pervasive wildlife images that one finds in promotional literature inside and outside the country (BTIA 2007). The "pristine" beauty of Belize and its wildlife has now become inseparable from its image as an ecotourism destination and has created a demand for viewing these wild species. Most prominent in my experience was a snorkeling trip I took to the reef near Caye Caulker where the other ecotourists in my group constantly kicked the coral and stirred up sand with their flippers (causing damage to corals). Of course, it is not common knowledge that this can be damaging to corrals, but what I found interesting was that the two individuals who did it were scuba divers who had undergone formal training and certification concerning interaction with marine life. ${ }^{45}$

\footnotetext{
${ }^{44}$ Many accounts of ecotourism in Belize note the environmental destruction that has occurred in and around Ambergris Caye and more specifically the town of San Padro. This destination is the longest established ecotourism destination in the country and has suffered massive inflation as well as environmental deterioration due to a high volume of tourists. Sewage treatment facilities and fresh water sources are some of the major concerns the island is experiencing (see Southerland 1998: 96-8; Duffy 2002: 61-4; see Stonich 2000 and 2005 for similar discussions of the Bay Islands, Honduras).

${ }^{45}$ Interview with snorkelers from Saskatchewan, Caye Caulker, 28, 12, 07.
} 
On the snorkel tour, the guide fed the marine life so that we were not only able to see particular species up close, but could even swim with and pet stingrays (see figure 4.2 and 4.3 below). Such tours are common in Belize especially at a place called Shark Ray Ally near Ambergris Caye where ecotourists are guaranteed a shark sighting. From what I had read, I assumed Shark Ray Ally was the only place such an experience was possible. Yet from what I saw, it would seem that the demand for such a close encounter with marine life has caused similar attractions to develop along the barrier reef.

There is much environmental concern about these trips, especially in Shark Ray Ally where ecotourists attempt to ride the harmless nurse sharks and pull on stingray tails. One worker at the marine reserve has expressed concern over ecotourists holding on to the shark's tails in order to have their picture taken and that slapping, riding and feeding the sharks and stingrays has made them uncharacteristically aggressive (Duffy 2002: 55). For me, it was not difficult to see that the behaviour of the thirty or so stingrays we encountered had been altered by ecotourism. As the rays began to lose interest with our tour group and disappear into the blue-because the food was gone-the tour guide started the boat and the sound of the engine brought the whole flock back in one wave of excitement looking for more. In effect these "wild" animals had been trained to pursue the sound of a boat engine searching for their next meal. As noted above, this attraction is very popular and its appearance in ecotourism advertising led to over 35000 people visiting Shark Ray Ally in 1997. The increased visitation has caused a significant amount of damage being done to the marine reserve and has led some to suggest the site be closed for two years in order for the damaged coral to rejuvenate (ibid: 56). 


\section{Figures 4.2 and 4.3: Ecotourists interacting with sting rays near Caye Caulker}
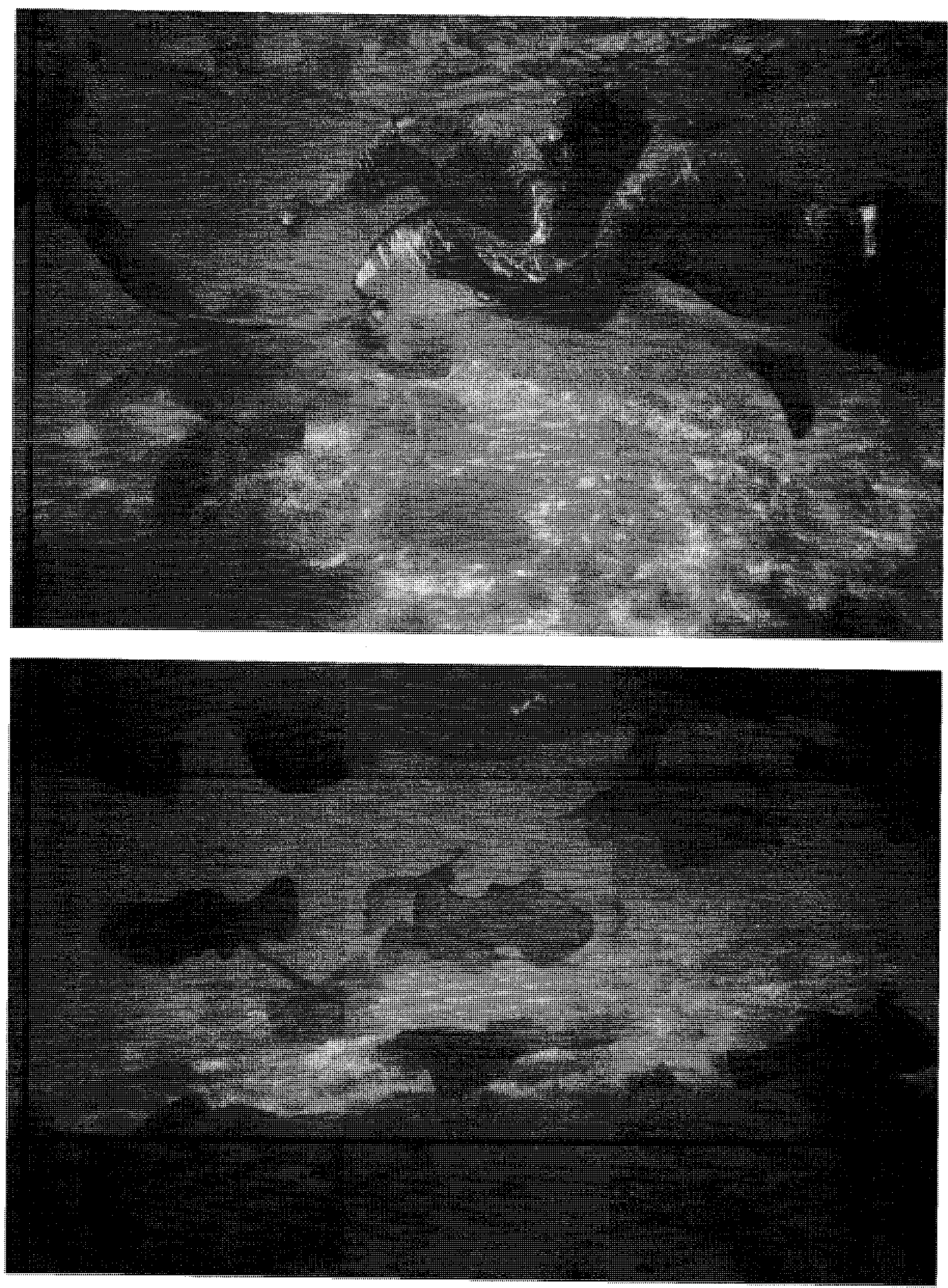

Pictures taken by author, December 28, 2007. 
Though this is an environmentally conscious idea, it is doubtful that it will take precedence over economic concerns. The ecotourism economies of Caye Caulker and Ambergris Caye have become heavily reliant on providing such experiences, and again, somewhat ironically, the closure of the nature reserves to protect nature is unlikely because it would threaten the small islands' economy as well as the national ecotourism industry.

These pressures on Belize's environment to present ecotourists with the authentic ecotourism experiences they desire are only some of the impacts associated with ecotourism development. They may sound similar to the problems associated with traditional forms of tourism and that is because they are. Ecotourist's holiday desires and expectations create very similar pressures to the traditional or mass tourism industry. This is especially true in how ecotourists imagine local people and communities and how the tourism industry presents them.

The image usually held in the minds of most ecotourists and presented by the ecotourism industry is characteristically a romanticized version of rural life in the Third World (Belsky 1999; Bruner 1991; Dupuis and Vandergeest 1996; Johnson 1989; West and Carrier 2004). For example, the village of Gales Point is presented as a traditional, quiet and conservation minded community that modernity has not yet infiltrated. This is signified by the one dirt road that runs through the village (Belsky 2000). Also, as mentioned above, the Garifuna men of Hopkins village fish and make canoes while the women dance and sing, and the Maya of Maya Center are forest dwelling people. This is what Bruner (1991: 240) refers to as the tourist text and as scholars like Said (1979) have demonstrated, the power of this discourse cannot be overlooked. These images and 
representations give meaning to the tourist encounter for both the ecotourist and the people of Belize (Escobar 1995; Lohman 1993).

An important narrative that runs through this encounter states that the ecotourist is a member of the modern world and even an elite member since they have the time, money and the discriminating taste to travel. Ecotourists to Belize are able to gaze upon the remnants of the ancient Mayan civilization, the pristine ecosystems of the jungles and reef all the while engaging with the exotic and unhurried "Caribbean" culture. This text can be seen in much of the Belizean advertising literature but in another sense it also abstracts a master narrative structure (Bruner 1991: 240). In the case of ecotourism, this master narrative consists of a modern person going on tour to experience exotic natures and cultures in order to recover a perceived historical time seen as pure and unpolluted by modern civilization. In other words they are exploring "mother nature's best kept secret". It is through this narrative's lens that much ecotourism to Belize is experienced and the interactions with local people and environments are conducted. "It is as much a structure of power as it is a structure of meaning" (ibid). After all, it is ecotourism that sets the terms of the encounter because the ecotourists have the power and the money and they know what they want to see and do. As discussed in Chapter Two and Three, it is important to note that I am not insinuating that Belizean people are passive receptacles who relate to, or even accept, the ecotourism narrative. Yet their ability to alter the tourist narrative or maneuver within it is limited. At the very least, the people of Belize are forced to see themselves through the eyes of the ecotourist, but whether this Lacanian reflection is perfectly cast or not is something for further study and consideration. As Thomas (1994) shows, in spaces of cultural interaction, even ones as dominant as 
colonialism, there always exists room for maneuver. Meaning that narratives and discourses such as those above can be accepted, misconceived, resisted or appropriated in a variety of different ways. ${ }^{46}$

The Belizean state along with the private sector and NGOs, draw upon the same narrative in order to present a specific image for consumption by ecotourists. As this construction is inspired in part by consumer expectations it will often be closely aligned with the ecotourism master narrative. As Smith and Duffy note

The construction of an 'authentic' destination image can assist governments in developing countries in the process of nation building and identity formation... In particular the marketing strategies of developing countries often emphasize images of environmentally unspoilt landscapes, political stability and culturally interesting local people (2003:125).

Lanfant contends that the international promotion of tourism demands that every place should have its own specific character and in the process of manufacturing this identity the seductive attributes of the place become crystallized in a publicity image (1995: 323).

These aspects of tourism promotion and national identity have a number of impacts on the people of Belize. First, by marketing Belize as a sparsely populated wilderness, the Belizean state, in line with NGOs and the private sector, is able to construct and enforce an image of the environment devoid of people and authenticate this image through tourism literature and images. This practice effectively depoliticizes the nature of ecotourism and the conservation areas created to support it (Ferguson 1990). The landscapes of Belize are presented as expansive and undisturbed while people are

\footnotetext{
46 See Picard 1995 for how the Balinese used 'cultural tourism' (a term they invented) to protect against the combined forces of the Indonesian government and the World Bank's large scale tourism development plans.
} 
always happy and welcoming (see figure 4.4$).{ }^{47}$ Second, this dominant narrative effectively silences and suppresses narratives that may highlight oppression, racism and conflict. In this case local politics and aspects of indigenous society are kept far from the tourist gaze. In the case of Belize, "mother nature's best kept secret”, sustainability is one of the highest order discourses for the tourism industry and it is not uncommon for sociocultural factors to be subordinated to environmental considerations (Munt 1994a).

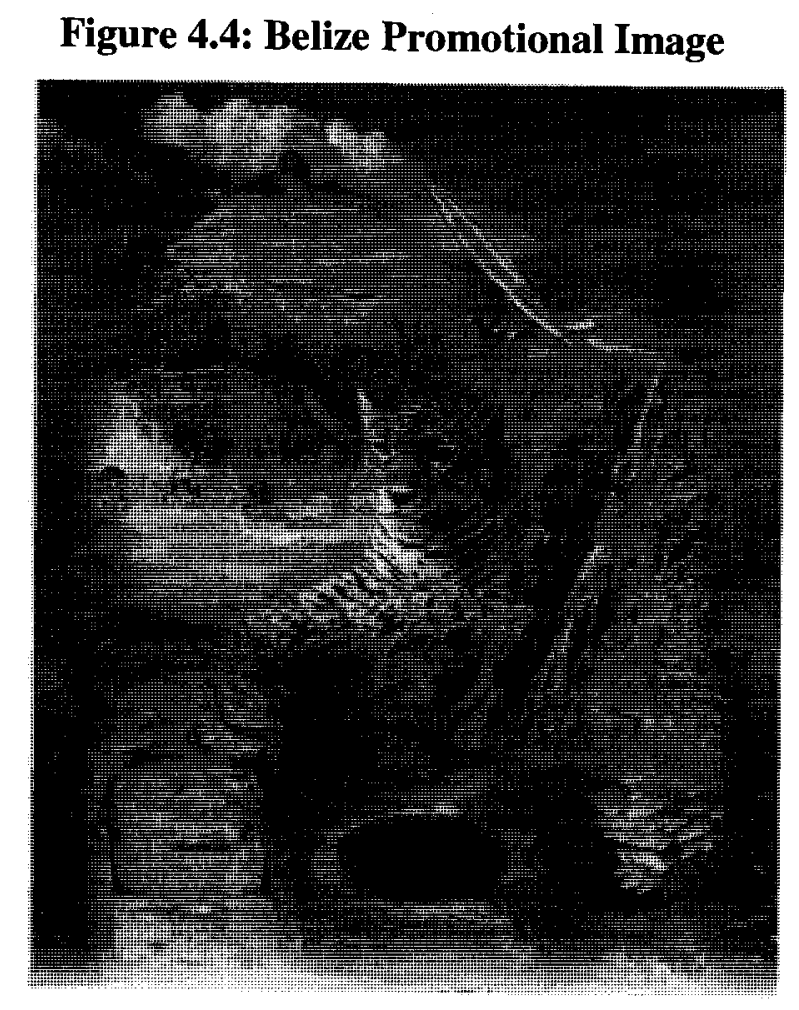

Source: thecityofbelize.com

The establishment of the Cockscomb Basin Wildlife Sanctuary in southern Belize is a good example of how conservation interests in line with the government of Belize seek to present the country as committed to environmental protection in order to attract tourists. The Jaguar Reserve was the first conservation and ecotourism development in

\footnotetext{
${ }^{47}$ The image below was part of a promotional pack for Belizean ecotourism distributed in 1997 (Smith and Duffy 2003: 131).
} 
Southern Belize and became a model for similar projects. Created in 1984, it was first established as a forest reserve and was later dedicated to protecting wildlife becoming the world's first jaguar reserve. The project was supported by the World Wide Fund and the car company Jaguar and in 2000 the European Union dedicated a grant of 1.28 million euros to support the co-management of the reserve (Duffy 2002: 105). Upon its creation it was agreed that the BAS would manage the area until the Maya community who formerly lived within the park boundaries developed the capacity to take over (Lindberg et al 1996).

Despite these promises it was evident when I spoke with Gregorio, whose family had been evicted from the area when he was a teen, that BAS had no intention to give the Maya a stake in the project. When I asked him about approaching the BAS to share in the benefits he told me that they had tried but "they came after us like dogs". Describing the situation, he told me that a few of the nine families "kicked out" of the park were able to move further south and continue their subsistence lifestyle. The men of the families that did not have this option are now employed as taxi drivers and guides servicing the conservation area and the Mayan women make crafts for sale to tourist. "It is hard", he said, "it was very difficult to adjust to a totally different lifestyle". Of growing concern to Gregorio is that fewer and fewer tourists are using the local men as guides. The various eco-lodges and larger hotels, many of which are foreign owned and operated (Medina 2005; Mowforth and Munt 2003: 279-284) offer tours to the Jaguar Reserve and largely bypass the village on their way through. These tours are offered by most ecotourist destination in a large surrounding area and they charge nearly twice the amount for guiding services that the local men do. Gregorio noted that they have "new" large vans 
and they carry up to 15 people at a time, something that he is unable to compete with in his small rundown car (which lost the muffler when he drove us to the sanctuary). ${ }^{48}$

The case of the Mayan community from the Cockscomb Sanctuary illustrates how the ecotourism narrative in Belize, which constructs the country as unified nation of different races and cultures, effectively erases conflict and political strife, silencing alternative representations of how things are. According to Gregorio, the BAS receives all of the park admission fees as well as receiving a huge amount of money in grants from various conservation agencies while "we get nothing". It is important to note that the self guided map of the Jaguar Reserve referred to above, produced by BAS, has site markers showing where Gregorio's house used to be and relates that the former Maya inhabitants "abandoned the site" rather than being evicted (BAS 2007).

The Belizean ecotourism apparatus, in accordance with the desired images and pursuits of ecotourists, constructs an image of Belize that (re)affirms a figment of the tourist's imagination (Bruner 1991: 241). This is not to say that the image is a fake or that it is inauthentic, what is presented to the ecotourist is an authentic representation of what they desire to see and experience. From the above discussion it becomes increasingly apparent that, like other forms of tourism, ecotourism is a very individualistic pursuit of experience. In the case of the Jaguar Reserve and the barrier reef, ecotourism seems to be causing more harm than good for resident people and the environment respectively.

Ecotourism's ability to present ecotourists with what they desire rather than the reality of living in a Third World destination oriented toward tourism seems to call the claims of ecotourism as an empowering and participatory sustainable development tool into question. It is not clear how the arrival of wealthy people from the First World who

\footnotetext{
${ }^{48}$ Interview with Gregorio, Cockscomb Basin Wildlife Sanctuary, Belize. 03, 01, 08.
} 
come to live out their exotic fantasies of relaxation, exploration and discovery in the Third World is supposed to benefit the people and places that are often objectified by their desire.

\section{Conclusion}

This chapter has shown that ecotourists are not all that different than everyday run of the mill tourists. They still seek individualistic pursuits of personal relaxation and leisure and have a definite immediate as well as long term impact on their destination. Ecotourism as a new form of tourism is said to be different than traditional tourism because it is said to exhibit social and environmental concern and those who engage in it reflect on their impact and orient their behaviour accordingly. Though this may be the intent of many ecotourists, most do not see or experience the impact they have on a destination. Contrary to popular ecotourism discourse, ecotourists' actions and their consumer choices show that they are oriented toward three interrelated pursuits beyond their concern with the environment and the well being of their hosts. The first is to distinguish themselves through their consumption of ecotourism experiences from other forms of tourism, specifically mass and luxury tourism, seen respectively as coarse and irresponsible and elitist and exploitative. In other words, ecotourists seem primarily concerned with not being categorized as a tourist and all the baggage that word entails. Second, and not unrelated, ecotourists seek out real holidays that are personalized and composed of a number of different activities which opposes their holiday to mass packaged holidays which have a set itinerary and no "real" distinguishing features. This in turn differentiates the ecotourists' holiday from others by socially and physically 
separating them from other tourists. The third pursuit is that ecotourists seek out what they deem to be more authentic and "real" experiences than other tourists by penetrating deeper into Third World cultures and environments. They seek experiences and closer contact with the natural and the exotic to substantiate themselves as ecologically or socially sensitive individuals hence gaining a degree of social respect and cultural capital at home. Affluent ecotourists are able to convey this distinction more easily through their discriminating consumption practices and the exclusiveness of their resorts and lodges. These individuals are better able, through their financial capital, to enforce a romantic tourist gaze and have destinations represent their holiday desires. On the other hand, the less affluent often deride this ability and seek out what, for them, constitutes an alternative or real experience.

All of these pursuits, or what I call the nature of ecotourism, are about creating and maintaining the desire for a genuine and true experience. These are experiences that may help ecotourists define their own self-identity over and against the exotic other they intend to visit. In a sense, ecotourists adopt a narrative about somehow improving the self and coming back a totally changed and newly experienced person. It is important to note that this is not simply an individualistic fantasy but that these experiences are actually recognized at home as markers of distinction. They go away, they explore, and they discover something out there and reportedly in themselves as well.

The tourist narrative is also a narrative of power. People and places are put under pressure as they are promoted and promote themselves in the image desired by their guests, and at the very least are forced to see themselves through the ecotourist's eyes. This does not mean they are powerless to resist or that the repositioning is always 
negative, but that it does occur on an uneven footing with far less room for the hosts to maneuver and impose their own narrative of a desired social order. 


\section{Chapter 5: Conclusion}

The particular perspective from which I observed ecotourism in Belize, that of an ecotourist, is a factor that played a large role in shaping my analysis and reflects the results that I have presented. What needs to be highlighted before continuing with these concluding remarks is a point from the introductory chapter concerning the nature of this study. As the trip I took to Belize was quite short as far as ethnographic fieldwork goes, the analysis was not concerned with gaining an intimate understanding of the intricacies of a community-based ecotourism project. In all likelihood such an analysis may have presented a very different picture of the way communities and individuals exhibit agency while they engage the forces of conservation and development prevalent in ecotourism initiatives. An opportunity to conduct such research by focusing directly on a Belizean community would have surely produced an understanding of the ways Belizean people feel about and act towards tourists and conservationists and could provide a glimpse into Belizean notions of progress and their pursuit of a desired future. Such an endeavor may be a topic for further inquiry and would most certainly provide more commentary from Belizean perspectives on the forces that are impacting their lives. This being the case, the position that we occupied while traveling Belize presented me with a very favorable position from which to cast my analytical gaze, especially concerning the appearance and workings of the larger ecotourism industry and the motivations, practices and behaviors of ecotourists. The most fundamental observations that I was able to make from this vantage point was that many ecotourists seemed unconcerned with the impact that they may have been having on the people and places they were visiting and that there was a rapidly increasing number of eco-lodges, hotels, resorts and vacation properties being 
developed that were surely the result of increasing demand. That is, the increasing desire to visit Belize and the attractions it offers was turning what is promoted as an ecotourism industry into something more reminiscent of the mass tourism industry. This does not mean that all ecotourism leads to mass tourism as efforts are made to adhere to and protect ecotourism's principles, but as Belize's tourism industry continues to grow, ecotourism and mass tourism will be increasingly forced to coexist and distinguishing between the two may become increasingly difficult. Going to Belize armed with a fair bit of knowledge concerning the heavily skewed land ownership there, it was apparent that the majority of ecotourism developments were not Belizean-owned and it would probably be fair to say that next to none of them were being considered for use by the average Belizean person. From this vantage point it was hard to see the participatory and empowering nature of ecotourism development and it became quite clear that Belizean ecotourism was having a hard time living up to its virtuous principles.

It is also important to note that the particular tone that this project has taken may give the impression that I feel tourism is on the whole a negative force that the world needs to do away with. I can assure the reader that this is not my position and that it would be ridiculous to assume that such a thing would even be possible. Rather, I argue that the negative connotations presented here are more to do with the analytical style from which $I$ have presented this argument. In presenting tourism as a social practice the object has been to present it in a light that attempts to show it as something strange or foreign. Throughout this project I have attempted to make an everyday, seemingly mundane, aspect of First World culture appear in a light that casts it as a strange and puzzling cultural practice. In this sense I have presented ecotourism in a way that goes 
beyond everyday experiences in order to present a glimpse of the patterns and meanings behind that world. In this process of going beyond taken for granted meanings my focus has been to allow a better understanding of ourselves as ecotourists, tourists or travelers.

Throughout the course of this analysis I have highlighted what appears to be a fairly large gap between ecotourism as a set of principles and ecotourism as it is practiced. On the one hand, ecotourism is a set of principles concerning a desired way of touristically engaging Third World people and landscapes that is meant to curb the pitfalls of the traditional industry. On the other hand, I have shown that ecotourism in practice can be seen as closely resembling, if not replicating, some aspects of the mass tourism industry in a number instances. There are numerous reasons why ecotourism has trouble achieving its desired impacts or lack thereof. A large amount of foreign ownership may block benefits from accruing to the desired recipients, economic shortsightedness by the industry itself and by national governments may be a factor, and a superficial commitment to social or environmental issues could be equally responsible.

In this thesis project I have chosen to highlight the nature of eco-travel and tourism itself as a major obstacle to achieving socially and environmentally just solutions to the problems associated with traditional tourism. When one observes tourism, eco- or otherwise, as a social practice in which primarily First World people with the time and money to travel visit Third World destinations, seemingly valued for their Third Worldliness and pressured to reflect the holiday desires of these travelers, ethical questions begin to arise. Questions such as: in whose interest is tourism taking place? Who is held accountable for the negative impacts that result? Who actually pays the price of these impacts? Whose representation of events structures the encounter between hosts 
and guests? That is, do tourists see themselves as guests visiting a destination or do they consider themselves entitled to a product they have purchased? Are Belizeans treated as hosts or as part of the landscape or service industry? Considering the answers to these questions that I have presented throughout this work, understanding tourists as "guest" seems to be a problematic label. If tourists are guests they are not the kind anyone I know would (re)invite to their home. They rarely clean up after themselves, they tend to pass judgment on you and your home, they expect everything to be cheap, and they sometimes act like they own the place.

The ecotourist promoted by popular discourse is said to be a self-reflexive individual. This means that the very nature of ecotourism as an alternative or responsible form of traveling requires the individual to look back upon their actions and adjust their behaviour accordingly and so orient their actions toward the environment and society that they seek to benefit. For me, the practice of ecotourism in Belize was difficult to distinguish from the traditional or mass tourism industry elsewhere. Those who the policy discourse would label as ecotourists did not seem as interested in their impacts as much as one might expect and instead, like conventional tourists, they seemed more focused on distinguishing themselves through the holiday they purchase and the experiences they gain. This seems to be a very self-oriented pursuit that takes little or no responsibility for an impact, let alone realizing that an impact exists beyond the short time of a holiday. If a socially responsible and ecologically friendly holiday were the main impetus behind ecotourism then it would seem logical to start by avoiding long haul air travel. The fact that this is not occurring suggests that the experiences and associated social distinction 
gained from such a holiday takes precedence over social and environmental concerns (West and Carrier 2004).

In reviewing the ecotourism literature there were surprisingly few accounts that pose questions about the actual activity of being an ecotourist and how this differs from the traditional or mass tourism industry. By doing so in this analysis, I have shown that there are certain motivating factors that cut across numerous forms of tourism no matter how differentiated tourism becomes. Tourism seems to be at its most basic level concerned with self-indulgence and an individualistic pursuit of experience. By engaging in the activity tourists mark themselves as socially distinct form others in the home society and gain a certain degree of cultural capital by doing so. In buying a "real" holiday, independent travel, or an eco-tour from international agents and companies, ecotourists might believe that their holiday is oriented toward conservation and development ends, but when confronted with the visible impacts of their holiday experience they tend to gloss over the negative aspects (Duffy 2002: 20-46). Much like traditional tourists, ecotourists are motivated by self-indulgence. In this, ecotourists are implicated as part of the process of ecotourism development that brings economic, social, political, cultural and environmental change (Duffy 2002: 46-7). Change caused by ecotourism and yet change that degrades the features ecotourists desire in a destination.

Curiously, the group of people who are arguably the most responsible for the impacts created by ecotourism or at the very least those who create the demand for a particular holiday experience, are the least accountable for the negative impacts that may result. The nature of ecotourism and the liminoid state of the tourist while on holiday seems to structure the encounter in a way that largely excludes meaningful reflection and 
concern for negative consequences and largely relegates these impacts to the less responsible "tourist". On the whole it is not in the nature of tourism to locate the negative repercussions of one's travels and then take responsibility for them. As Bruner (1991: 241) put it when discussing African tourism, "Western tourists are not paying thousands of dollars to see children die in Ethiopia; they are paying to see the noble savage, a figment of their imagination", and I add, this is often what they get. The same can be said for ecotourism in Belize. People pay to tour "wild", "natural" and "pristine" landscapes and visit the smiling exotic people of that country. Ecotourists are not there to see the poverty, inequality and hardship faced by many Belizean people let alone to take responsibility for any contribution that they may be making to this state of affairs or its perpetuation.

In light of what has been said throughout this document, I argue that ecotourism's popularity does not represent a concern with providing sustainable and participatory conservation and development as much as it does a growing interest in experiencing the people and places of the Third World. But the Third World sought out by ecotourists and the Third World occupied by its residents is often a very different place.

Ecotourism represents a time when an individual seeks to find their "real" life and where they can meet their "true" self, if only momentarily (Lanfant 1995: 9; Cohen 1979). Therefore, tourists choose to visit a place they see as authentic in order to discover this identity that they cannot find in their everyday lives. This implies that ecotourists do not seek to experience the object of their desire on its own terms; rather they are seeking signs that offer themselves as authentic representations of exotic people and landscapes. In this sense what the tourist is seeking more closely resemble popular imaginings of 
Caribbean beaches, dense tropical jungles and exotic others. This representation, by its very nature, highlights various features of a destination and its hosts while concealing less attractive aspects that might threaten these edenic images. This is not to say that what ecotourists experience is a false representation of Belize but that the experiences ecotourists most often seek and attain are not as concerned with the issues that the policy discourse suggests they are and thus less concerned with reflecting on the practice and its impacts. A history of colonialism, slavery, exploitation, racism, an unsympathetic approach to wildlife and the human modification of the environment over thousands of years are but a few of the less prevalent aspects found in ecotourism in Belize and yet ones that are essential to understanding its context and revealing its politics.

One of the focuses of this project has been to explore a fundamental contradiction in the use of ecotourism as a sustainable development strategy, that is, from the inside (various Belizean views) tourism is often seen as a means to create change and bring about modernity, while from the outside view the tourist, and especially the ecotourist, seek characteristics which they deem exotic, primitive and immutable (Lanfant 1995: 10). In other words, at the same time that tourism makes rural communities emerge from their perceived isolation and sets them out on the road to modernity, they are pressured to reinvent their past and preserve their traditions in order to maintain the image that tourists have of them (ibid). As Chapter Three has demonstrated human actors exhibit a great deal of agency even in relation to what seem like the most determinate structures of power and domination. The way Belizeans today negotiate the various agendas presented in ecotourism development and the various forms that their responses may take is a 
question that I could not answer adequately here but is a topic that deserves further inquiry (see Belsky 1999, 2000, 2003; Johnson 1998; Wilk 2006).

This study implies that the motivations and desires of ecotourists seeking a particular natural and cultural experience create a real pressure for people to represent these images to the tourists in order to keep the industry viable. Of course, it would be false to assume that people in Belize do not actively respond to ecotourism development as if they were passive receptacles somehow duped into acting and existing in the ways ecotourists imagine them to. It would be equally false to assume that everyone in Belize feels these pressures or that those who do experience them in the same way. My theoretical stance also suggests that it would be inaccurate to assume that Belizeans do not play a role in shaping the representations held by foreign others or that no one is actually benefiting from ecotourism. I can say with great confidence that many Belizeans are capitalizing on the tourists that are coming to their country and spending large sums of money to more or less take a walk in their back yard. The pressure I refer to comes from the overarching narrative of ecotourism in the Third World that partially structures the encounter for both hosts and guests. The practices and behaviors of these groups are arguably defined in part by this narrative which suggests that the powerful and more modernized tourists come to view them, the poor and powerless people of the Third world who live much closer to "real" nature. The Third World ecotourist narrative is also a narrative of power and one which at the very least forces the hosts to see themselves and the environment through the eyes of their guests far more often than the tourist is made to see their behaviour and practice through the eyes of the average Belizean. In terms of gazing and acting upon the environment, this is most evident in the way 
stingrays and sharks are presented to ecotourists as tame and accessible pets and in the way that the coastal swamps of Belize are remade in the image of a Caribbean post card. These developments that are overtly for tourists and tourists only have consequences for the intended recipients of sustainable development. In Belize, a large number of people seem to be bearing the cost of conservation and tourism development in terms of a diminishing resources base, rising prices and a loss of access to land, while only marginally sharing in the benefits, often in the form of low paying seasonal jobs (Belsky 2003: 100). These consequences cannot be removed from the influence created by the growing demand of travelers from the First World seeking a "real" holiday experience that often includes an unadulterated view of "pristine" environments and the need to make these environments an exclusive domain from which the gaze can be cast.

This thesis has set out a number of factors that call into question the ability of ecotourism to provide a new development strategy. By doing so, I have attempted to place ecotourism within debates that relate to broader effects that international economic and political systems have on the Third World. It is significant to note that the economic aspect of tourism that focuses on growth and profit are the most obvious hindrances to a sustainable, participatory or empowering style of development. The fact that ecotourism does not offer a significant challenge to existing economic, social and political structures can be seen to contribute to its popularity within the larger tourism industry and one of the main reasons that it produces similar impacts as the traditional tourism industry.

Ecotourism runs into problems attaining its goals because it is not the radical alternative that its proponents claim it to be. Ecotourism is cast in the light of the economic system that created it, meaning that neoliberal marketing strategies often 
dictate that countries exploit their comparative advantage. For countries like Belize, this usually means that they must promote their nature and culture for consumption by foreign tourists in hopes of getting the IMF to lay them the golden egg of an upwardly mobile economy. Destinations are encouraged or pressured to conform to particular tourist ideals of nature and culture ignoring the politics of creating a destination for rich white foreigners to realize their desires and fantasies.

Promoters of ecotourism tend to suggest that it is an apolitical industry where a simple consumer choice has the ability to create benefits for economic development and environmental conservation. But as ecotourism is an expression of consumer culture, like a choice of clothes, it signifies social distinction, and the ecotourist actions are a response to a market of goods. The decision to travel to an ecotourism destination is not an innate impulse, but is developed under the influence of the social environment. Ecotourism is a social 'position marker', like a second car or home, and indicates a person's social standing (Dufffy200: 41). Accordingly, the representation posed by many ecotourism proponents does not take into consideration the deeply political nature of the choices made by ecotourists who demand particular experiences on their holiday and which place a distinct economic value on people, places and resources. Nor does this representation take into consideration the relationships of power and issues of social justice that result from extracting cultural capital in the form of experience drawn from a destination nudged into exploiting its advantage of providing tourists with pleasure.

As mentioned earlier, I am not saying that tourism should be banned, an impossible feat, nor do I attempt to make policy recommendations to ameliorate negative aspects. The main thrust of this analysis is to show that claims of a truly empowering, 
participatory and socially just tourism development are undermined by the very nature of the tool being used, or possibly by the notion that a "tool" is even applicable to the situation. Tourism development of any kind is based on capitalist market principals that value growth. Though there may be a few ecotourism operators out there that are adamantly committed to social and environmental issues, judging by the logic of the industry these operators are likely to remain a very small minority. The marketability of ecotourism and the neoliberal economic climate that it is intricately bound to ensures that large-scale private (often foreign) owners and operators will be the main beneficiaries. Though there is surely a gradient of ecotourists spanning from the most responsible and informed to the seemingly irresponsible and unconcerned ("tourist"), the practice of ecotourism on the whole does not represent the responsible and self-reflexive qualities that ecotourism boosters suggest it does. Much like Duffy (2002) notes, ecotourists are a part of Beck's "risk society" and despite their good intentions they are largely unconcerned with seeing the aggregate impacts of their holiday or the larger, social and cultural structures that the practice of ecotourism is embedded in.

The focus of this project as a whole also presents an opportunity for reflection on a topic that is often left unexplored in anthropological literature generally speaking. The reflection I refer to is one that concerns the obvious similarities between anthropology (especially ethnography) and tourism (Crick 1995) and the similar tendency of anthropologists to omit social and cultural structures (such as the size and extent of international tourism) that their practice is embedded in.

Tourists are strangers residing temporarily in other cultures; they are usually more affluent than their hosts; they have an interest in the other derived in advance from their 
own culture; while at the destination they are essentially awkward and marginal; they use economic resources to obtain the experiences they value; when they return home they reestablish a more permanent identity, relate their experience and enhance their status by recounting it. All these traits, arguably characterize anthropologists (Crick 1995: 212).

It is apparent that tourists, more now than ever, occupy the same geographic space where ethnographic fieldwork is conducted yet anthropological interest in contemporary tourism is of marginal concern (Crick: 207). This relative omission becomes even stranger if tourism is acknowledged as representing the largest movement of human populations across cultural boundaries, a process that should put it squarely in the domain of anthropological inquiry. Could it be that there is a perception that anthropological and touristic identities overlap and thus there exists an anxiety to explore this issue? Errington and Gewertz (1989: 53, n.2) admit that they and others have omitted references to tourists in their publications and in so doing they also admit that they have weakened their contribution to the task of understanding world political economy. It would seem that the avoidance of acknowledging tourists in contexts which are claimed as anthropological could be seen in much the same light as the touistic critique of tourism and similar to the tourist identity politics discussed in this thesis.

I believe it to be obvious that continuities between the two social identities (ethnographer and tourist) exist and hold that they overlap in a number of respects. Though this is my theoretical position, I acknowledge that this is an issue that needs to be investigated and discussed further. This being said it is quite obvious that the feelings anthropologists have toward tourists are quite similar to the touristic "desire to go beyond the other "mere; tourist to a more profound appreciation of society and culture" 
(MacCannell 1989:10). Errington and Gewertz (1989:37) describe their competitive encounters with tourists and travelers in Papua New Guinea and they even admit that they were motivated in some of the same ways as the tourists (ibid: 46). Crick (1995:209) also demonstrates that a sense of jealousy, competitiveness and defensiveness is frequently present whenever anthropologists discuss the tourist presence. In reference to the omission of tourists in ethnography and the contempt often felt for them, he says that "it is clear that people do not compete with or attempt to deny the existence of others who are of no significance" (ibid). Therefore, could it be that these reactions are the result of anthropologists recognizing that tourists are our close relatives and thus feel the need to separate ourselves from them? "Perhaps the other represents precisely those aspects of the self which we wish to disown" (Crick 1995:206).

I raise these considerations in closing because they represent a contradiction that arises in the preceding project. In the preceding pages, I am seemingly criticizing the ecotourist for attempting to attain a more authentic experience. In this sense, my analysis tends to insinuate ecotourists are unable to go further than the mere "tourist" and attain a more genuine understanding of the natures and cultures they seek while at the same time my theoretical position has held that a "local" perspective surely exists. That is, there is an authenticity or back stage that I believe is penetrable by an anthropologist, though I was unable to penetrate it, and yet I claim that this backstage does not exist for the ecotourist. Though this is a large topic that deserves more attention than I am able to give it here I do hold that there is a distinction between the anthropologist and the ecotourist and that this distinction lies largely in the intent of each. I hold that the anthropologist is intent on attaining a much deeper understanding than the run of the mill ecotourist and is 
concerned with, not only learning for the self but disseminating findings and contributing to the knowledge and direction of a discipline. In relation to the ecotourist, this does not mean that they are incapable of attaining a "native point of view" but that the intent and motivation embodied in their practice structure the encounter differently and in a less reflexive manner. That is to say, ecotourists, or tourists for that matter, are not dammed to inauthenticity but that they are simply less likely to reflect on the self and the social and cultural structures that shape their encounter with a destination. That being said, no matter how aware we become of the continuities between anthropology and tourism the "local perspective" that both anthropologists and tourists seek, though in varying form and degrees of intensity, is a perspective that surely exists and one that either practice cannot do without. 


\section{Work Cited}

Agrawal, A. and Clark Gibson. 1999. Enchantment and Disenchantment: The Role of Community in Natural Resource Conservation. World Development, 27(4):629649.

Alexander, Sara. 'Resident Attitudes toward conservation and black howler monkeys in Belize: the Community Baboon Sanctuary', Environmental Conservation 27(4):341-350.

Ashcraft, Norman. 1973. Colonialism and Underdevelopment: Processes of Political Economic Change in British Honduras, New York: Teachers Collage Press.

BAS (Belize Audubon Society). 2007a. Cockscomb Basin Wildlife Sanctuary: Trail Map, Belize City: BAS.

2007b. 'Open letter to Hon. John Briceno on Rapid Coastal Development', Advocacy Updates 1(3).

Bebbington, Anthony. 2000. 'Reencountering Development: Livelihood Transitions and Place Transformations in the Andes', Annals of the Association of American Geographers, (90)3: 495-520

Belize Development Trust. 2002. Report \# 495: 'Poverty Assessment Report-Belize'. Submitted to Caribbean Development Bank by Kairi Consultant LTD. In association with the National Assessment Team of St. Belize. Accessed Dec 10, 2007. < http://ambergriscaye.com/BzLibrary/trust495.html >

Belize Discover.com. Map of Belize. Accessed March 19, 2008.

$<$ http://www.belizediscover.com/images/map-distric-belize-info.gif>

Belize High Commission, London. 2007. Tourism in Belize, Accessed January 28, 2008. <http://www.belizehighcommission.com/tourism bze.htm>

Belize Tourism Board. 2007. 'Tourism Statistics-Tourism revenues.' Accessed December 9, 2007. < http://www.belizetourism.org/belize-tourism/tourismrevenues.html>

2005. White Paper on Updating the National Tourism Strategy for Belize. Belizetourism.org Accessed December 9, 2007. <http://www.belizetourism.org/belize-tourism/tourism-revenues.html $>$

Belsky, Jill. 1999. 'Misrepresenting communities: The politics of community-based rural ecotourism in Gales Point Manatee, Belize', Rural Sociolog, 64(4): 641-666. 
2000. 'The meaning of the Manatee: An examination of community based ecotourism discourse and practice' in C. Zerner (Ed.) People, Plants and Justice: Conservation and resource extraction in Tropical developing countries, New York: Columbia University Press. pp. 285-308.

2003. 'Unmasking the Local: Gender, Community, and the Politics of Community-Based Rural Ecotourism in Belize', in Steven R. Brechin, Patrick C. West, Peter Wilshusen and Crystal Fortwangler (eds.) Contested Nature: Power, Protected Areas and the Dispossessed: Promoting International Conservation with Justice in the 21st Century, Albany, NY: Suny Press. pp. 89-101.

Biersack, Aletta and James Greenberg (eds). 2006. Reimagining Political Ecology, Durham: Duke University Press.

Biodiversity and Environmental Research Data System of Belize. 2005. Map of Protected Areas of Belize. Accessed December 8, 2007. $<$ http://www.biodiversity.bz/find/protected_area/>

Bolland, Nigel O. 1977. The Formation of a Colonial Society, London: Johns Hopkins University Press.

1986. Belize: A New Nation in Central America, London: Westview Press.

2003.Colonialism and Resistance in Belize: Essays in Historical Sociology, Viego del Carmen, Belize: University of West Indies Press.

Boo, .1990. Ecotourism: the potentials and pitfalls, Vols. 1 \& 2, Washington, DC: World Wildlife Fund.

Bourdieu, Pierre. 1984. Distinction: A Social Critique of the Judgment of Taste, London: Routledge.

Brandon, Katrina.1996. Ecotourism and Conservation: A Review of Key Issues, Washington, D.C: World Bank

Britton, Stephen. 1982. 'The Political Economy of Tourism in the Third World', Annals of Tourism Research, 9: 331-358.

Brockington, Dan. 2002. Fortress Conservation: The Preservation of the Mkomazi Game Reserve, Tanzania, Bloomington Indiana: Indiana University Press.

Bruner, Edward M. 1989. 'Review: Of Cannibals, Tourists and Ethnographers', Cultural Anthropolog, 4(4): 438-445.

1991. 'Transformation of Self in Tourism', Annals of Tourism Research 18: 238250. 
2005. Culture on Tour, Chicago: University of Chicago Press.

Bryant, Raymond. 1991. 'Putting Politics First: The Political Ecology of Sustainable Development', Global Ecology and Biogeography Letters, 1(6): 164-166.

BTIA (Belize Tourism Industry Association). 2007a. 'Membership and Industry Information', Accessed February 1, 2008. $<$ http://www.btia.org/about mission.php> 2007b. Destination Belize: Mother Natures Best Kept Secret, Belize City: BTIA.

BTB (Belize Tourism Board). 2005. White Paper: Considerations for Updating the National Tourism Strategy for Belize, accessed at Belizetourism.org February 19, 2008.

<http://www.belizetourism.org/component/option,com remository/Itemid, 170/fu $\underline{\text { nc,select/id,86/> }}$

2008. 'About the BTB'. Accessed February 2, 2008.

<http://www.belizetourism.org/about-the-btb/introduction-to-the-btb.html >

Burks, Margaret. 2006. Linking livelihoods and Sustainable Tourism for Parks and People in Belize, M.A. Dissertation. Virginia Polytechnic Institute and State University: Falls Church Virginia.

Cater, Erlet. 1994. 'Ecotourism in the Third World-Problems and Prospects for Sustainability' in Erlet Cater and Gwen Lowman (eds.), Ecotourism: A sustainable option?, London: John Wiley and Sons. pp. 69-87.

Cater, Erlet and Gwen Lowman. 1994. Ecotourism: A Sustainable Option?, New York: John Wiley and Sons.

Cebellos Lascurain, H. 1996. Tourism, Ecotourism and Protected Areas, Gland, Switzerland: IUCN.

Chan Chich Lodge. 2008. Site produced by Natural light Productions, accessed February 19, 2008. < http://www.chanchich.com/home.html>

CIA (Central Intelligence Agency). 2007. 'World Fact Book: Belize', Accesses December 10, 2007. < https://www.cia.gov/library/publications/the-worldfactbook/geos/bh.html\#Econ> 
Cohen, Erik. 1972. 'Toward a Sociology of International Tourism', Social Research, 39: 164-182.

1979. 'A Phenomenology of tourist Experiences', Sociology, 13: 179-201.

1984. 'The Sociology of Tourism: approaches, issues and findings', Annual Review of Sociology, 10: 373-392.

1988. 'Authenticity and Commodification in Tourism', Annals of Tourism Research, 15: 371-386.

1995. 'Contemporary Tourism - trends and challenges: Sustainable authenticity or contrived post-modernity?', In Richard Butler and Douglas Pearce (eds), Change in Tourism: people, places, processes, London: Routledge. pp.12-29.

Crewe, Emma and Elizabeth Harrison. 1998. Whose Development?: An Ethnography of Aid, London: Zed Books.

Duffy, Rosaleen. 2002. A Trip Too Far, London: Earthscan.

Dupuis, M.E. and Peter Vandergeest (eds). 1996. Creating the Countryside: the Politics of Rural Environmental Discourse, Philadelphia: Temple University Press.

Eagles, Paul F. Stephen F. McCool and Christopher D. Hayne. 2002. Sustainable tourism in protected areas: guidelines for planning and management, Gland, Switzerland: IUCN.

Edeleman, Marc. 1999. Peasants against Globalization: rural social movements in Costa Rica, Stanford California: Stanford University Press.

Edelman, Marc and Angelique Haugerud (eds.) 2005. The anthropology of development and globalization: from Classical Political economy to contemporary neoliberalism, Malden. MA: Blackwell Publishing.

Eltringham, Peter. 2007. Rough Guide to Belize, London: Rough Guides.

Errington, F. and Deborah Gewertz. 1989. 'Tourism and Anthropology In a Post-Modern World', Oceania, 60: 37-54.

Escobar, A. 1995. Encountering Development: the making and unmaking of the Third World, Princeton, New Jersey: Princeton University Press.

1996. 'Constructing Nature: Elements for a Poststructural Political Ecology' in Richard Peet and Michael Watts (eds), Liberation Ecologies: environment, development, social movements, London: Routledge. pp. 46-68. 
1999. 'After Nature: Steps to an Antiessentialist Political Ecology', Current Anthropology, (40)3:291-293.

Fennell, David. 1999. Ecotourism: an Introduction, London: Routledge.

Ferguson, James. 1990. The Anti-Politics Machine: "Development", Depoliticization and Bureaucratic Power in Lesotho, Minneapolis: University of Minnesota Press.

Gould, Kenneth. 1999. 'Tactical Tourism: A Comparative Analysis of Rainforest Development in Ecuador and Belize, Organization \& Environment, 12(3): 245262.

Graburn, N.H. H. 1977. 'Tourism: the sacred Journey', in V. Smith (ed.), Hosts and Guests: the Anthropology of Tourism, Philadelphia: University of Pennsylvania Press. pp. 17-31.

2001. Secular Ritual: A General Theory of Tourism, in V. Smith and Maryann Brent (eds.), Hosts and Guests Revisited: Tourism issues of the $21^{\text {st }}$ Century, Chico: Cognizant Communications. pp. 42-50.

Greenberg, Jerry. Idaz Greenberg and Michael Greenberg. 2000. Mangroves: Trees In The Sea, Miami: Seahawk Press.

Grillo, R.D. and R.L. Stirrat. 1997. Discourses of Development: anthropological perspectives, New York: Berg.

Hall, C. M. 1994. 'Ecotourism in Australia, New Zealand and the South Pacific: Appropriate Tourism or a New Form of Ecological Imperialism?', in Erlet Cater and Gwen Lowman (eds.), Ecotourism: A sustainable option?, London: John Wiley and Sons. pp.137-157.

Harrison, Julia. 2003. Being a Tourist: Finding Meaning in Pleasure Travel, Vancouver: UBC Press.

Harvey, David. 1989. The Condition of Postmodernity, Oxford: Blackwell

Horwich, Robert H. and Jonathan Lyon. 1998. 'Community-Based Development as a Conservation Tool: The Community Baboon Sanctuary and the Gales Point Manatee Project'. In Richard B. Primach, David Bray, Hugo A. Galletti, and Ismael Ponciano (eds.), Timber, Tourists, and Temples: Conservation and development in the Maya Forests of Belize, Guatemala, and Mexico, Washington DC: Island Press. pp. 343-363.

1999. 'Rural Ecotourism as a Conservation Tool'. In Tej Vir Singh and Shalini Singh (Eds.) Tourism Development in Critical Environments. New York: Cognizant Communication Corporation. Pp. 102-119. 
Jacobs, N. D. and A. Castenada (eds). 1998. 'Belize National Biodiversity Strategy', Belmopan, Belize: Ministry of Natural Resources and Environment

Johnson, Melissa. 1989. Nature and Progress in Rural Creole Belize: Rethinking Sustainable Development, $\mathrm{PhD}$ dissertation, University of Michigan.

2003. 'The Making of Race and Place in Nineteenth-Century British Honduras', Environmental History, 8(4): 598-617.

Judd, Karen. 1998. 'In the Name of the People: Populist Ideology and Expatriate Power in Belize', in Howard Johnson and Karl Watson (eds.) The White Minority in the Caribbean, Princeton, NJ: Markus Wiener Publishers. pp. 133-158

Kambach, Belkis. 2008. "Relishing Belize: Ruins, Rainforest and Reef”, GoNomad.com, Accessed February 2, 2008. $<$ http://www.gonomad.com/destinations/0012/belkis toucan.html $>$

Lanfant, Marie-Francoise. 1995. 'International Tourism, Internationalization and the Challenge to Identity', in Marie-Francoise Lanfant, John Allcock and Edward Bruner (eds.) International Tourism: Identity and Change, London: Sage. pp. 2443.

Lash, S. 1990. Sociology of Postmodernism, London: Routledge.

Lea, John. 1988. Tourism and Development in the Third World, London: Routledge.

Leach, M., Robin Mearns and Ian Scoones. 1999. Environment Entitlements: Dynamics and Institutions in Community-Based Natural Resource Management, World Development, 27(2): 225-247.

Lew, Alan A. 1998. 'The Asia-Pacific ecoturism industry: putting sustainable tourism into practice', in Michael Hall and Alan Lew (eds.) Sustainable Tourism: A Geographical Perspective, New York: Addison Wesley Longman. pp. 92-106.

Li, Tania M. 1996. 'Images of Community: Discourse and Strategy in Property Relations', Development and Change, 27: 501-527.

Lindberg, Kreg and Jeremy, Enriquez. 1994. An Analysis of Ecotourism's Economic Contribution to Conservation and Development in Belize. Vols. 1 and 2. Washington, D.C.: World Wildlife Fund.

Lindberg, Kreg, Jeremy Enriquez and Keith Sproule. 1996. 'Ecotourism Questioned: Case Studies from Belize', Annals of Tourism Research, 23(3): 542-562. 
Lindberg, Kreg and Donald Hawkins. 1993. Ecotourism: a guide for planners and managers, Bennington, Vermont: The Ecotourism Society.

Lohman, Larry. 1993. “Green Orientalism.” The Ecologist, 23(6): 202-204.

MacCannell, D. 1989. The Tourist: a new theory of the leisure class, New York: Schocken Books.

McLaren, Deborah. 1998. Rethinking Tourism and Ecotravel, Bloomfield, LT: Kumarian Press.

McMinn, Stuart and Erlet Cater. 1998. 'Tourist Typology: Observations from Belize', Annals of Tourism Research, 25(3): 675-699.

Medina, L.K. 2004. Negotiating Economic Development: identity formation and collective action in Belize, Tuscon: University of Arizona Press.

2005. 'Ecotourism and Certification: Confronting the Principals and Pragmatics of Socially Responsible Tourism', Journal of Sustainable Tourism, 13(3): 281295.

Moberg, Mark. 1992. 'Structural Adjustment and Rural Development: Inferences from a Belizean Village', The Journal of Developing Areas, 27: 1-20.

Mongaby.com. 2007. The State of Forests and Ecotourism in Beliz: An interview with Colin Young, a Belizean Ecologist, November 16, 2007. Accessed January 27, 2008.

$<$ http://news.mongabay.com/2007/1116interview young belize.html>

Moreno, Peter S. 2005. 'Ecotourism Along the Meso-American Caribbean Reef: The Impacts of Foreign Investment', Human Ecology, 33(2): 217-244.

Mowforth, M. and Ian Munt. 2003. Tourism and Sustainability: Development and the New Tourism In the Third World, London: Routledge.

Moss, D. 2001. “'People's Knowledge', Participation and Patronage: Operations and Representations in Rural Development", in Bill Cook and Kathari Uma (eds.), Participation: The new tyranny?, London: Zed Books. pp. 16-35

Munt, Ian. 1994a. 'Eco-tourism or ego-tourism?', Race \& Class, 36(1): 49-60.

1994b. 'The "Other" Postmodern Tourism: Culture, Travel and the New Middle Classes', Theory, Culture \& Society, 11: 101-123. 
My Belize Adventure. 2006. Map Showing Belize Districts, Orchid Travel Network. Accessed March 29, 2008.

$<$ http://www.mybelizeadventure.com/site graphics/districtmap 400.gif $>$

O’Connor, James. 1998. Natural Causes: Essays in Ecological Marxism, New York: Guilford Press.

Nygren, Anja. 1999. Local Knowledge in the Environment-Development Discourse: From dichotomies to situated knowledges. Critique of Anthropology, 19(3): 267288.

PACT (Protected Area Conservation Trust). 'Home Page'. Accessed March 15, 2008. http://www.pactbelize.org/

PBS (Public Broadcasting Service). 2008. Map of Belize, WGHB. Accessed March 29, 2008. Available online at <http://www.pbs.org/frontlineworld/stories/belize/map.html>

Pattullo, Polly. 1996. Last Resorts: The Cost of Tourism in the Caribbean, London: Cassell.

Peet, Richard. 2002. 'Ideology, discourse, and the geography of hegemony: From socialist to neoliberal development in post apartheid South Africa', Antipode, 34: 54-84.

Peet, Richard and Michael Watts. 1996. Liberation Ecologies: environment, development, social movements, London: Routledge.

Picard, Michel. 1995. 'Cultural Heritage and Tourist Capital: Cultural Tourism in Bali', in Marie-Francoise Lanfant, J. Allcock and E. Bruner. (eds.) International Tourism: Identity and Change, London: Sage.

Pine Ridge Lodge. 2008. Site produced by Natural Light Productions, accessed February 19, 2008. < http://www.pineridgelodge.com/>

Platt, Elizabeth. 1998. 'Forest Management and Conservation in Belize: A Brief Background' in Richard B. Primach, David Bray, Hugo A. Galletti, and Ismael Ponciano (eds.), Timber, Tourists, and Temples: Conservation and development in the Maya Forests of Belize, Guatemala, and Mexico, Washington DC: Island Press. pp. 125-136.

Pleumarom, Anita. 1996. Ecotourism: A new "Green Revolution" in the Third World, Third World Network: Tourism Investigation \& Monitoring Team. Accessed February 25, 2008. < http://www.twnside.org.sg/title/eco2.htm> 
1999. Tourism, Globalization and Sustainable Development. Third World

Network: Tourism Investigation \&Monitoring Team. Accessed February 25, 2008. < http://www.twnside.org.sg/title/anita-cn.htm $>$

Poon, Auliana (1989). 'Competitive Strategies for Caribbean Tourism: The New versus the Old', Caribbean Affairs, 2(2): 74-91.

Redington, Norman Hugh. A Sketch of Rastafari History, the St. Pachomias Orthodox Library. Accessed March 18, 2008. < http://www.nomadfx.com/old/rasta1.html>

Reifler-Bricker, V. 1981. The Indian Christ, the Indian king: the historical substrate of Maya myth and ritual, Austin: University of Texas Press.

Rangan, Haripriya. 1996. 'From Chipko the Uttaranchal: Development, Environment and Social Protest in Garhwal Himalayas, India' in Richard Peet and Michael Watts (eds.), Liberation Ecologies: Environment, development, social movement, London: Routledge. pp. 205-226.

Sachs, Wolfgang. 1993. 'Global Ecology and the Shadow of Development' in Wolfgang Sachs (ed), Global Ecology: A New Arena of Political Conflict, Halifax, NS: Fernwood Publishing. pp. 3-21.

Said, Edward. 1979. Orientalism, New York: Pantheon Books

Scott, James C. 1985. Weapons of the Weak: everyday forms of peasant resistance. New Haven: Yale University Press.

Shiva, Vandana. 1993. 'The Greening of The Global Reach' in Wolfgang Sachs (ed), Global Ecology: A New Arena of Political Conflict, Halifax, NS: Fernwood Publishing. pp. 149-156

Slauder, Lan. 2008. 'Belize First: News and Opinion Blog about Belize and the Caribbean Coast', updated January 6, 2008. Accessed January 29, 2008. $<$ http://www.belizefirst.com/current.html $>$

Smith, M. and Rosaleen Duffy. 2003. The Ethics of Tourism Development, London: Routledge.

Smith, Valene and Maryann Brent. 2001. Hosts and Guests Revisited: Tourism Issues of the $21^{\text {st }}$ Century, New York: Cognizant Communication.

Sproule, K. and Barry Didato. 1998. Ha Long Bay: North Vietnam's (still rough) Jewel, TIES. Accessed February 21, 2008. $<$ http://www.ecotourism.org/WebModules/WebMember/MemberApplication/onli neLib/searchResult.asp $>$ 
Statistics Belize. 2007. Statistical Institute of Belize: Labor Force Survey, accessed December 8, 2007

$<$ http://www.statisticsbelize.org.bz/dms20uc/dynamicdata/docs/20071112161943 2.pdf $>$

Stinson, J. 2004. Exploring a Middle Ground for Ecotourism Research: A Stakeholder Analysis of the Indian Creek Trail Project in Belize, M.A. Thesis, Carleton University.

Stonich, S. 2000. The Other Side of Paradise: Tourism, Conservation and development in the Bay Islands, Cognizant Communication Corporation, Elmsford, NY.

2005. 'Enhancing Community-Based Tourism Development and Conservation in the Western Caribbean', in Tim Wallace (ed), Tourism and Applied Anthropologists: Linking Theory and Practice, Berkley: University of California Press. pp. 77-87.

Stronza, Amanda. 2000. "Because it is Ours": Community Based Ecotourism in the Peruvian Amazon, PhD dissertation: University of Florida.

2001. Anthropology of Tourism: Forging New Ground for Ecotourism and other Alternatives, Annual Review of Anthropology,.30: 261-283.

2005. 'Hosts and Hosts: The Anthropology of Community-Based Ecotourism in the Peruvian Amazon' in Tim Wallace (ed.) Tourism ands Applied Anthropologists: Linking Theory and Practice, Berkley: University of California Press. pp.170-190.

Sundberg, Juanita. 1998. "NGO Landscapes in the Maya Biosphere Reserve, Guatemala" Geographical Review, 88(3): 388-412.

Sutherland, Anne. 1998. The Making of Belize: Globalization in the Margins, London: Bergin and Garvey

Suvantola, Jaakko. 2002. Tourists Experience of Place, Hampshire: Ashgate Publishing.

TIES (The International Ecotourism Society). 2006. Fact Sheet: Global EcotourismUpdated edition. The International Ecotourism Society, accessed October 28, 2007. <www.ecotourism.org>

Thomas, N. 1994. Colonialism's Culture: Anthropology, Travel and Government, Princeton: Princeton University Press.

Toucan Trail. 2006. Belize Tourism Board, Site Produced by Natural light productions, accessed February 19, $2008<$ http://www.toucantrail.com/Belize-on-aBudget/Hopkins-Village.html> 
Turner, Victor. 1974. The Ritual Process, Harmondsworth: Penguin.

Turner, Victor and Edith Turner. 1978. Image and Pilgrimage in Christian Culture, New York: Columbia University Press.

UNEP (United Nations Environmental Program) Tourism. 2002. 'United Nations Environmental Program (UNEP) Sustainable Tourism Page', Last updated October 9, 2002. Visited March 24, 2007. $<$ http://www.uneptie.org/pc/tourism/sust-tourism/env-3main.htm>

2003. 'Ecotourism Main Page', accessed October 20, 2007.

http://www.uneptie.org/pc/tourism/ecotourism/home.htm\#whatisecotour

UNWTO (World Tourism Organization) 2006. 'International Tourism up by $5.5 \%$ to 808 Million Arrivals in 2005', 24 January 2006, accessed October 28, 2007. $<$ http://www.worldtourism.org/newsroom/Releases/2006/january/06 01 24.htm>

2007. 'Tourism Highlights 2007 Edition. Facts and Figures section'. Accessed October 28, 2007. <www.unwto.org>

Urry, J. 1990. The Tourist Gaze, London: Sage.

1991. 'The Sociology of Tourism', in C.P Cooper (ed.) Progress in Tourism, Recreation and Hospitality Management, Vol 3, London: Belhaven Press.

1992. 'The Tourist Gaze and the Environment', Theory, Culture and Society, 9: 126.

Watts, Michael. 2000. 'Contested Communities, Malignant Markets and Gilded Governance: Justice, Resource Extraction and Conservation in the Tropics', in Charles Zerner (ed.), People, Plants and Justice: Conservation and resource extraction in Tropical developing countries, New York: Columbia University Press. pp. 21-51.

Wearing, Stephen and Neil, John. 1999. Ecotourism: Impacts, Potentials and Possibilities. Oxford: Butterworth Heinmann.

Wearing, Stephen and Michael Wearing. 1999. 'Decommodifying Ecotourism: Rethinking Global-Local Interactions With Host Communities', Society and Leisure, 22(1): 39-70.

West, Paige. and James Carrier. 2004. 'Ecotourism and Authenticity: Getting Away From It All?', Current Anthropology, 45(4): 483-498. 
West, Paige. James Igo and Dan Brockington. 2006. 'Parks and Peoples: The Social

Impact of Protected Areas', The Annual Review of Anthropology, 35: 251-277.

West, Patrick C. Crystal L. Fortwangler, Valentine Agbo, Michael Simsik and Nestor Sokpon. 2003. 'The Political Economy of Ecotourism: Pendjari National Park and Ecotourism Concentration in Northern Benin', in Steven Brechin, Peter Wilshusen, Crystal Fortwangler, Patrick West (eds.), Contested Nature: Promoting International biodiversity with Social Justice in the Twenty-first Century, Albany: State University of New York Press. pp. 103-115.

Wikipedia. 2007. Topographical Map of Belize. Accessed December 8, 2007. $<$ http://en.wikipedia.org/wiki/Geography of Belize>

Wilk, Richard. 2006. 'But the Young Men Don't Want to Farm Any More”: Political Ecology and Consumer Culture in Belize', in Aletta Biersack and James Greenberg (eds), Reimagining Political Ecology, Durham: Duke University Press. pp. 149-170.

Wilshusen, Peter, Steven Brechin, C. Fortwangler, and P. West. 2003. "Contested Nature: Conservation and Development at the Turn of the Twenty-first Century" in Steven Brechin, Peter Wilshusen, Crystal Fortwangler, Patrick West (eds), Contested Nature: Promoting International biodiversity with Social Justice in the Twenty-first Century, Albany: State University of New York Press. pp. 1-22.

Woost, Michael. 1997. "Alternate Vocabularies of Development? 'Community' and 'Participation' in Development Discourse in Sri Lanka", in R.D. Grillo and R.L. Stirrat (eds.), Discourses of Development: anthropological perspectives, Oxford: Berg Publishing. pp. 229-253.

World Ecotourism Summit. 2002. Quebec Declaration on Ecotourism. Quebec City, Canada. Accessed November 1, 2007. <http://www.uneptie.org/pc/tourism/documents/ecotourism/WESoutcomes/Quebe c-Declar-eng.pdf>

WTO [World Tourism Organization (UNWTO)]. 2006. "International Tourism up by 5.5\% to 808 Million Arrivals in 2005." Accessed September 10, 2007. $<$ http://www.worldtourism.org/newsroom/Releases/2006/january/06_01_24.htm>

Ziffer, K. 1989. Ecotourism: an uneasy alliance, Washington DC: Conservation International. 